\title{
STUDIES ON ENDOGENOUS HORMONAL CHANGES DURING GRAIN DEVELOPMENT IN WHEAT GENOTYPES
}

\section{GUTAM SRIDHAR}

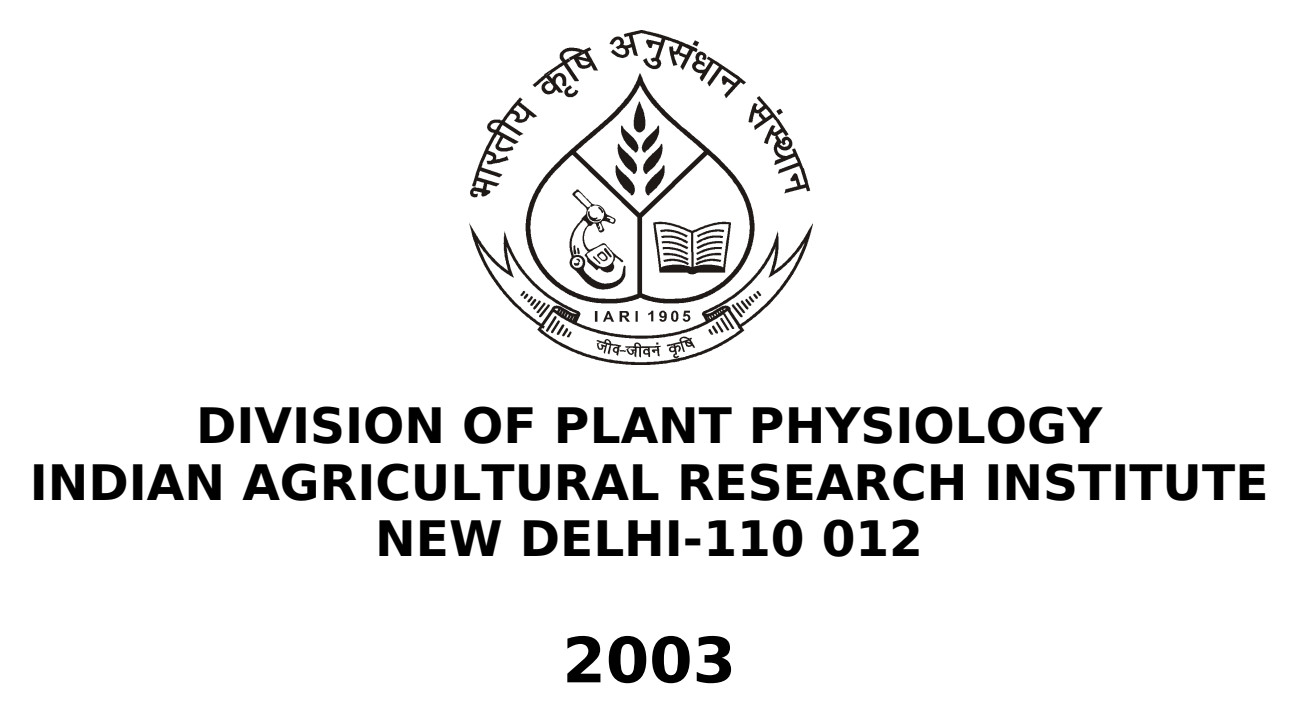




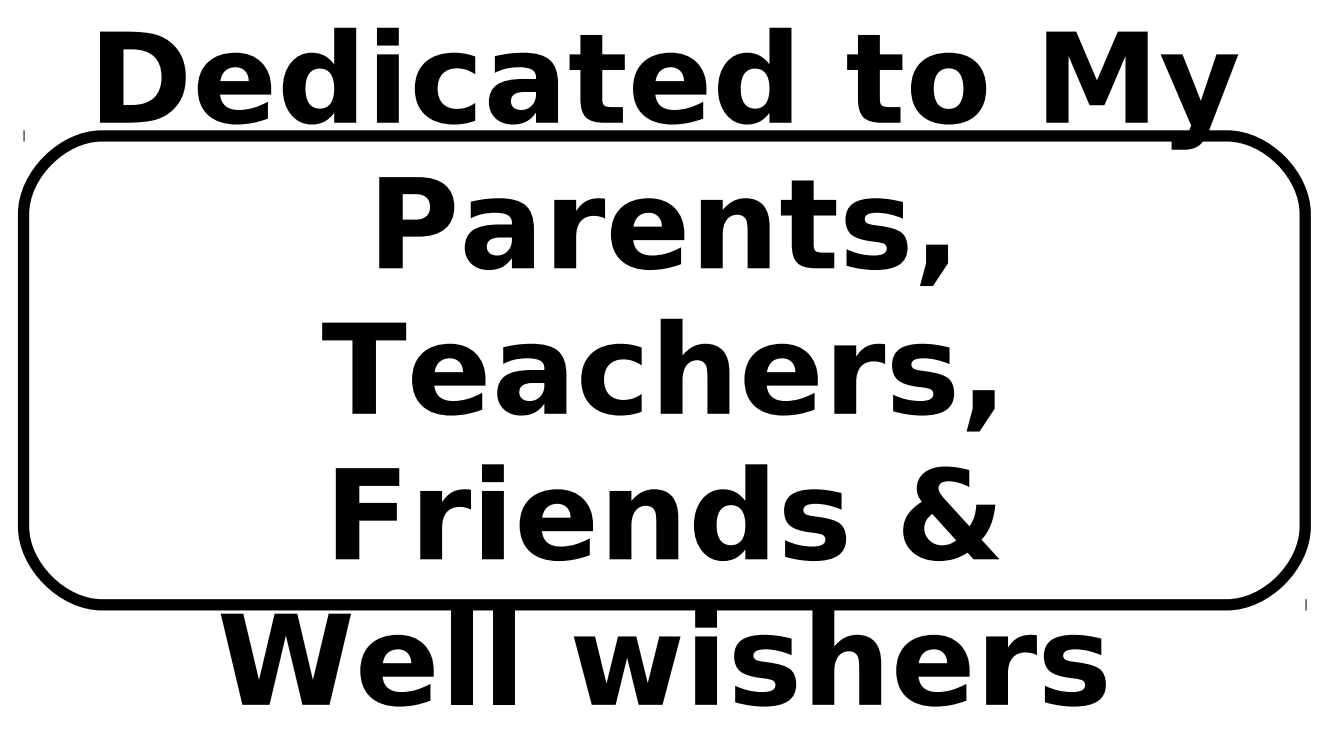




\section{ACKNOWLEDGEMENTS}

I express my deep sense reverent and gratitude to the chairman of my advisory committee Dr. Virendra Nath, Principal Scientist, Division of Plant Physiology for his inspiring guidance during the course of this investigation. I am immensely indebted to him for his affection and help rendered to me in several ways. I must acknowledge that it has been a rare privilege for me to work under his valuable guidance during my research programme.

I express my gratitude and reverence to Dr. G.C. Srivastava, Co-Chairman of my Advisory committee and Head, Division of Plant Physiology for his unstinted support, inspiring attitude and ever-willing help throughout the period of my study and research.

I sincerely thank all the members of my Advisory Committee, Dr. Santosh Kumari, Dr. S.D. Singh, Dr. Ranbir Singh who helped me now and then with useful suggestions and guidance. I am particularly grateful to Dr. Santosh Kumari for helping me in extraction of plant hormones, critically going through the manuscript during my course of investigation.

I express my sincere thanks to Dr. P.S. Deshmukh, Professor, Division of Plant Physiology, for his inspiring suggestions, love and affection during my study and research.

A formal note of acknowledgement is scarcely adequate to express my deep sense of gratitude to Dr. S.S. Singh, Principal Scientist \& Progamme Leader, Wheat Improvement, Division of Genetics, for providing me the seed material, Dr. Devakumar and Dr. Prem Dureja, Principal Scientists, Division of Agricultural Chemicals, for providing me the necessary facilities and guidance in analyzing the hormones by HPLC, Dr. Malavika Dadlani, Principal Scientist, Mrs. Veena Vashisht, Division of Seed Science and Technology, for providing me the necessary facilities for sugar and starch estimation in seeds. 
It is a privilege to express my gratitude to Dr. M. Pandey, Former Professor, Dr. U.K. Sengupta, Dr. J.D.S. Panwar, Dr. R.K. Sai Ram, Dr. M.C. Ghildiyal, Dr. Madan Pal, Dr. V.P. Singh, Dr. C. Viswanathan and other scientists and faculty, Division of Plant Physiology for their inspiring suggestions, constant help during the course of the investigation.

I find no suitable words and appreciation to Dr. M.B. Chetti, Professor and Head, Department of Crop Physiology, University of Agricultural Sciences, Dharwad for his constant guidance, valuable suggestions, fruitful criticism and ever ending affection. I confess that it had been a proud privilege for me to be associated with him since my M. Sc. (Agri.) programme. I am also thankful to Mrs. Abhinetri Chetti and lavanya for their ever lasting love and affection bestowed on me.

I am very thankful to Mrs. Sangeetha Khetrapal, Dr. Attar Singh, Dr. Sita Ram, Dr. D.V. Singh, and Mrs. Smitha for their ever-willing help and kind cooperation during my studies.

I am very thankful to all my seniors Dr. B. Sreekanth, Dr. Pankaj Kumar, Dr. Pravin Prakash, Dr. T. Sivakumar, Dr. V.G.S. Naidu, Dr. Renu Pandey, Satchidanand \& Vijaya and to all my batch mates and juniors, Rajib-Das, Sumesh, Kiran, Smitha, Sarika, Pushpalatha, Jagadeeshan, Prabhu, Vaibhav, Chandra-Gupta, Vijai, Sujatha, Naveen, Linga, Ezhilmathi, Tejpal-Singh for their kind help, guidance, love and care showed on me during my stay at the campus.

My stay at the campus was very fantastic and rich because of my friends, I am very much indebted to Siddhartha \& Sumi, Chakri \& Maya, Tsering \& Dekyi, Meera \& Satya, Salim, Chalpi, Laddu, Malthakka, Padmajakka, Muniratnam sir, Kalps, Rapaka, Vijay, Suwerna, Pratik, Subrato-Dutta \& Mittu, Patil, SuriBabu, Naidu, Debasis, Vasu, Tallatam, G.V., Seshu sir, Srinu, Phani, Nirupa, Chukka, Dipali, Krishna Rao, Sambaiah, Barathidasan, Hemanth, Anji, Senthil, Patro, Prasad, Sribash Roy, Parag, Girish, Azghar, Ramesh, Suresh-A, Lijo, Anil, Jagan, Regi, Tarun Amit, chandrashekar, Bijul, Mrinal, Siva Kumar, Jagdish, Jain, Lal, Khayuum, Trinadh, Suchi, Rampi, Prasanta da, Ranjan da, Petikam, Janiah, Jeevan, 
Manohar, Biju, Gavas, Prasad-tv, Venku, Satish, Praveen, Suresh, Vani, JP, Emmanuel, SP-Ananadakumar, Mahavishunu, Bhurhan, Anoop-Das, Satish-Kawade, Sandeep, Rambabu, Velumurgan, Ashok, Adarsha, Dayanand, Dr. Rajendra-Prasad, Chandru, Mohan, Surendra, Dr. Kaplana, Pratima, and many others. This list is not an end, many more persons are to be acknowledged.

My deep sense of gratitude is due to Mrs. and Mr. Hooda for their love, affection and constant help during my stay at this campus. I will be failing in my duty if I forget to extend my sincere thanks to all those at IARI, New Delhi and also at UAS, Dharwad who rendered their helping hand either directly or indirectly, kind co-operation and contribution to this endeavour.

One uses the choicest of words to measure the encouragement rendered by someone who is close to heart. But, I find any such measure inadequate to quantify the sacrifice, help, love and affection shown to me by beloved friend Parus and sister Radhoos.

I find no words to express my indebtedness for being the reason of my happiness, smile on my face, charm in my life and confidence of my future i.e., my Sailu kuttu.

Above all I must thank my mother, father, brothers, sisters, chinnanas, chinnamas, uncle, aunty, brother-in-laws, vadina, niece, nephew, and grand father for their sacrifices, encouragement and affection for the success of my studies.

I am grateful to IARI for all the necessary facilities and for the award of Institute Fellowship during my period of study.

Finally, I must be grateful to D. Vijay who has neatly designed my manuscript and was there when I am in need and Mounica for helping in formatting the manuscript of this thesis in the final form.

Date: $31-12-2003$

(Gutam Sridhar)

New Delhi 


\section{INTRODUCTION}

The success of food grain production in India over the years is attributed mainly to the performance of wheat crop. Wheat is the most important Rabi season crop in the country, occupying about 50 per cent of the total area under food crops and accounting for more than 70 per cent of the total grain production in Rabi The present world wheat production is about 600 million tonnes. During the crop year 2000, India harvested 75.57 million tonnes of wheat and for the last four years it is the second largest producer of wheat in the world (Anonymous, 2002). The latest estimate for the 2002-2003, is about 70.26 million tones from an area of 24.34 million hectares with a productivity $2.9 \mathrm{t} / \mathrm{ha}$. (Anonymous, 2004).

The native Indian wheat grain is globally recognized for its quality and has always been in demand from overseas clients. One reason for its popularity is that, unlike other cereals, wheat contains a high amount of gluten, the protein that provides the elasticity necessary for excellent bread making. Although over 30, 000 varieties of wheat exist, two major types are bread and durum wheat. The durum wheat, which is used today to make pasta, macaroni etc., is a tetraploid; while, the one which is used for batter based products is hexaploid (Triticum aestivum). Durum is a high value crop owing to its 
use in value-added products. The commercially grown hexaploid bread and tetraploid pasta wheat occupy one fourth of the world's cultivated area and account for 30 per cent of total world grain production (Salunkhe et al., 1985).

The development of new plant architecture with semi-dwarf types replacing the traditional tall types resulted in increasing wheat yields from 1.0 t/ha in early 1960's to nearly 2.9 t/ha in late 1990's was a remarkable achievement, due to which, India witnessed green revolution. Still, to keep pace with the burgeoning population, it is expected that India would need 109 million tons of wheat by 2020 and to achieve this, the productivity has to be increased to 4.0 t/ha from the present level of $2.9 \mathrm{t} / \mathrm{ha}$. Efforts are being made in this direction and Indian Agricultural Research Institute (IARI) has initiated strategic research to develop new plant types in 1994-95. The process of creating a new variety takes several years. Nevertheless, the new plant types developed at IARI in 2000 has large panicles, higher number of grains per spike, 1000-grain weight, biomass and increased sink size.

Efficient assimilate partitioning has generally being considered as a factor in the regulation of plant productivity, but the basis of its control has not been fully exploited. However, Jenner (1974) affirmed that the genotypic variation in grain weight of wheat results from the interaction between potential storage capacity/volume and realization 
of this potential. The variation in grain filling is also the result of interaction between the availability of assimilates to the grain, metabolism of intermediates and synthesizing complex (Jenner and Rathjen, 1978).

The concept of source response to requirement of sink envisages that the path of assimilate flow is not a limiting factor. Vascular bundles could resist the movement of assimilates but this resistance might be overcome by strong sink. The question, thus, arises as what is the basis for differences in translocation behavior between cultivars (Bhardwaj and Verma, 1985). There are many reports that auxins, gibberellins, abscisic acid are involved in the regulation of grain development (Karssesn, 1982; Davies, 1987; Kende and Zeevaart, 1997; Hansen and Grossmann, 2000). Suggestions have been made that plant hormones exert regulatory effects on the direction and rate of translocation of assimilates, though such a control has been denied by Wardlaw and Moncur (1976).

Experiments initiated at Division of Plant Physiology, IARI, by Virendra Nath and his associates has shown that the exogenous application of benzyl adenine (@ $2 \mu \mathrm{g} /$ ear) at the base of wheat ear in PBW-343 and triticale (DT-46) at 6 days after anthesis (DAA) significantly increased photosynthetic rate of flag leaf and developing ear (Sivakumar and Virendra Nath, 2000). A study of shriveling problem in triticale (poorly filled grains); BA treatment increased grain 
dry matter accumulation which in turn resulted in better filling of grains and increased grain weight, better filling of grains. Thus it appears that variation in grain weight between wheat and triticale might be due to different availabilities of growth promoting hormones such as cytokinins (CKs) and assimilates (Sivakumar et al., 2001).

To understand role of cytokinins and abscisic acid ( $A B A)$ during grain development in wheat PBW-343 and triticale, DT-46 and Eronga83, endogenous level of both hormones were quantified with High Performance Liquid Chromatography (HPLC) along with invertase activity in developing grains from 15 to 35 DAA at an interval of 10 days and noticed that high level of $A B A$ content in the grains of triticale might inhibits the grain growth by reducing photo assimilates unloading to the developing grains in the earlier phase of grain development, however, its reduction in later phase might be causing gain shriveling due to improper maturation of the gains. The high level of invertase activity in wheat might have increased the phloem unloading process effectively to the developing grains from the source leaves and rachis, which might be the factor contributing for better grain development $\mathrm{n}$ wheat than triticale (Sivakumar, 2002).

However little is known about the grain filling rate, which is a key factor in increasing the yield potential of new plant types developed at IARI, and whether and how plant hormones are involved in the process. Keeping this in view, the present work regarding grain filling rate among hexaploid and tetraploid wheat genotypes and 
quantification of endogenous levels of IAA, gibberellic acid $\left(\mathrm{GA}_{3}\right)$ and ABA during post anthesis was initiated with the following objectives,

1. to determine the grain growth rate in various wheat genotypes,

2. to determine the changes in endogenous hormonal content in the grains during grain development and

3. to correlate changes in endogenous hormonal content with grain development and yield components. 


\section{REVIEW OF LITERATURE}

The role of plant growth hormones during the grain development process and their effect on different physiological processes is reviewed here under different crops.

\section{1 HORMONAL REGULATION OF GRAIN DEVELOPMENT}

Plant hormones are considered as key regulators to seed development (Davies, 1987; Brenner and Cheik, 1995). The evidence for the regulatory functions of cytokinins has been obtained by correlation between grain weight and the level of endogenous cytokinins in barley and wheat by Michael et al. (1970) and Herzog and Geisler (1982). The highest amounts of cytokinins were recorded at the early growth stages, viz., heading or anthesis or at milk stage, suggesting that the cytokinins may play important role in grain development (Takagi et al., 1989). Analysis of cytokinin levels in developing grains of wheat and rice grains has shown a large transient increases in zeatin ( $Z$ ) and zeatin riboside (ZR) contents, which coincided with the period of maximum endosperm cell division (Morries et al., 1993). Analysis of maize grains by Dietrich et al. (1995) reported that Z and ZR concentrations peaked 9 days after pollination (DAP) and during the period 8-10 DAP, significant increase in cytokinin oxidase specific activity, thus indicating that the cytokinin 
catabolism was enhanced as endosperm cell division stopped. Yang et al. (2000) reported that grain filling per cent was significantly correlated with $Z+Z R$ contents in the grains and roots at the early and middle grain filling stages, but IAA and $\mathrm{GA}\left(\mathrm{GA}_{1}+\mathrm{GA}_{3}+\mathrm{GA}_{4}\right)$ contents in the grains and roots were not significantly correlated with the grain filling per cent suggesting that the cytokinins in the grains and roots during the early phase of grain development play an important role in regulating the grain filling pattern and consequently influence the grain filling percentage.

In an experiment, Borkovec et al. (1990) reported that the higher levels of zeatin and zeatin riboside contents in grains of wheat cultivars and suggested that at the time or before anthesis there would be substantial accumulation (due to intensive transport, probably from the roots) of cytokinins, available for the early grain development. Wheeler (1976) reported that the change in cytokinin activity in the ears was possibly related to the early flowering in the middle of the ear. In an experiment, Herzog (1982) reported that the effects of exogenous cytokinins (CK's) were consistent with the spikelet removal, suggesting that CK's participate in a joint regulation of source and sink activity during grain filling.

Results of Asthir et al. (1998) revealed that gibberellins and cytokinins act as positive modulators of grain sink activity, whereas, ABA acts as a negative modulator. It was confirmed by Ahmadi and Baker (1999) by exogenous application of $A B A,(0.1 \mathrm{mM})$ that there 
was a reduction in transport of sucrose into the grains and lowered the ability of starch synthesis in intact grains. Ober (1991) demonstrated that $A B A$ could be translocated from leaf tissue to grains and acts as a sensory link between developing reproductive structures and maternal tissues deprived of water and also ABA may influence early establishment of sink size through regulation of cell number. Lee et al., (1989) stated that by limiting sucrose supply to the ear, did not alter the levels of IAA or zeatin/zeatin riboside in either grains or bracts of detached ears except for ABA, which increased in the distal and proximal grains showing the regulatory role of ABA. Both field and pot trials of Goldbach (1975) indicated that $A B A$ content in the grain increased up to the start of grain ripening and then decreased gradually with the cessation of dry matter accumulation and rapidly later as the moisture content of the grain decreased.

Experiments with ${ }^{14} \mathrm{C}$-IAA by Wardlaw and Moncur (1976) suggested that the auxin production in the developing grain was not responsible for the assimilate translocation through the peduncle. Bangerth et al. (1985) reported that the IAA content in grains at various positions within wheat cultivars (Solo and Kolibri) increased rapidly from approximately 8 to 20-30 days after anthesis, and then decreased. Differences in spikelet IAA content in different regions of the ear and among florets within a spikelet were positively correlated with the differences in dry matter accumulation. IAA inhibited the 
seed set and grain filling in later developed panicles due to apical dominance on grain development (Xu et al., 1997). The levels of endogenous growth regulators (IAA, ABA, GA and zeatin) were estimated in the developing wheat grains collected at 10, 20, 30 and 40 days after anthesis (DAA) using GLC by Singh et al. (1989) and found that Zeatin (11.0 $\mu \mathrm{g} / \mathrm{grain})$ and GA (0.45 $\mu \mathrm{g} / \mathrm{grain})$ contents were maximum at 10 and 20 DAA, respectively; whereas, IAA and ABA contents were highest ( 4.3 and $2.2 \mu \mathrm{g} / \mathrm{grain}$, respectively) at 30 DAA. They suggested that growth regulators act as mobilizing centers in the developing grains.

Grains in the upper and/or the lower part of the panicle were analysed for endogenous plant hormones by Duan et al., (1999) and found peak contents of $\mathrm{ABA}$ and/or $\mathrm{GA}_{1+3}$ in the developing grains at about the same stage when the highest rate of increase of grain appeared in the upper and in the lower part of the panicle, respectively. After heading, the IAA content in developing grains decreased steadily in both upper and the lower parts of the panicle, while $\mathrm{GA}_{4+7}$ content decreased at first and then increased, and decreased again. At early grain-filling stage, the $A B A$ and $G_{1+3}$ contents in the developing grains were higher in the upper than in the lower part of the panicle.

There was an increase in ABA content during grain development in wheat and loss of $A B A$ from the grain occurred on cessation of grain growth and drying of the grain (King, 1979). In pot trials with 
spring wheat cultivars Kolibri and Solo, the dry weight distribution and auxin levels were investigated at various positions on the ear by Aufhammer and Bangerth (1982). They found that auxin levels reach the maximum before the dry weight increase. The auxin levels between different grain fractions from the basal, central or upper regions of the ear were found to be positively correlated with grain weight. Bhardwaj and Verma (1987) reported that the developing grains are capable of producing higher levels of auxins and could mobilize greater proportions of assimilates from flag leaf to grains, leading to their higher accumulation in grains and resulting in bold size grains at maturity.

You et al. (1997) showed that the contents of IAA and $\mathrm{GA}_{1+3+4+7}$ were less in young wheat panicles of male sterile lines, WAV41A and KV41A compared to V41B during the period when the young panicle developed. It was suggested that the level of male sterility is related to the loss of endogenous hormone especially, IAA. Hess et al. (2002) quantified the hormones in the developing embryo and ovules in wheat and found that IAA content remained low through 9 days post anthesis (DPA) at about $6 \mu \mathrm{mol} \mathrm{kg}^{-1}$ dry weight and then increased sharply to about $38 \mu \mathrm{mol} \mathrm{kg}^{-1}$ dry weights by 19 and 25 DPA. In contrast, embryo IAA content decreased from about $38 \mu \mathrm{mol} \mathrm{kg}^{-1}$ dry weight at 13 DPA to about $15 \mu \mathrm{mol} \mathrm{kg}^{-1}$ dry weights at 19 and 25 DPA. Endosperm ABA content fluctuated between 1.0 and $4.5 \mu \mathrm{mol} \mathrm{kg}{ }^{-1}$ dry weight between 6 and 25 DPA; while embryo ABA content fluctuated 


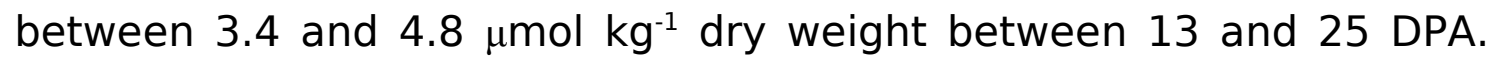
They were of the opinion that these hormonal changes may be involved in the co-ordinated development of embryos in ovule.

\section{2 PHYSIOLOGICAL PARAMETERS}

Saha et al. (1980) reported that the total photosynthetic area above the flag leaf node, comprising leaf sheath, flag leaf, peduncle and head, was highly correlated with grain yield per ear and among them, the highest correlation was found for flag leaf area. A strong dependence of flag leaf photosynthesis in wheat was found on the level of requirement for assimilates by the developing grains (Birecka and Dakic Wlodkowska, 1963; King et al., 1967). However, photosynthesis was shown to be independent of the level of assimilate requirement by the ear (Lupton, 1968; Apel et al., 1973; Austin and Edrich, 1975). Pearman et al. (1979) reported that the photosynthetic productivity of the second leaf during the grain filling period was about half that of the flag leaf.

Herzog (1980) reported that in the first half of the linear phase of growth phase (14 to 28-35 days from heading), the grain development was not related to leaf characteristics like chlorophyll content, assimilation rate per unit area and no marked transport of assimilates from the leaves took place. In the second half of the linear growth phase (28-35 to $42-49$ days from heading) the relation between leaf characteristics and grain growth became closer and the 
latter was correlated with the degree of leaf senescence. Vos et al. (1979) reported that under controlled conditions of high irradiance, maximum rates of photosynthesis in the wheat varieties Opal and Orca were 29.4 and $23.5 \mathrm{mg} \mathrm{CO} / \mathrm{dm}^{2} / \mathrm{h}$, respectively. Measurements of net photosynthesis of the flag leaf blade and ear for each at intervals after anthesis indicated that at the completion of grain development period, a sources of carbohydrate were still available for continued development at all temperatures (Chowdhury and Wardlaw, 1978). Three tall and 33 short bread wheats derived from Norin 10, eight short durum wheats and four triticales were examined by Fischer et al. (1981), and among the short bread wheats, photosynthetic activity four weeks before anthesis and pre-anthesis growth rate were positively correlated with the mature plant height. Photosynthetic activity was also positively correlated with the growth rate during grain filling and yield. Muller (1986) reported that the estimated characteristics of maximum net photosynthetic rate, gas phase diffusive conductance and photorespiration rates decreased from ear emergence to waxy ripeness.

Caley et al. (1990) observed that the peak photosynthetic activity at $20 \mathrm{~d}$ after anthesis was coinciding with the maximum chlorophyll content in the pericarp green layer. Dong (1991) reported that the canopy photosynthesis during grain filling was positively correlated with the grain yield and 1000-grain weight. Pande et al. (1995) found that the rate of post-anthesis flag leaf photosynthesis 
reduced drastically in IWP-5308 genotype resulting in lower grain density. Gent and Kiyomoto (1992) reported that wheat yields are correlated with the photosynthesis and dark respiration per unit ground area from heading to anthesis $(r=0.7)$.

Wang et al. (1997) reported that over 60 per cent of total ${ }^{14} \mathrm{CO}_{2}$ assimilated by late sown winter wheat during grain filling was assimilated in the leaf blades; while, 15, 11 and 11 per cent was in the spikes, leaf sheaths and stem internodes, respectively. Foti (1994) reported that the net photosynthesis of durum wheat spikes was almost completely due to activity in the awns and spikes grown without awns produced a grain dry weight almost 8 per cent lower than awned spikes. Guo et al. (1995) observed that sink capacity increased with the higher increase in leaf photosynthesis and the translocation of photosynthates to ears. Flag-leaf photosynthesis measured by Reynolds et al. (1994) at booting, anthesis and at grain filling stages on different sowing dates was significantly correlated with the grain yield. Shuting (1994) found maximum values for canopy apparent photosynthesis (CAP) between 4-6 $\mathrm{g} \mathrm{CO}_{2} / \mathrm{m}^{2} / \mathrm{h}$ at anthesis stage and it decreased with the age and at grain filling stage.

Liu (1980) reported that the chlorophyll content was positively correlated with the net photosynthetic rate, but, Ashraf et al. (1995) reported that the leaf chlorophyll content was not correlated with higher yield in the genotypes tested. Austin et al. (1987) reported 
that the diploid species have greater total chlorophyll and chl. a/b ratio than hexaploids. Siddique et al. (1989) were of the opinion that decrease in chl. a/b ratio in modern varieties indicates a decrease in PSII reaction center complex relative to light harvesting chl. a/b protein complexes and thus suggesting a loss of adaptation to high irradiance.

Stomatal conductance was also significantly correlated with the performance at all the three stages. The rate of post-anthesis flag leaf photosynthesis declined drastically in IWP5308 when compared with the Sel-111, which could explain its lower grain density. The study showed that the rate of post-anthesis flag leaf photosynthesis and water relation parameters of the developing grain could largely explain the constraints in realization of potential synthetic and storage capacity of wheat genotypes with improved structural components (Pande et al., 1995).

Pramod Kumar et al. (1998) reported that the stomatal conductance and transpiration rate, although possessed a significant positive association with photosynthesis, their association with grain yield was not significant. Frederick (1997) found in the cultivars of wheat that flag leaf $\mathrm{CO}_{2}$ exchange rate (CER) and stomatal conductance began to decrease near the beginning of grain filling. The photosynthesis was found to be positively and significantly associated with stomatal conductance, transpiration rate and total biomass in buck wheat (Subrahmanyam and Dutta, 2000). 


\section{3 SUGARS AND STARCH}

Jiang et al. (2001) reported that total soluble sugars and sucrose contents in the grain of winter wheat (Triticum aestivum) decreased during grain filling stage. Studies of Kumar (1980) revealed that the levels of total sugars, reducing and non-reducing sugars, fructose and sucrose increased up to 14 days after anthesis (DAA) and then declined up to 28 DAA in wheat. The active starch synthesis started at 14 DAA and continued up to 35 DAA and starch phosphorylase activity was especially higher during early grain development, while starch synthase I (ADP glucose a-glucan 4- $\alpha$ glucosyltransferase) had a maximum activity during grain filling (Mengel and Judel, 1981). Major differences between as well as within genotypes for protein and carbohydrate accumulation during seed development over the growth stages were observed by Singhal et al. (1989) and the 18-24 days after anthesis was favorable for carbohydrate biosynthesis.

The experiments of Kumar and Singh (1981) revealed that active starch synthesis started from 14 days onwards and continued until 35 days after anthesis and the free sugars (total, reducing and non-reducing sugars and sucrose) per grain closely followed the changes in the rate of starch accumulation and, in general, were maximum at 14-day stage followed by a decline up to 28 days, with no significant alteration afterwards. None of the sugars had a 
significant relationship with either grain size or starch content. Similarly, Zamski and Grunberger (1995) found a gradual increase in insoluble sugar concentration (starch and fructan) in the ear peduncle during the first month after anthesis, followed by a sharp decrease later in both control and GA treated plants.

Jenner (1979) stated that there is a mechanism operating during the early stages of grain development (before grain-filling begins), which can influence the capacity of the endosperm to accumulate starch, while the capacity to accumulate protein is not subject to the same kind of control. During grain filling (12-27 days after anthesis) there was a decrease in sucrose consumption in highyielding varieties than the low yielding ones (Biryukov and Komarova, 1986). The former accumulated more dry matter in the ear than the latter; while, the latter tended to accumulate more dry matter in the ear-bearing stem. The lower yielding group had a higher starch/sugar ratio than the high yielding group.

Changes in carbohydrate metabolism in developing wheat grains were studied by Kaur and Singh (1987) and found that most of the biochemical activities occurred between 20 and 30 DAA. Jenner et al. (1990) concluded that the rate and duration of starch and protein deposition in the grain are essentially independent events and are controlled and influenced by different factors. Caley et al. (1990) suggested that starch synthase may be a rate-limiting enzyme for starch accumulation and hence the dry weight. They also concluded 
that termination of starch deposition might not be due to lack of starch synthase activity. The starch content was found to increase during grain maturation and reached $65.1,70.2$ and 74.4 per cent in the wheat cultivars Roblin, Dongnong 7742 and Xinkehan 9, respectively (Liu and Li, 1996)

In field studies at Rajkot, Chanda et al. (1999) observed that the absolute rates of starch and dry matter accumulation were highest in Lok-1 followed by Sonera and Raj-1555. The reducing and non reducing sugars were found to be high during early stage and declined with advancement in growth up to almost middle of the grain growth. However, at later stages, there was again increase in the levels of reducing and non reducing sugars. Takahashi et al. (1994) were of the opinion that water soluble sugars accumulate in the culm during day time and are translocated to the grains at night. While total soluble sugars increased throughout the grain development (Sekhon and Singh, 1994).

\section{4 GROWTH PARAMETERS}

Takahashi et al. (1993) divided the grain filling period in wheat into four phases:

- Initial grain filling (from anthesis to cessation of culm elongation) where assimilates are used mainly for culm elongation and the dry weight of the grains increase slightly. 
- Early grain filling (from cessation of culm elongation to milk ripe stage) where assimilates are used for both grain growth and culm reserve.

- Late grain filling (from milk ripe stage to termination of photosynthesis) where assimilates are used entirely for grain growth and the culm reserve is also translocated to the grain and - Final grain filling (from the end of photosynthesis to maturity) where grain growth is supported only by translocation of the culm reserve, because assimilates are no longer being actively produced.

LAl measurements made by Whitfield (1990) between ear emergence and physiological maturity ranged from a maximum of 8 to a minimum of 0.2 . The leaf area, LAl and leaf area duration were found to have high significant positive association with grain yield (Saharan et al., 1985). While, the differences for CGR, specific leaf area and leaf area ratio were evident and significant between the cultivars, but had no relationship with yield. El-Gawad et al. (1985) found higher LAl at heading in cultivars Stork, Giza 155 and Sakha; while, NAR and RGR increased with age until harvest and highest whole plant RGR was achieved at 65-80 days after sowing.

Crop growth analysis by Gales (1983) showed that total dry matter production was strongly correlated with light absorption, which depended on seasonal variation in LAI. Plant growth analysis of spring wheat cultivars by Spitters and Kramer (1986) showed that 
relative growth rate decreased steadily with time due to decline in leaf area/unit plant weight (LAR) and reduction in leaf weight ratio. Herzog (1980) reported that grain growth was slow in the lag phase (0-14 days from heading) and the specific leaf dry weight increased in six winter wheat cultivars. The green area duration from heading to ripening has been found to be very closely correlated to grain yield (Welbank et. al., 1966 and Spiertz et. al., 1971).

Rahman et al. (2000) reported that leaf photosynthesis and crop growth rate were highest at anthesis (70-75 DAS) and leaf area index was maximum at booting stage (60 DAS). Van et al. (1996) stated that wheat cultivars with highest leaf area ratio had higher RGR. He further stated that plants potential RGR is one of the many traits that influence the final biomass production in annual crop species like wheat. Under optimal conditions, plants with higher inherent RGR can potentially produce more biomass and exploit resources to a larger extent than those with lower growth rate. Pramod Kumar et. al. (1998) reported that a positive association of leaf photosynthetic rate, total dry matter production, specific leaf weight, absolute growth rate, relative growth rate, net assimilation rate and harvest index with grain yield in various wheat genotypes.

Simane et al. (1993) concluded that biomass allocation is the major factor explaining variations in RGR among the investigated durum wheat (Triticum turgidum L. var. durum) cultivars. Subrahmanyam and Dutta (2000) reported that the specific leaf mass 
of buckwheat exhibited a strong positive association with the rate of photosynthesis and total dry matter. But, according to Ashraf et al. (1995), leaf area was not correlated with grain yield in the tested genotypes of wheat. Gent and Kiyomoto (1992) reported in their experiments in 1986 and 1987, that the grain yield was positively correlated with positively high leaf area before heading $(r=0.8)$. While, Frederick (1997) reported a decline in LAI prior to grain filling.

\section{5 TRANSLOCATION AND GRAIN FILLING}

The growth of a wheat grain follows a recognized pattern of three phases. Following anthesis, there is a short period of exponential growth, sometimes referred to as the lag phase. During the lag phase, the endosperm cells divide rapidly and the potential size of the grain is determined (Brocklehurst, 1977). During the second phase, starch is deposited in the endosperm with an increase in grain milk and become dough-like consistency. In this phase, the rate at which dry matter is deposited in the grains is usually considered to be constant. The final phase begins when lipids start depositing in the phloem strands supplying the grain with assimilate and the growth of the grain ceases (Zee and O'Brien, 1970). Estimated grain growth rates during the liner phase was $0.5 \mathrm{mg} \mathrm{day}^{-1}$ (Simons and Crookston, 1979) to $2.3 \mathrm{mg} \mathrm{day}^{-1}$ (Sofield et al., 1977) depending upon the temperature, genotype, grain position, moisture and nutrient status of the plant. 
The pattern of translocation of ${ }^{14} \mathrm{C}$-labelled compounds in flag leaf assimilates in wheat (Triticum aestivum L. cv. Gabo) during grain development indicated that there was greater assimilate requirement by the ear, the more rapid was the speed of movement of assimilates through the peduncle to the ear and lower was their concentration (Wardlaw and Moncur, 1976). Cruz-Aguado et al. (1999) reported that changing inherent source-sink ratio modified the pattern of flag leaf ${ }^{14} \mathrm{C}$ assimilate partitioning and resulted in increased retention of ${ }^{14} \mathrm{C}$ in flag leaf and changed the pattern of outflow to other organs. The participation of stem reserves in grain filling and the existence of genotypic differences corroborated in response to availability of photoassimilates.

Blum et al. (1994) observed genotypic differences in the pattern of allocation and mobilization of dry matter in the stem of wheat. Yang et al. (2001) stated that remobilization and transfer of the prestored food in vegetative tissues to the grains in monocarpic plants require the initiation of whole plant senescence. Herzog (1982) concluded that changing the ratio of source and sink size influence grain weight by creating different intrinsic growth potentials in the grains. The estimated duration of grain growth from anthesis to physiological maturity vary from 17 days (Van Sanford, 1985) to 38 days (Gebeyehou et al., 1982). The genotypes with highest grain dry weight had shorter duration and higher maximum rates of grain filling (Duguid and Brule-Babel, 1994). 


\section{6 YIELD AND YIELD COMPONENTS}

Grain yield of wheat is determined by the number of ears per unit area, number of grains per ear and grain weight (Evans, 1978). Grain number and the duration of grain filling determine individual grain weight (Ralph, 1984). Grain weight is also determined by factors that affect grain volume (Millet and Pinthus, 1984). Differences in grain weight of wheat genotypes as well as differences in weight between the grains within a single wheat spike have been found to be due primarily to differences in the rate of dry matter accumulation in the grain (Pinthus and Sar-Shalom, 1978; Simmons and Crookston, 1979).

Whether grain filling and yield are limited by sink capacity or assimilate supply depends strongly on the cultivar and environmental conditions. It is thus probable that there will be more than one route to increased yield and that the most appropriate route will depend on cultivars and weather (Peat, 1985). The hexaploids generally have more grains per ear than the tetraploids and the biomass and grain yield/plant will be in the order of hexaploids, followed by diploids and tetraploids (Kosina, 1981; Guzy et al., 1989).

Tuttobene et al. (1996) reported that there was increase in grain yield of durum wheat increased with an increase in LAI up to a value of 7.8 for Amedeo and 10.2 for Creso. Results of the Zamski and Grunberger (1995) suggested that of the two high-yielding wheat 
cultivars that usually give identical yields, the one with long multispikelet ears (LE) and lighter grains had significantly greater unexpressed potential for high yield than the cultivars with shorter ears (SE) and heavier grains. The size of flag leaf was found to be significantly correlated with grain yield/ear $(r=0.512)$ and a relatively close correlation ( $r=0.874)$ existed between the grain number/ear and grain weight/ear (Apel and Lehmann, 1970). The grain fresh and dry weights increased up to 40 DAA and decreased thereafter with maturation in the studies of Singh et al. (1989) and the rate of dry matter accumulation was maximum ( $1.8 \mathrm{mg} / \mathrm{grain} /$ day) between 20 30 DAA. Duan et al., (1999) reported that the grain fresh weight and grain filling rate at early grain development stage in rice (Oryza sativa L.) were higher in the upper than in the lower part of panicles during grain filling. Cai (1991) reported that rate of grain filling increased to its highest rate at about 20 days after the beginning of filling and then decreased.

Flag leaf labeled at flowering transported nearly 90 per cent of ${ }^{14} \mathrm{C}$ assimilates to stem and glumes, and then reallocated to grain before maturity Duan et al., (2000). While 70 per cent of total ${ }^{14} \mathrm{C}$ assimilates in the flag leaf were exported to grain, which was the predominant sink during grain filling. At the dough stage, only 13 per cent of assimilates were exported to grain; while about 25 per cent were partitioned to roots first and then redistributed to grain before the full ripe stage. The grain fresh weight and grain filling rate at the 
early grain development stage in rice (Oryza sativa L.) were found to be higher in the upper than in the lower part of panicles during grain filling (Duan et al., 1999; 2000).

Rawson and Ruwali (1972) divided the central spikelets of the main ear in Kalyansona into 5 groups (a to e) from base to the apex. They found that the grain growth rates for the greater part of filling were in the order of $b>a>c>d>e$ and the final weight/grain for these florets was 42, 40, 37, 26 and 12 mg, respectively. Assimilate deposition in the ears of spring wheat cvs. Kolibri and Solo (high and low individual grain weights, respectively) was studied by Stamp and Geisler (1976) and found that there was little difference between the two cultivars in the rate of assimilate deposition in the ears during first three weeks after ear emergence, but from the 4th and 5th weeks, the rate of dry matter accumulation in individual grains was 26-29 per cent greater in Kolibri; than in Solo, which was mainly responsible for the higher grain weight in Kolibri even though there was longer period (5 days) of assimilate deposition.

Average harvest index and 100-grain weight were higher in spring wheat populations with long grain-filling period (GFP) than those with shorter GFP lines (Sharma, 1994). Many researchers reported a positive correlation between GFP and grain yield (Spiertz et al., 1971; Gebeyehon et al., 1982). 
Guzy et al. (1989) reported that among fourteen diploids, tetraploids and hexaploids of Triticum aestivum accessions, biomass and grain yield per plant were highest for the hexaploids followed by diploid and tetraploids while, the spike number was highest in diploids followed by hexaploids and tetraploids. Bamakhramah et al. (1984) examined twenty-nine accessions of Triticum for different yield components and found that mean whole plant and main shoot harvest index for the ploidy groups exhibited significant $(p<0.01)$ increase from diploid to tetraploids and from tetraploids to hexaploids. They further found a marked reduction in shoot number and per cent of fertile shoots per plant and increase in grain number per spikelet and grain size from diploids to early tetraploids. 


\section{MATERIALS AND METHODS}

Experiments were carried out to study the endogenous hormonal changes during grain development in three hexaploid (DL 1266-1, DL 1266-2 and PBW 343) and three tetraploid (HD 4530, 8498 and PDW 233) wheat lines grown in cement pots of $30 \mathrm{~cm} \times 30$ $\mathrm{cm} \times 50 \mathrm{~cm}$ size at the Pot culture of the Division of Plant Physiology, Indian Agricultural Research Institute, New Delhi during Rabi seasons of 2001-02 and 2002-03. The details of materials used and methods adopted during the course of investigation are given in this chapter.

\subsection{PLAN OF EXPERIMENT}

The experiment consisted of the following details, Location : Pot culture, Division of Plant Physiology, IARI, New Delhi

Plant material:-

Hexaploid lines : DL 1266-1, DL 1266-2 (new plant types) and PBW 343

Tetraploid lines: HD 4530, HI 8498 and PDW 233

\subsection{SAMPLING PROCEDURE}


The heading and flowering dates of individual panicles were labeled and recorded. Ten to twelve labeled panicles were sampled at 7, 15, 25 and 35 days after anthesis (DAA) in each line. The spikelets were divided into two parts: one was frozen in liquid nitrogen for hormonal assay and the other one dried in oven at $80^{\circ} \mathrm{C}$ till a constant weight was achieved, then dehulled and weighed for determining the grain growth rate. For recording growth analysis parameters, five pots were selected at random and the plants were sampled at 5, 15, 25 and 35 DAA and at harvest. Stem, leaves and ear portions of the plants were separated and the data pertaining to growth analysis were recorded.

\subsection{GROWTH AND MORPHOLOGICAL CHARACTERS}

\subsubsection{Plant height}

The plant height was recorded from base of the plant to the growing tip in five plants at different dates of sampling and the average plant height was expressed in centimeters.

\subsubsection{Number of tillers per plant}

The tillers were counted separately for five different plants and the average value was recorded.

\subsubsection{Leaf Area (LA)}


Leaf area was measured by leaf area meter (LICOR 3100) and expressed as $\mathrm{cm}^{2} /$ plant.

\subsubsection{Leaf weight (LW)}

After the leaf area was recorded, the samples were dried at $80^{\circ}$ C for till a constant weight was achieved and dry weights were recorded ad expressed as g/plant.

\subsection{GROWTH ANALYSIS}

For recording growth analysis, five pots were taken at each sampling. Leaves stem and ear portions were separated and their dry weights were determined. Leaf area was measured using leaf meter (LICOR - 3100, USA). The data of dry weights of different plant parts, total dry weight and leaf area were used for computing various growth parameters. Grain growth rate, absolute grain growth rate, relative growth rate of ear and absolute growth rate of ear was also recorded simultaneously.

\subsubsection{Grain growth rate (GGR)}

Grain growth rate was recorded at an interval of 10 days from 5-35 days after anthesis and at maturity according to Zhu et al. (1988).

Grain growth rate $=\frac{\log _{\mathrm{e}} W_{2}-\log _{\mathrm{e}} W_{1}}{\mathrm{t}_{2}-\mathrm{t}_{1}} \mathrm{~g} / \mathrm{g} /$ day 
where,

$W_{1}$ and $W_{2}$ are dry weights of grains at time $t_{1}$ and $t_{2}$, respectively.

\subsubsection{Absolute growth rate seed (AGR)}

The absolute grain growth rate was calculated by using the formula given by Radford (1967) and expressed in g/day.

Absolute grain growth rate $=\frac{W_{2}-W_{1}}{t_{2}-t_{1}}$ g/day

where,

$W_{1}$ and $W_{2}$ are dry weights of grains at time $t_{1}$ and $t_{2}$, respectively.

\subsubsection{Relative growth rate of ear (RGR)}

Relative growth rate of ear was recorded at an interval of 10 days from 5-35 days after anthesis and at maturity according to Zhu et al. (1988).

Grain growth rate $=\frac{\log _{e} W_{2}-\log _{e} W_{1}}{t_{2}-t_{1}} \quad g / g /$ day where,

$W_{1}$ and $W_{2}$ are dry weights of ears at time $t_{1}$ and $t_{2}$, respectively.

\subsubsection{Absolute growth rate of ear (AGR)}


The absolute grain growth rate was calculated by using the formula given by Radford (1967) and expressed in g/day.

Absolute grain growth rate $=\frac{W_{2}-W_{1}}{t_{2}-t_{1}}$ g/day where,

$W_{1}$ and $W_{2}$ are dry weights of ears at time $t_{1}$ and $t_{2}$, respectively.

\subsubsection{Relative growth rate (RGR)}

Relative growth rate is the increase in dry weight per unit dry weight per unit time and is expressed as $\mathrm{g} / \mathrm{g} /$ day and calculated by the formula of Blackman (1919) as follows,

Relative growth rate $=\frac{\log _{\mathrm{e}} \mathrm{W}_{2}-\log _{\mathrm{e}} \mathrm{W}_{1}}{\mathrm{t}_{2}-\mathrm{t}_{1}} \mathrm{~g} / \mathrm{g} /$ day

where,

$W_{1}$ and $W_{2}$ are total dry weights of samples at $t_{1}$ and $t_{2}$, respectively.

\subsubsection{Net assimilation rate (NAR)}

Net assimilation rate is the rate of increase in dry weight per unit leaf area per unit time (Watson, 1952) and is expressed as $\mathrm{g} / \mathrm{m}$. ${ }^{2} /$ day. It was calculated by the formula of Radford (1967) as follows, Net assimilation rate $=\frac{\left(W_{2}-W_{1}\right)\left(\log _{e} L_{2}-\log _{e} L_{1}\right)}{\left(L_{2}-L_{1}\right)\left(t_{2}-t_{1}\right)} \quad \mathrm{g} / \mathrm{cm}^{2} /$ day where, 
$W_{1}$ and $W_{2}$ are total dry weights of plant at time $t_{1}$ and final $t_{2}$ respectively and $L_{2}$ and $L_{1}$ are the total leaf area at time $t_{1}$ and $t_{2}$, respectively.

\subsubsection{Leaf area ratio (LAR)}

Leaf area ratio was calculated as the green leaf area $\left(\mathrm{cm}^{2}\right)$ divided by total dry matter $(\mathrm{g})$.

Lead area ratio $=$ Leaf area $/$ total dry matter $\left(\mathrm{cm}^{2} / \mathrm{g}\right)$

\subsubsection{Specific leaf area (SLA)}

Specific leaf area was computed as green leaf area $\left(\mathrm{dm}^{2}\right)$ divided by green leaf weight $(g)$.

Specific leaf area $=$ Leaf area/leaf weight $\left(\mathrm{dm}^{2} / \mathrm{g}\right)$

\subsubsection{Specific leaf weight (SLW)}

Specific leaf weight was computed as green leaf weight $(\mathrm{g})$ divided by green leaf area $\left(\mathrm{dm}^{2}\right)$.

Specific leaf weight $=$ Leaf weight/leaf area $\left(\mathrm{dm}^{2} / \mathrm{g}\right)$

\subsection{PHYSIOLOGICAL PARAMETERS}

\subsubsection{Measurement of Photosynthetic rate and Stomatal conductance}

Photosynthetic rate of the flag leaf of all the lines was measured at 10, 20 and 30 DAA using the portable photosynthetic 
system, (LICOR 6200, USA). This is a closed system that measures changes in $\mathrm{CO}_{2}$ concentration over time. Measurements were made between 10:00 A.M. to 12:00 noon. The leaf was enclosed in assimilation chamber and the net exchange of $\mathrm{CO}_{2}$ between the flag leaf and the atmosphere was measured. The photosynthetic rate was expressed as $\mu \mathrm{mol} \mathrm{CO}_{2} \mathrm{~m}^{-2} \mathrm{~s}^{-1}$ and the stomatal conductance was expressed as $\mathrm{cm} \mathrm{s}^{-1}$.

\subsubsection{Chlorophyll content}

The chlorophyll content of the flag leaf at 10, 20 and 30 DAA was estimated by Hiscox and Israelton (1979). In this method, $50 \mathrm{mg}$ of leaf samples were incubated in $7.0 \mathrm{ml}$ dimethyl sulfoxide (DMSO) at $65^{\circ} \mathrm{C}$ for 2 hours. At the end of the incubation period, supernatant was decanted and the volume was made up to $10 \mathrm{ml}$ with DMSO. The absorbance of the extract was read at 645 and $663 \mathrm{~nm}$ in spectronic20 keeping DMSO as blank. The amount of chlorophyll was calculated by using the following formulae;

Chlorophyll $\mathrm{a}=(12.7 \times \mathrm{A} 663)-(2.69 \times \mathrm{A} 645) \mathrm{x}^{\mathrm{V}}$ $(\mathrm{mg} / \mathrm{g}$ fr. wt.)

$$
1000 \times W
$$

Chlorophyll b $=\left(22.9 \times\right.$ A 645) $-\left(4.68 \times\right.$ A 663) $x^{V}$ fr. wt.)

$$
1000 \times W
$$

Total Chlorophyll $=\left(20.2 \times\right.$ A 645) $-(8.02 \times \text { A 663) })^{\mathrm{V}}$ fr. wt.) 
$1000 \times W$

where,

A645 and A663 are the absorbance at 645 and $663 \mathrm{~nm}$, respectively;

$\mathrm{V}=$ volume of solvent and $\mathrm{W}=$ the weight of the sample $(50$ $\mathrm{mg})$.

\subsection{HORMONE EXTRACTION}

\subsubsection{Procedure}

Endogenous plant hormones were extracted by the modified procedures of Sundberg (1990), Kojima (1995) and Yang et al (2000).

Samples corresponding to $2.0 \mathrm{~g}$ dehulled and frozen grains were homogenized in a mortar (on ice) with $80 \%$ methanol supplemented with $10 \mathrm{mg} / \mathrm{l}$ butylated hydroxytoluene (BHT) as an antioxidant. The homogenate was filtered and the solid residue was further extracted twice with the same solvent. The methanolic extracts were kept for continuous stirring at $4{ }^{\circ} \mathrm{C}$ in the dark for about 4 hours and centrifuged at $10,000 \mathrm{rpm}$ for $10 \mathrm{~min}$ at the same temperature. The supernatants were combined and concentrated to a water residue in vacuum at $40 \circ \mathrm{C}$ by rotatory evaporation. The volume was adjusted to $10 \mathrm{ml}$ with $0.05 \mathrm{M}$ Na-phosphate buffer, $\mathrm{pH}$ 7.5, and neutral compounds were removed by partitioning with $2 \times 5$ $\mathrm{ml}$ fresh diethyl ether in a $20 \mathrm{ml}$ glass vial. The ether was layered on 
to the aqueous phase and the two-phase system was gently stirred for 3 min on a multipoint magnetic stirrer.

After discarding the ether phase, the aqueous phase was adjusted to $\mathrm{pH} 2.7$ with $1 \mathrm{M} \mathrm{HCl}$ and partitioned as described above with $3 \times 5 \mathrm{ml}$ fresh diethyl ether. Saving the aqueous phase for further purification of gibberellins, the combined ether phases were reduced to dryness (anhydrous $\mathrm{Na}_{2} \mathrm{SO}_{4}$ was added to remove water from the ether phase) and used for the estimation of IAA and ABA.

The aqueous phase after partitioning against diethyl ether was partitioned two times against $10 \mathrm{ml}$ of ethyl acetate and the aqueous phase was discarded. The ethyl acetate layer was partitioned two times against $10 \mathrm{ml}$ of $0.2 \mathrm{M} \mathrm{K}_{2} \mathrm{HPO}_{4}$ and the organic layer was discarded. The aqueous phase was adjusted to $\mathrm{pH} 2.5$ with $\mathrm{H}_{3} \mathrm{PO}_{4}$. The acidified phase was partitioned two times against $10 \mathrm{ml}$ of ethyl acetate. The ethyl acetate layer was dried over anhydrous $\mathrm{Na}_{2} \mathrm{SO}_{4}$ overnight and used for the estimation of GA.

\subsubsection{Hormone analysis}

The dried extracted samples were reconstituted in $5 \mathrm{ml}$ HPLC grade methanol and were analysed by a Thermo Separation Product model Spectra System P2000 liquid chromatograph, equipped with a variable wavelength UV-150, UV-VIS detector and a Rheodyne injector (20 $\mu$ loop), and connected to Datajet reporting integrator. 
The chromatographic conditions were as follows,

Stationary phase : LiChrosorb RP $18(7 \mu \mathrm{m})$ packed in a stainless steel

column ( $250 \mathrm{~mm} \times 4.6 \mathrm{~mm}$ i.d.)

Mobile phase : Methanol:Water $(60: 40 \mathrm{v} / \mathrm{v})$

Flow rate $\quad: 0.7 \mathrm{ml} / \mathrm{min}$

Detector : $265 \mathrm{~nm}$

Sensitivity $\quad: 0.08$ a.u.f.s

The retention time of the peaks in authentic hormones and in the samples obtained by the chromatograph was compared and the peak area was measured with single channel computing integrator and was used to quantify the amount of hormone present in the sample.

\subsection{ESTIMATION OF TOTAL SOLUBLE SUGARS}

Total soluble sugars in seeds were estimated colorimetrically in two replications as per the procedure given by Dubois et al. (1951).

\subsubsection{Extraction}

Five grams of seed sample was boiled in water for 20 minutes and after cooling, it was ground in about $15 \mathrm{ml}$ of distilled water. The homogenate was centrifuged at 3,000 rpm for 15 minutes. The 
supernatant was used for soluble sugar estimation. The remaining pellet was stored in refrigerator for starch estimation.

\subsubsection{Estimation}

To $0.1 \mathrm{ml}$ of aliquot, $1 \mathrm{ml}$ of 5 per cent phenol solution was added, to which, $5 \mathrm{ml}$ of concentrated $\mathrm{H}_{2} \mathrm{SO}_{4}$ was added with the help of automatic dispenser in such a way that it hits the surface of reaction mixture directly. The contents were shaken and cooled at room temperature. A blank was prepared in the same way with water instead of the aliquot. The intensity of the colour was read at $490 \mathrm{~nm}$ in a spectrophotometer (Beckman DU-640, USA). A standard curve was prepared using 10 to $100 \mu \mathrm{g} / \mathrm{ml}$ of glucose solution. Total soluble sugars were calculated using the standard curve.

\subsection{ESTIMATION OF STARCH}

The starch content in the seeds was estimated by the method of Colowick and Kaplan (1957).

\subsubsection{Extraction}

The pellet obtained after centrifugation earlier for the estimation of sugars was dried overnight in an oven at $110^{\circ} \mathrm{C}$ and cooled in a desiccator. From this, $0.25 \mathrm{~g}$ was taken into centrifuge tube, to which, $5 \mathrm{ml}$ of water was added and stirred with a glass rod, then $6.5 \mathrm{ml}$ of $52 \%$ perchloric acid was added by continuous stirring 
for five minutes. The extraction was repeated two times and the supernatant was collected in $100 \mathrm{ml}$ volumetric flask and then the volume was made up to $100 \mathrm{ml}$ with distilled water.

\subsubsection{Estimation}

The amount of glucose present in the aliquot was determined by phenol sulphuric acid method as described by Dubois et al. (1951). The starch content was calculated according to formula, Starch = glucose $\times 0.9$

\subsection{YIELD AND YIELD COMPONENTS}

Plants were harvested when the ears were fully matured. Each pot was taken as replication and the yield and yield components viz., number of ears per plant, ear weight, number of grains per ear, 1000seed weight, total seed yield per plant were recorded. Finally harvest index was calculated as ratio of the economic yield to the biological yield and expressed in per cent and fruiting co-efficient was also calculated as ratio of grain yield to the total dry matter at harvest.

\subsection{STATISTICAL ANALYSIS}


The experimental data was subjected to statistical analysis following completely randomized block design as described by Panse and Sukhatme (1967). 


\section{EXPERIMENTAL RESULTS}

Experiments were conducted to study the hormonal changes during grain development in hexaploid and tetraploids of wheat during Rabi seasons of 2001 and 2002 at Pot culture of the Division of Plant Physiology, Indian Agricultural Research Institute, New Delhi. It was intended to determine grain growth rate and changes in biophysical, biochemical, growth and endogenous hormonal levels in the grains during grain growth and development. It was also intended to relate the changes in endogenous hormonal levels with grain growth during both the seasons. Since, the trend was similar during both the seasons, the data were subjected for pooled analysis and the results are presented in this chapter.

\subsection{YIELD PERFORMANCE OF HEXAPLOID AND TETRAPLOID WHEATS}

Varieties with the difference in the production of grains among tetraploid and hexaploids wheat genotypes were examined for two consecutive seasons and studied for morphological as well as physiological parameters of seed yield and the data are furnished in Table $1 \& 2$ and also represented graphically in Fig. 1 . 
High yield of hexaploids was associated with the high 1000-gain weight (Table $1 \&$ Fig. 1). The number of ears/plant was almost at par. Data on grain weight/plant showed that hexaploids were having more seed yield as compared to tetraploids. Leaf area recorded at 25 DAA clearly indicated that it is much more in hexaploids (DL-1266-1 \& DL1226-2) followed by PBW-343 (Table 2 \& Fig.1). As regarded to fruiting coefficient (seed yield per gram of total dry matter produced) was much more in hexaploids than tetraploids. Thus it is obvious that hexaploids had recorded higher seed yield/plant by virtue of having more 1000-grain weight.

\subsection{YIELD AND YIELD COMPONENTS}

Genotypic differences in yield and yield components at harvest among hexaploids and tetraploids of wheat are presented in Table 3. The grain yield differed significantly between the genotypes and among the genotypes, hexaploids recorded significantly higher grain yield over tetraploids. Among hexaploids the maximum grain yield was recorded in DL-1266-2 (17.54 g/plant), while among tetraploids the maximum grain yield of $12.51 \mathrm{~g} /$ plant was recorded in HD-4530.

The seed number/ear also varied significantly among the genotypes and the genotypes DL-1266-2 and PDW-233 respectively recorded higher seed number/ear among hexaploids and tetraploids. The data on seed weight/ear presented in Table 18 indicated 
significant differences between the genotypes with DL-1266-2 of hexaploids having significantly higher seed weight/ear, but it was on par with DL-1266-1, PBW-343 and HI-8498. The lowest seed weight of 2.01 g/ear was recorded in HD-4530; however, it was on par with PBW-343 of hexaploids. The data on 1000-grain weight indicated that it was maximum in DL-1266-2 of hexaploids, which was on par with DL-1266-1 and were significantly superior over all other genotypes, irrespective of hexaploids or tetraploids. However, the other genotypes did not differed significantly with each other. The chaff weight/ear also differed significantly among genotypes with DL-12661 and DL-1266-2 of hexaploids having significantly higher values over all other genotypes. However, the lowest chaff weight of $1.12 \mathrm{~g} / \mathrm{ear}$ was recorded in HD-4530 of tetraploids. The data on harvest index showed that it was higher among hexaploids compared to tetraploids. The maximum harvest index of 58.9 was recorded in DL-1266-2 of hexaploids, which was on par with other genotypes among hexaploids. The lowest harvest index of 45.46 was recorded in PDW233 of tetraploids.

\subsection{MORPHOLOGICAL CHARACTERS}

The data on various morphological characters viz., plant height, tiller number/plant, ear number/plant and ear length were collected at harvest and presented in Table 4. The data indicated significant differences between the genotypes for all the parameters. It was 
observed that among the genotypes, the plant height and ear lengths were significantly higher in hexaploids over tetraploids. Among hexaploids, the plant height was significantly higher in DL-1266-1 over all others except, DL-1266-2. It did not differ significantly with HD-4530 of tetraploids. Similarly, the genotypes PBW-343 among hexaploids and $\mathrm{HI}-8498$ among tetraploids had significantly lower plant height and were at par with each other. The genotypes PDW233 and HD-4530 among tetraploids also did not differ significantly with each other.

It was observed that hexaploids had significantly higher ear length compared to tetraploids. But, no significant differences were observed between the genotypes among hexaploids and tetraploids. The data on tiller number indicated significant differences between the genotypes with PBW-343 of hexaploids having significantly higher tiller number over all others except, PDW-233 of tetraploids. Similarly, DL-1266-1 and DL-1266-2 of hexaploids and PBW-343 and HI-8498 of tetraploids did not differ significantly among themselves. It was observed that PBW-343 of hexaploids had significantly higher ear number/plant but did not differ significantly with any of the genotypes among tetraploids. The lower ear number of 3.7 was recorded in DL1266-2, which was on par with DL-1266-1.

\subsection{PLANT GROWTH AND DEVELOPMENT}


The data on various plant growth and development parameters were computed and presented in Tables 5 to 14 .

\subsubsection{Leaf area $\left(\mathrm{cm}^{2} /\right.$ plant $)$}

The data on leaf area presented in Table 5 indicated significant differences among the genotypes at all the days after anthesis (DAA). The leaf area increased from 5-25 DAA and declined thereafter at 35

DAA in all the genotypes. The genotype DL-1266-2 recorded significantly higher leaf area over all other genotypes, irrespective of hexaploids or tetraploids. At 15 DAA, the genotype DL-1266-2 had significantly higher leaf area over all others and the genotypes DL1266-1 and PBW-343 of hexaploids and PDW-233, PBW-343 and HI8498 of tetraploids did not differ significantly with each other. A similar trend was observed at 25 and 35 DAA with DL-1266-2 having significantly higher leaf area over all other genotypes.

\subsubsection{Leaf dry weight (g/plant)}

The leaf dry weight presented in Table 6 showed significant differences among genotypes and the mean leaf dry weight increased from 5 to 25 DAA and decreased at later stages. In general, hexaploids showed significantly higher values over tetraploids at all the stages. Among hexaploids, at 5 DAA, the genotype DL-1266-1 recorded higher value. But, it did not have significant difference with 
other genotypes. Among the tetraploids, a similar tread was seen with the genotype PDW-233 having significantly lower value. Similarly at 15, 25 DAA and at harvest, the genotypes DL-1266-2 and PDW-233 recorded significantly higher and lower values, respectively. All the hexaploids and tetraploids did not differ significantly among themselves at 25, 35 DAA and at harvest.

\subsubsection{Specific leaf area $\left(\mathrm{dm}^{2} / \mathrm{g}\right)$}

The data on specific leaf area presented in Table 7 indicated significant differences among the genotypes at all the days after anthesis. Among the genotypes, the hexaploids had higher SLA over tetraploids at 5 and 35 DAA; while, tetraploids had higher SLA at 15 and 25 DAA. The genotype DL-1266-2 among hexaploids and PDW233 among tetraploids recorded significantly higher SLA over others in their respective groups at 5DAA. While, PBW-343 among hexaploids and $\mathrm{HI}-8498$ among tetraploids had significantly lower SLA. At 15 DAA, the genotypes belonging to tetraploids recorded higher values over hexaploids. Among the genotypes, PDW-233 of tetraploids had significantly higher SLA over all other genotypes irrespective of hexaploids or tetraploids. While, DL-1266-1, DL-12662, PBW-343, HD-4530 and HI-8498 were at par with each other. A similar trend was observed at 25 DAA with PDW-233 having significantly higher value over others, but was on par with PBW-343, HD-4530 and HI-8498. At 35 DAA DL-1266-2 of hexaploids recorded 
significantly higher SLA over all other genotypes while PDW-233 recorded significantly lower value.

\subsubsection{Specific leaf weight $\left(\mathrm{g} / \mathrm{dm}^{2}\right)$}

The data on specific leaf weight presented in Table 8 indicated significant differences among the genotypes at all the stages. The hexaploids had higher values at 15 and 25 DAA; while at 35 DAA, tetraploids recorded higher values. At 5 DAA, PBW-343 recorded higher value over all other genotypes irrespective of tetraploids or hexaploids. While, the genotypes DL-1266-2 and PDW-233 belonging to hexaploids and tetraploids respectively had significantly lower values but were on par with each other. No significant differences were found between any of the genotypes among hexaploids at 15 DAA. While, PDW-233 of tetraploids had significantly lower SLW over all others at this stage. At 25 DAA, the genotypes DL-1266-1, DL1266-2 of hexaploids and HD-4530 and HI-8498 of tetraploids were at par with each other. Similarly, PBW-343 of hexaploids and HD-4530 and HI-8498 of tetraploids did not differ significantly with each other. However, none of the genotypes among tetraploids differed significantly with each other. At 35 DAA, the lowest SLW of 0.65 was recorded in DL-1266-2 of hexaploids, which was on par with PBW-343, HD-4530 and HI-8498. A maximum SLW of 0.78 was recorded in PDW233 of tetraploids. 


\subsubsection{Leaf area ratio $\left(\mathrm{cm}^{2} / \mathrm{g}\right)$}

The data pertaining to leaf area ratio showed significant differences among the genotypes at all the stages (Table 9). In general, it decreased continuously from 5 to 35 DAA in all the genotypes and in general, the genotypes belonging to hexaploids had higher LAR at 25 and 35 DAA; while, the genotypes belonging to tetraploids had higher LAR at 5 and 15 DAA. The maximum LAR of 25.6 was recorded in HD-4530 belonging to tetraploids but was on par with PBW-343 of hexaploids and PDW-233 and HI-8498 of tetraploids. Significantly lower LAR was recorded in DL-1266-1 of hexaploids but was on par with all the genotypes among hexaploids and PDW-233 of tetraploids at 5 DAA. A similar trend was noticed at 15 DAA with DL1266-1 of hexaploids having significantly lower LAR but was on par with DL-1266-2 and PBW-343 of hexaploids and PDW-233 of tetraploids.

The leaf area ratio decreased at 25 DAA compared to 15 and 5 DAA. Among genotypes, PBW-343 of hexaploids recorded significantly higher LAR of 14.6 over all other genotypes except, DL-1266-2, irrespective of tetraploids or hexaploids. Whereas, the lowest LAR of 12.32 was recorded in PDW-233 of tetraploids, but it was on par with HI-8498. At 35 DAA, the genotype DL-1266-2 recorded significantly higher LAR, but it was on par with PBW-343 and HD-4530. The lowest 
LAR of 8.19 was recorded in DL-1266-1 of hexaploids which was on par with PDW-233 of tetraploids.

\subsubsection{Stem dry weight (g/plant)}

The data on stem dry weight presented in Table 10 indicated significant differences between the genotypes at all the days after anthesis, except at 25 DAA. Among genotypes, the stem dry weight was significantly higher in hexaploids compared to tetraploids at all the stages. At 5 DAA, the genotype DL-1266-2 belonging to hexaploids recorded significantly higher stem dry weight over all other genotypes, irrespective of hexaploids or tetraploids but was on par with DL-1266-1. Similarly, the genotypes PBW-343 of hexaploids PDW-233, HD-4530 and HI-8498 of tetraploids did not differ significantly with each other. A similar trend was observed at 15 DAA with DL-1266-2 having significantly higher stem dry weight of 9.57 g/plant followed by DL-1266-1 (9.31 g/plant).

At 25 DAA also, DL-1266-2 recorded higher stem dry weight, but was on par with all the genotypes except HI-8498 belonging to tetraploids. However, no significant differences were observed between the genotypes at this stage. At 35 DAA, the genotypes belonging to hexaploids did not differ significantly with each other. 
Similarly the genotypes belonging to tetraploids also were at par with each other. At harvest, DL-1266-1 of hexaploids had significantly higher stem dry weight, but was on par with DL-1266-2 and both differed significantly with all other genotypes, irrespective of hexaploids or tetraploids. No significant differences were observed between the genotypes among tetraploids and these genotypes also were on par with PBW-343 of hexaploids.

\subsubsection{Ear dry weight (g/plant)}

The data on ear dry weight indicated significant differences between the genotypes at all the stages (Table 11). The data further indicated that the ear dry weight increased continuously from 5 DAA until harvest in all the genotypes. At 5 DAA, the genotype DL-1266-2 belonging to hexaploids recorded significantly higher ear dry weight over all other genotypes except DL-1266-1 of hexaploids. However, no significant differences were observed between any of the genotypes among tetraploids and these genotypes were at par with each other and with PBW-343 of hexaploids.

It was further observed that the ear dry weight was significantly higher in hexaploids compared to tetraploids at all the stages until harvest. At 15 DAA, the genotype DL-1266-2 belonging to hexaploids recorded significantly higher ear dry weight over all other genotypes. 
Similarly, no significant differences were observed between any of the genotypes among tetraploids. At all other stages, i.e. at 25, 35 DAA and harvest, tetraploids showed no significant differences. But, hexaploids differed significantly at these stages. The genotypes DL1266-2 recorded significantly higher ear dry weight at all the stages. At harvest with DL-1266-2 recorded significantly higher ear dry weight of $27.89 \mathrm{~g} /$ plant.

\subsubsection{Total dry weight (g/plant)}

The data on total dry weight presented in Table 12 indicated significant differences among the genotypes at all stages. Among the genotypes, the genotypes belonging to hexaploids recorded higher total dry weight at all the stages compared to tetraploids. It was further observed that the total dry weight increased continuously from 5 DAA until harvest in all the genotypes. At 5 DAA, the genotype DL-1266-2 belonging to hexaploids recorded significantly higher total dry weight over all other genotypes among hexaploids and tetraploids, except DL-1266-1. None of the genotypes among tetraploids differed significantly with each other and also PBW-343 of hexaploids. At 15 DAA, again DL-1266-2 followed by DL-1266-1 of hexaploids recorded significantly higher total dry weight over all other genotypes. 
The genotypes belonging to tetraploids did not differ significantly with each other at this stage. Similarly the genotypes DL1266-1 and PBW-343 of hexaploids were at par with ach other. A similar trend was noticed at 25 and 35 DAA with DL-1266-1 and DL1266-2 of hexaploids having significantly higher total dry weight over all other genotypes. However, a lower total dry weight of 24.08 g/plant was recorded in $\mathrm{HI}-8498$ at 25 DAA and $28.06 \mathrm{~g} /$ plant in PDW233 at 35 DAA. The genotype DL-1266-2 of hexaploids continued to maintain higher total dry weight at harvest also, but it was on par with DL-1266-1. The genotypes belonging to tetraploids did not differ significantly among themselves and these genotypes also were on par with PBW-343 of hexaploids.

\subsubsection{Relative growth rate (g/g/day)}

The mean relative growth rate decreased continuously from 515 DAA to 25-35 DAA and at 35 DAA-harvest, it has slightly increased in all the genotypes of both hexaploids and tetraploids (Table 13). The relative growth rate was significantly higher in the genotypes belonging to tetraploids at 5-15, 15-25 and 25-35 DAA; while, it was higher among hexaploids at the 35 DAA-harvest stage. At 5-15 DAA, the genotypes belonging to tetraploids recorded significantly higher rates of RGR compared to hexaploids. Among the genotypes, tetraploids showed no significant differences but hexaploids differed significantly. Interestingly, the new plant types recorded lower of 
lower rates. At 15-25, there were no significant differences among tetraploids and hexaploids. But at 25-35 DAA, the genotypes showed significant differences among themselves. And at this stage, the hexaploid genotype DL-1266-2 recorded lowest RGR of $0.01 \mathrm{~g} / \mathrm{g} / \mathrm{day}$. Other genotypes of hexaploids were at par with PDW-233 of tetraploid. When compared at 35 DAA-harvest stage, the genotype DL-1266-1 belonging to hexaploids recorded significantly higher RGR than any other genotype however, it was on par with the genotype DL-12661.

\subsubsection{Net assimilation rate $\left(\mathrm{mg} / \mathrm{cm}^{2} /\right.$ day $)$}

The net assimilation rate decreased continuously from 5-15 DAA to 25-35 DAA in all the genotypes, irrespective of hexaploids or tetraploids (Table 14). It was observed in general, that the genotypes belonging to tetraploids had higher NAR at all the stages compared to hexaploids. At 5-5 DAA, the genotype PDW-233 of tetraploids had higher NAR, but it was on par with all other genotypes in that group and also with PBW-343 among hexaploids. Significantly lower NAR was recorded in DL-1266-1 of hexaploids compared to all other genotypes, except DL-1266-2. At, 15-25 DAA, the genotypes belonging to tetraploids recorded significantly higher NAR over hexaploids but were on par with each other. The genotype PBW-343 of hexaploids had significantly lower NAR compared to all other genotypes but it was on par with other genotypes in that group. At 
25-35 DAA, the genotypes $\mathrm{HI}-8498$ of tetraploids recorded significantly higher NAR over all other genotypes irrespective of hexaploids or tetraploids. Similarly, the genotype DL-1266-1 of hexaploids recorded lower NAR over all other genotypes at this stage.

\subsection{SEED AND EAR GROWTH PARAMETERS}

The data on various seed and ear growth parameters were computed and presented in Tables 15 to 19 .

\subsubsection{Absolute growth rate of ear ( $\mathrm{mg} / \mathrm{day})$}

The data on absolute growth rate of ear presented in Table 15 indicated significant differences between the genotypes at all the stages. The AGR of ear decreased from 5-15 DAA to 25-35 DAA and increased at 25-35 DAA and decreased thereafter among hexaploids and tetraploids. Among hexaploids, the AGR of ear was maximum at 5-15 DAA and decreased there after and again at 25-35 DAA, it increased until 35 DAA-harvest. At 5-15 DAA, the genotype DL-12662 of hexaploids recorded significantly higher AGR over all other genotypes. The lowest AGR of $0.202 \mathrm{~g} /$ day was recorded in $\mathrm{HI}-8498$ of tetraploids at this stage. At 15-25 DAA also, DL-1266-2 of hexaploids recorded significantly higher AGR over all other genotypes. The genotype PBW-343 of hexaploids and PDW-233 and HD-4530 of tetraploids were at par with each other. A lower AGR of $0.197 \mathrm{~g} / \mathrm{day}$ 
was recorded in HI-8498 of tetraploids, but it was on par with PDW233 and HD-4530.

At 25-35 DAA, the genotype DL-1266-2 followed by DL-1266-1 of hexaploids recorded significantly higher AGR over all other genotypes. At 35 DAA-harvest, the genotype DL-1266-1 belonging to hexaploids recorded significantly higher AGR. A lower AGR of 0.116 g/day was registered in HI-8498 of tetraploids and among hexaploids, it was with PBW-343 (0.178 g/day). The new plant types, at all the stages, recorded significantly higher RGR values than any other genotype

\subsubsection{Relative growth rate of ear (g/g/day)}

The data pertaining to relative growth rate of ear presented in Table 16 indicated significant differences between the genotypes at all the stages. It was observed that RGR of ear was significantly higher in the genotypes belonging to hexaploids compared to tetraploids at all the stages except at 25-35 DAA where a slight increase in RGR of tetraploids was seen. Here also, the hexaploid new plant type DI-1266-2 recorded higher rate than other genotypes though it was at par with PDW-233 and HI-8498. The RGR decreased continuously from 5-15 DAA until 35 DAA-harvest in all the genotypes. At 5-15 DAA, the genotypes DL-1266-1 and DL-1266-2 belonging to hexaploids had higher RGR, thought they were at par 
with each other. The tetraploids showed no significant differences. Significantly lower RGR was recorded in HI-8498 of tetraploids over all other genotypes at this stage. At 15-25 DAA, all the genotypes irrespective of tetraploid or hexaploid, showed no significant differences. At 25-35 DAA DL-1266-2 recorded higher rate but it was on par with PDW-233 and HI-8498. The genotype PBW-343 belonging to hexaploids recorded significantly lower RGR over all other genotypes, except with HD-4530 at this stage. At 35 DAA-harvest, the genotype DL-1266-1 of hexaploids had significantly higher RGR and the genotype HD-4530 of tetraploids had lowest RGR and it was at par with other genotypes within the tetraploids and also with PBW343 of hexaploids.

\subsubsection{Seed weight (mg/grain)}

The data on seed weight presented in Table 17 indicated significant differences between the genotypes at all stages. It was observed that the seed weight increased continuously from 5 DAA until harvest in all the genotypes, irrespective of hexaploids or tetraploids. It was further observed from the mean values that, the hexaploids had significantly higher seed weight compared to tetraploids at all the stages. At 5 DAA and at all the stages of growth, the genotypes DL-1266-1 and DL-1266-2 belonging to hexaploids recorded significantly higher seed weight while, all other genotypes did not differ significantly with each other. 
At 15 DAA, the genotypes DL-1266-1 and DL-1266-2 again had significantly higher seed weight over all other genotypes except with $\mathrm{HI}-8498$. Here at this stage, and the lowest seed weight $(11.83 \mathrm{mg})$ was recorded in HD-4530 of tetraploids. At 25 DAA and other later stages, the genotypes DI-1266-1 and DL-1266-2 among hexaploids had significantly higher seed weight compared to all other genotypes though they were at par with each other. At harvest, DL-1266-1 and DL-1266-2 of hexaploids recorded significantly higher seed weight of $60.15 \mathrm{mg}$ and $61.25 \mathrm{mg}$ respectively over all other genotypes, while, all other genotypes were at much lower weights and showed any significant differences with each other.

\subsubsection{Absolute growth rate of seed $(\mathrm{mg} / \mathrm{day})$}

The data on absolute growth rate of seed indicated significant differences between the genotypes at all the stages (Table 18). The data further indicated that the AGR of seed increased from 5-15 DAA to 15-25 DAA and decreased thereafter until 35DAA-harvest in all the genotypes. Among the genotypes, the mean values indicated that the AGR was higher among hexaploids compared to tetraploids at all the stages. At 5-15 DAA, the genotype DL-1266-2 belonging to hexaploids recorded significantly higher AGR over all other genotypes but it was on par with DL-1266-1. The lowest AGR of $0.671 \mathrm{mg} /$ day 
was recorded in HD-4530 of tetraploids, but it was on par with all other genotypes in tetraploids.

A similar trend was noticed at other stages with DL-1266-2 of hexaploids having significantly higher AGR over all other genotypes. At 15-25 DAA, highest AGR was recorded in DL-1266-1 (2.201 $\mathrm{mg} /$ day) and DL-1266-2 (2.212 mg/day). At 35 DAA-harvest, the genotypes DL-1266-1 and DL-1266-2 were significantly superior over all other genotypes, irrespective of hexaploids or tetraploids and the genotypes within tetraploids did not differ significantly among themselves and also with the PBW-343 of hexaploids.

\subsubsection{Grain growth rate (g/g/day)}

The grain growth rate of seed decreased continuously from 515 DAA to 35 DAA-harvest in all the genotypes (Table 19). It was further observed that GGR was more in the hexaploids at all the stages. At 5-15 DAA, the genotypes DL-1266-2 belonging to hexaploids recorded significantly higher RGR but was on par with other hexaploids and also with PDW 233 of tetraploids. The lower RGR was also recorded in $\mathrm{HI}-8498$ of tetraploids.

At 15-25 DAA, the genotype DL-1266-1 recorded higher RGR but was on par with genotypes in hexaploids and also with PDW 233 of tetraploids. Significantly lower RGR of $0.077 \mathrm{~g} / \mathrm{g} / \mathrm{day}$ was recorded 
in HI-8498 of tetraploids compared to all other genotypes. Similarly, at 25-35 DAA also DL-1266-1 of hexaploids recorded significantly higher RGR but was on par with other hexaploids. At 35 DAA-harvest the genotypes did not show any significant differences.

\subsection{BIOPHYSICAL AND BIOCHEMICAL PARAMETERS}

The data on various biophysical and biochemical parameters were collected and presented in Tables 20 to 27 .

\subsubsection{Stomatal conductance $(\mathrm{cm} / \mathrm{s})$}

The data on stomatal conductance presented in Table 20 indicated significant differences between the genotypes at all the days after anthesis. It was observed that the stomatal conductance was higher in the genotypes belonging to hexaploids compared to tetraploids at all the stages. At 7 DAA, the genotypes DL-1266-1 and DL-1266-2 of hexaploids recorded significantly higher stomatal conductance over all other genotypes. The lowest stomatal conductance of $1.408 \mathrm{~cm} / \mathrm{s}$ was recorded in PDW-233 and it was on par with HI-8498 among tetraploids. At 15 DAA also DL-1266-1 and DL-1266-2 maintained higher stomatal conductance and PDW-233 had lower stomatal conductance. At 25 DAA no significantly differences were observed in the stomatal conductance between any 
of the genotypes among hexaploids and they also did not differed significantly with HD-4530 of tetraploids. However, PDW-233 of tetraploids recorded significantly lower stomatal conductance over all other genotypes irrespective of hexaploids or tetraploids. It was further observed at 35 DAA that no significant differences were observed between the genotypes of hexaploids or tetraploids. However, the genotypes of hexaploids differed significantly with tetraploids in stomatal conductance.

\subsubsection{Flag leaf photosynthetic rate $\left(\mu \mathrm{mol} / \mathrm{m}^{2} / \mathrm{s}\right)$}

Flag leaf photosynthetic rate recorded at 5, 15, 25 and 35 DAA indicated significant differences among the genotypes at all the stages (Table 21). In general, the mean values indicated that the flag leaf photosynthetic rate was higher among the hexaploids compared to tetraploids at all the stages. It was noticed that DL-1266-2 of hexaploids recorded significantly higher flag leaf photosynthetic rate over all other genotypes irrespective of hexaploids or tetraploids at 7 DAA. While, HD-4530 of tetraploids recorded significantly lower flag leaf photosynthetic rate over all other genotypes. At 15 DAA, no significant differences were observed between DL-1266-1 and DL1266-2 of hexaploids and PDW-233 of tetraploids. Similarly, the genotype PBW-343 of hexaploids, PDW-233 and HI-8498 of tetraploids were at par with each other. At 25 DAA, the genotypes DL1266-1and DL-1266-2 of hexaploids and HD-4530 of tetraploids were 
at par with each other. Maximum photosynthetic rate was observed in DL-1266-2 of hexaploids $\left(21.23 \mu \mathrm{mol} / \mathrm{m}^{2} / \mathrm{s}\right)$ and the minimum photosynthetic rate of $16.89 \mu \mathrm{mol} / \mathrm{m}^{2} / \mathrm{s}$ was observed in PBW-343 of hexaploids at this stage. The photosynthetic rate decreased continuously from 7 until 35 DAA in all the genotypes irrespective of hexaploids or tetraploids. At 35 DAA, no significant differences were observed between the genotypes among hexaploids, while the lowest photosynthetic rate of $9.97 \mu \mathrm{mol} / \mathrm{m}^{2} / \mathrm{s}$ was recorded in $\mathrm{HD}-4530$ of tetraploids.

\subsubsection{Flag leaf chlorophyll 'a' content (mg/g fr. wt.)}

The data on flag leaf chlorophyll 'a' content presented in Table 22 indicated significant differences between the genotypes at 10, 20 and 30 DAA. The chlorophyll 'a' content was maximum at 10 DAA and declined continuously until 30 DAA in all the genotypes. Among the genotypes, the mean chlorophyll a content was higher in hexaploids compared to tetraploids at all the stages. It was observed that no significant differences were observed between genotypes among hexaploids and these genotypes did not differ significantly with PDW233 and HD-4530 of tetraploids at 10 DAA. However lower chlorophyll ' $a$ ' content was recorded in HI-8498 of tetraploids over all other genotypes. At 20 DAA, the genotypes DL-1266-2 of hexaploids recorded higher chlorophyll ' $a$ ' content over all other genotypes 
irrespective of hexaploids or tetraploids. No significant differences were observed between the genotypes among tetraploids and the genotypes PDW-233 recorded the lowest chlorophyll 'a' content at this stage. At 30 DAA also, the genotype DL-1266-2 of hexaploids maintained significantly higher chlorophyll 'a' content over all other genotypes. While, the genotype PDW-233 of tetraploids recorded significantly lower chlorophyll 'a' content at this stage compared to all other genotypes.

\subsubsection{Flag leaf chlorophyll 'b' content (mg/g fr. wt)}

The flag leaf chlorophyll ' $b$ ' content presented in Table 23 indicated significant differences among the genotypes at all the stages. Among the genotypes, hexaploids recorded higher chlorophyll ' $b$ ' content over tetraploids at all the stages. The flag leaf chlorophyll ' $b$ ' content was higher at 10 DAA and declined continuously until 30 DAA in all the genotypes. At 10 DAA, the genotype DL-1266-2 of hexaploids recorded significantly higher chlorophyll ' $b$ ' content over all other genotypes, except DL-1266-1. However, no significant differences were observed between the genotypes among tetraploids. A similar trend continued at 20 DAA with DL-1266-2 followed by DL1266-1 having significantly higher chlorophyll 'b' content compared to all other genotypes and the rest of genotypes were at par with each other. At 30 DAA, the genotype DL-1266-2 of hexaploids and PDW233 of tetraploids recorded significantly higher and lower chlorophyll 'b' content respectively. 


\subsubsection{Flag leaf total chlorophyll content (mg/g fr. wt.)}

The data on flag leaf total chlorophyll content indicated significant differences among the genotypes at all the stages (Table 24). It was observed that the total chlorophyll content was maximum at 10 DAA and declined continuously thereafter until 30 DAA and the genotypes belonging to hexaploids had higher total chlorophyll content over tetraploids at all the stages. At 10 DAA, no significant differences were observed between the genotypes among hexaploids or tetraploids. However, the maximum chlorophyll content was recorded in DL-1266-2 of hexaploids and the minimum in PDW-233 of tetraploids at all the stages. At 10 DAA, no significant differences were observed between genotypes among hexaploids and tetraploids. However the genotype DL-1266-2 of hexaploids and PDW-233 of tetraploids recorded higher and lower total chlorophyll respectively over all other genotypes. At 30 DAA, the genotypes DL-1266-2 and PBW-343 of hexaploids recorded significantly higher total chlorophyll content over all other genotypes while, PDW-233 had significantly lower total chlorophyll content over all other genotypes, but was on par with HD-4530 of tetraploids.

\subsubsection{Chlorophyll a/b ratio}


The data on chlorophyll $\mathrm{a} / \mathrm{b}$ ratio presented in Table 25 indicated that it was maximum at 10 DAA and declined thereafter continuously up to 30 DAA. Among the genotypes, tetraploids had higher a/b ration at 10 and 30 DAA; while, hexaploids had higher ratio at 20 DAA and no significant differences were observed between the genotypes at 10 DAA. At 20 DAA, the genotype DL-1266-2 belonging to hexaploids had significantly higher chlorophyll a/b ratio over DL1266-1 and HD-4530. While, all other genotypes were at par with each other. At 30 DAA, no significant differences were observed between the genotypes among hexaploids and the genotype HI-8498 of tetraploids recorded significantly lower ratio over all other genotypes, irrespective of hexaploids or tetraploids except PDW-233.

\subsubsection{Total sugars content (mg/g dry wt.)}

Total sugars content varied significantly among the genotypes at all the stages (Table 26). It was further observed that the total sugars content was significantly higher in the genotypes belonging to hexaploids compared to tetraploids at all the stages and it decreased continuously from 15 DAA until harvest in all the genotypes. At 15 DAA, the genotype DL-1266-2 followed by DL-1266-1 recorded significantly higher total sugars content over all other genotypes; while, the rest of genotypes were at par with each other at this stage. The lowest total sugars content ( $106.41 \mathrm{mg} / \mathrm{g}$ dry wt.) was recorded in PDW-233 of tetraploids. At 25 DAA, the genotype DL-1266-2 
belonging to hexaploids recorded significantly higher total sugars content (91.84 mg/g dry wt.) compared to all other genotypes, irrespective of hexaploid or tetraploid. While, the other two genotypes i.e., DL-1266-1 and PBW-343 among hexaploids were at par with each other. Similarly, no significant differences were observed between any of the genotypes among tetraploids at this stage. At 35 DAA, the genotype DL-1266-2 of hexaploids recorded significantly higher total sugars content over all other genotypes irrespective of hexaploids or tetraploids. The genotypes DL-1266-1 and PBW-343 of hexaploids and PDW-233, HD-4530 and HI-8498 of tetraploids did not differ significantly among themselves. A similar trend continued at harvest with DL-1266-2 having significantly higher total sugars content over all other genotypes.

\subsubsection{Starch content ( $\mathrm{mg} / \mathrm{g}$ dry wt.)}

The data on starch content presented in Table 27 indicated significant differences among the genotypes at all the stages. The starch content increased continuously from 15 DAA until harvest in all the genotypes. Among the genotypes, the mean starch content was higher in hexaploids compared to tetraploids at all the stages. At 15 DAA, the genotype DL-1266-2 followed by DL-1266-1 recorded significantly higher starch content over all other genotypes, irrespective of hexaploids or tetraploids. The lowest starch content of $222.0 \mathrm{mg} / \mathrm{g}$ dry wt. was recorded in PDW-233 of tetraploids and the 
maximum starch content was $342.0 \mathrm{mg} / \mathrm{g}$ dry wt. in DL-1266-2 of hexaploids. No significant differences were observed between the genotypes among hexaploids at 25 DAA. Similarly, the genotypes among tetraploids also were at par with each other. However, the maximum starch content was recorded in DL-1266-2 of hexaploids and minimum in PDW-233 of tetraploids. At 35 DAA, DL-1266-2 continued to maintain higher starch content (699 mg/g dry wt.) But, it was on par with DL-1266-1 of hexaploids. None of the genotypes among tetraploids differed significantly in starch content at this stage. At harvest also, no significant differences were observed between the genotypes of either hexaploids or tetraploids. However, the maximum starch content of $710.0 \mathrm{mg} / \mathrm{g}$ dry wt. was recorded in DL-1266-2 of hexaploids and the minimum in HI-8498 of tetraploids (614.0 mg/g dry wt.).

\subsection{ENDOGENOUS HORMONAL CONTENT IN GRAINS}

The endogenous hormonal content in the developing grains of hexaploid and tetraploid wheat is presented in Tables 28 to 30.

\subsubsection{Indole acetic acid content ( $\mu \mathrm{g} / \mathrm{g}$ fr. wt.)}

The indole-acetic acid content (IAA) among the genotypes differed significantly at all the days after anthesis (Table 28). The IAA content increased from 7 to 15 DAA in both hexaploids and 
tetraploids and declined thereafter at 25 and 35 DAA in all the genotypes. Further, among the genotypes, the IAA content was significantly higher in hexaploids compared to tetraploids at all the stages. At 7 DAA, the genotype DL-1266-2 followed by DL-1266-1 recorded significantly higher IAA content over all other genotypes. While, no significant differences were observed between the genotypes among tetraploids and with PBW-343 of hexaploids.

At 15 DAA, a similar trend continued with DL-1266-2 followed by DL-1266-1 having significantly higher IAA content over all other genotypes. The lower IAA content of $19.84 \mu \mathrm{g} / \mathrm{g}$ fr. wt. was recorded in PDW-233 of tetraploids and it was on par with HI-8498 and PBW343. At 25 DAA, no significant differences were observed between the genotypes either among hexaploids or among tetraploids, but still the maximum IAA content was recorded in DL-1266-1 of hexaploids and minimum in PDW-233 of tetraploids. At 35 DAA also, no significant differences were observed between the genotypes either among hexaploids or among tetraploids. The maximum IAA content of 11.16 $\mu \mathrm{g} / \mathrm{g}$ fr. wt. was recorded in DL-1266-1 of hexaploids and the minimum of $9.09 \mu \mathrm{g} / \mathrm{g} \mathrm{fr}$. wt in PDW-233 of tetraploids.

\subsubsection{Gibberellic acid content ( $\mu \mathrm{g} / \mathrm{g}$ fr. wt.)}

The data on gibberellic acid (GA) content presented in Table 29 indicated significant differences between the genotypes at all the 
stages. The gibberellic acid content decreased continuously from 7 to 35 DAA among both hexaploids and tetraploids and among the genotypes the mean GA content was significantly higher in hexaploids compared to tetraploids at all the stages. It was observed that at 7 DAA, the genotype DL-1266-2 followed by DL-1266-1 of hexaploids recorded significantly higher GA content over all other genotypes, irrespective of hexaploids or tetraploids. The genotypes among tetraploids did not vary with each other at this stage and were also on par with PBW-343 of hexaploids.

At 15 DAA, DL-1266-2 of hexaploids recorded significantly higher GA content over all other genotypes and the genotype HI-8498 of tetraploids recorded the lowest GA content of $17.58 \mu \mathrm{g} / \mathrm{g} \mathrm{fr}$. wt. But, it was on par with PDW-233 and HD-4530 of tetraploids and PBW343 of hexaploids. At 25 DAA, no significant differences were observed among the genotypes between tetraploids and hexaploids. However, the genotypes belonging to hexaploids recorded higher GA content over the genotypes belonging to tetraploids. A similar trend continued even at 35 DAA with the genotypes among hexaploids having higher GA content over the genotypes of tetraploids. The maximum GA content of $4.56 \mu \mathrm{g} / \mathrm{g}$ fr. wt. was recorded in DL-1266-1 of hexaploids and minimum in $\mathrm{HI}-8498$ of tetraploids $(2.14 \mu \mathrm{g} / \mathrm{g} \mathrm{fr}$. $w t)$.

\subsubsection{Abscisic acid content ( $\mu \mathrm{g} / \mathrm{g}$ fr. wt.)}


The abscisic acid content presented in Table 30 indicated significant differences between the genotypes at all the stages with the genotype belonging to hexaploids having higher values compared to tetraploids at all the stages. It was further observed that $A B A$ content increased from 7 to 25 DAA and decreased thereafter at 35 DAA. At 7 DAA, no significant differences were observed between the genotypes of either hexaploids or tetraploids. But, the genotypes of hexaploids had higher ABA content over tetraploids. The maximum ABA content of $10.47 \mu \mathrm{g} / \mathrm{g}$ fr. wt and the minimum of $6.46 \mu \mathrm{g} / \mathrm{g} \mathrm{fr}$. wt. were recorded in DL-1266-2 and HI-8498 of hexaploids and tetraploids, respectively.

At 15 DAA, the genotype DL-1266-2 belonging to hexaploids recorded significantly higher ABA content over all other genotypes, irrespective of groups. However, the genotypes among tetraploids did not differ significantly with each other. Similarly, the genotypes DL1266-1 and PBW-343 of hexaploids were at par with each other. At 25 DAA, DL-1266-2 followed by DL-1266-1 had significantly higher GA content over all other genotypes. However, the genotypes belonging to tetraploids were at par with each other. At 35 DAA, a similar trend continued with DL-1266-2 and DL-1266-1 of hexaploids having high ABA content over all other genotypes and the lowest ABA content was observed in HD-4530 of tetraploids. However, no significant differences were observed between the genotypes among tetraploids. 


\subsection{CORRELATION STUDIES}

The correlation co-efficients among hormonal content and with the grain growth parameters is presented in Tables 31 to 34 .

\subsubsection{Correlation co-efficients among endogenous hormones}

The data on correlation co-efficients between endogenous hormones among hexaploids and tetraploids of wheat grains presented in Table 31 indicated that IAA at 7 DAA had significant positive correlation with IAA at 15 DAA, GA and ABA at 7 DAA and ABA at 25 and 35DAA. While, IAA at 15 DAA was found to have highly significant correlation with only GA and ABA at 7 DAA. The correlation between IAA at 25 DAA with the endogenous hormones at other stages indicated that it had a highly significant positive correlation only with IAA at 30 DAA, while IAA at 30 DAA was found to have highly significant correlation with GA at 21 DAA and ABA at 15 DAA. GA at 7 DAA was again found to have highly significant correlation with GA at 15 and 21DAA and ABA at 7 DAA. While, GA at 15 DAA was found to have highly significant correlation with GA at 21 DAA and ABA at 7 and 15 DAA while GA 25 DAA was found to have high

significant correlation only with ABA at 15 DAA. The inter-relationship between the other endogenous hormones and days after anthesis were found to be non significant. 


\subsubsection{Correlation between hormonal content and absolute grain growth rate.}

The data on correlation co-efficients between hormonal content and absolute grain growth rate presented in Table 32 indicated that the AGR of grains were significantly correlated with all the endogenous hormonal content at different days after anthesis except that IAA at 30 DAA did not have any significant correlation with absolute grain growth rate at 5-15 DAA and ABA at 21 DAA did not have any significant correlation with 15-25 DAA and 25-35 DAA.

It was further observed that correlation co-efficients between IAA at 7 DAA and AGR 5-15 and 15-25 DAA were highly significant. IAA at 15 DAA showed highly significant correlation with AGR at all the stages. IAA at 25 DAA also showed highly significant correlation with AGR at all the stages except at 5-15 DAA where it was less significant. IAA at 35 DAA showed highly significant correlation with AGR only at 35 DAA-harvest. GA at 7 DAA was highly significantly correlated with 5-15 and 15-25 DAA; while, GA at 35 DAA was highly significantly correlated with 25-35 DAA and 35 DAA-harvest. ABA at 7 and 35 DAS was highly significantly correlated with 5-15 DAA.

\subsubsection{Correlation co-efficients of hormonal content with grain growth rate}


The correlation co-efficients between hormonal content and the grain growth rate (Table 33) among hexaploids and tetraploids of wheat indicated significant correlation between the grain growth rate at 5-15 DAA and the hormonal content at different days after anthesis. At all other stages, the was no significant correlation with the hormonal content except that the IAA at 21 DAA showed significant correlation with 15-25 DAA, 25-35 DAA and 35 DAAharvest and GA 30 at DAA showed significant correlation with 25-35 DAA and 35 DAA-harvest.

\subsubsection{Correlation between some selected characters.}

The data on interrelationship between various yield, growth, biochemical, biophysical and endogenous hormonal levels presented in Table 34 indicated that the grain yield was found to have highly significant positive relationship with total dry matter at harvest, seed AGR at 25-35 DAA, seed RGR at 35 DAA-harvest, 1000-grain weight, stomatal conductance at 15 DAA, total chlorophyll content at 20 DAA, total sugars content at 15 DAA, starch content at harvest and IAA at 15 DAA. While, it had negative significant relationship with tiller number, NAR at 5-15 DAA and ear RGR at 5-15 DAA. The specific leaf weight at 25 DAA was found to have a very highly significant correlation with seed RGR at 35 DAA-harvest only. It had a negative significant correlation with NAR at 5-15 DAA and ear RGR at 5-15 DAA. Similarly, the total dry matter at harvest was found to have 
negative significant correlation with NAR at 5-15 DAA and ear RGR at 5-15 DAA. It had a high significant positive correlation with seed RGR at harvest, 1000 grain weight, total chlorophyll at 20 DAA, total sugars at 15 DAA, starch content at harvest, IAA at 15 DAA, GA at 7 DAA and ABA at 21 DAA. The stomatal conductance at 15 DAA was found to have highly significant correlation with total sugars at 15 DAA while it had negative significant relationship with ear RGR at 515 DAA. While photosynthetic rate was found to have a highly significant positive correlation with seed AGR at 25-35 DAA, seed RGR at 35 DAA-harvest and GA at 7 DAA while it had a significantly negative relationship with ear RGR at 5-15 DAA. 


\section{LIST OF FIGURES}

Fig.

No.

Title

1. Yield performance of hexaploid and wheat tetraploid wheat genotypes

2. Seed weight at different growth stages of wheat genotypes

3. Grain growth rate of different wheat genotypes

4. Endogenous hormonal content in developing grains of hexaploid wheat DL-1266-1

5. Endogenous hormonal content in developing grains of hexaploid wheat DL-1266-2

6. Endogenous hormonal content in developing grains of hexaploid wheat PDW-343

7. Endogenous hormonal content in developing grains of tetraploid wheat PDW-233

8. Endogenous hormonal content in developing grains of tetraploid wheat HD-4530

9. Endogenous hormonal content in developing grains of tetraploid wheat $\mathrm{HI}-8498$

10. Total sugar content in developing grains of wheat genotypes

11. Starch content in developing grains of wheat genotypes 
1. Yield performance of hexaploid and tetraploid wheat genotypes

2. Physiological parameters of seed yield of hexaploid and tetraploid wheat genotypes

Genotypic differences in yield and yield

3. components at harvest among hexaploid and tetraploid wheat

Genotypic differences in morphological

4. characters at harvest among hexaploid and tetraploids of wheat

5. Genotypic differences in leaf area ( $\mathrm{cm}^{2} /$ plant) among hexaploid and tetraploid wheat

6. Genotypic differences in leaf weight (g/plant) among hexaploid and tetraploid wheat

7. Genotypic differences in specific leaf area (dm${ }^{2} / \mathrm{g}$ ) among hexaploid and tetraploid wheat

8. Genotypic differences in specific leaf weight $\left(\mathrm{g} / \mathrm{dm}^{2}\right)$ among hexaploid and tetraploid wheat

9. Genotypic differences in leaf area ratio $\left(\mathrm{cm}^{2} / \mathrm{g}\right)$ among hexaploid and tetraploid wheat

10. Genotypic differences in stem dry weight (g/plant) among hexaploid and tetraploid wheat

11. Genotypic differences in ear dry weight (g/plant) among hexaploid and tetraploids of wheat

12. Genotypic differences in total dry matter (g/plant) among hexaploid and tetraploid wheat

13. Genotypic differences in relative growth rate (g/g/day) among hexaploid and tetraploid wheat

Genotypic differences in net assimilation rate 14. $\left(\mathrm{mg} / \mathrm{cm}^{2} /\right.$ day) among hexaploid and tetraploid wheat 
15. ear (g/day) among hexaploid and tetraploid wheat

Genotypic differences in relative growth rate of

16. ear (g/g/day) among hexaploid and tetraploid wheat

17. Genotypic differences in seed weight (mg/grain) among hexaploid and tetraploid wheat

Genotypic differences in absolute growth rate of

18. seed (mg/day) among hexaploid and tetraploid wheat

19. Genotypic differences in grain growth rate (g/g/day) among hexaploid and tetraploid wheat

Genotypic differences among hexaploid and

20. tetraploid wheats in flag leaf stomatal conductance $(\mathrm{cm} / \mathrm{s})$

Genotypic differences among hexaploid and

21. tetraploid wheats in flag leaf photosynthetic rate ( $\mu \mathrm{moles} / \mathrm{m}^{2} / \mathrm{s}$ )

Genotypic differences among hexaploid and

22. tetraploid wheat in flag leaf chlorophyll ' $a$ ' content (mg/g fr.wt.)

Genotypic differences among hexaploid and

23. tetraploid wheat in flag leaf chlorophyll ' $b$ ' content (mg/g fr. wt.)

Genotypic differences among hexaploid and

24. tetraploid wheats in flag leaf total chlorophyll content (mg/g gr.wt.)

Genotypic differences among hexaploid and

25. tetraploid wheat in flag leaf total chlorophyll $a / b$ ratio

Genotypic differences among hexaploid and

26. tetraploid wheat in total sugars content $(\mathrm{mg} / \mathrm{g}$ dry wt.) of developing grains

Genotypic differences among hexaploid and

27. tetraploid wheat in starch content ( $\mathrm{mg} / \mathrm{g}$ dry $\mathrm{wt})$ of developing grains

Genotypic differences in endogenous content of

28. Indole-acetic acid (IAA) content ( $\mu \mathrm{g} / \mathrm{g} \mathrm{fr}$. wt.) of developing grains among hexaploid and tetraploid wheat 
Genotypic differences in endogenous Gibberellic

29. acid $\left(\mathrm{GA}_{3}\right)$ content $(\mu \mathrm{g} / \mathrm{g} \mathrm{fr}$. wt.) of developing grains among hexaploid and tetraploid wheat Genotypic differences in endogenous Abscisic

30. acid (ABA) content $(\mu \mathrm{g} / \mathrm{g} \mathrm{fr}$. wt.) of developing grains among hexaploid and tetraploid wheat Correlation co-efficients between the

31. endogenous hormones among hexaploid and 57 tetraploid wheat

Correlation co-efficients between hormonal

32. contents and absolute grain growth rate among hexaploid and tetraploid wheat

Correlation co-efficients between hormonal

33. contents and grain growth rate among hexaploid and tetraploid wheat

Correlation coefficients between few selected

34. characters among hexaploid and tetraploid wheat

Yield attributes and physiological parameters of

35. seed yield per cent wise over hexaploid wheat DL-1266-2 


\section{LIST OF PLATES}

\begin{tabular}{|c|c|c|}
\hline $\begin{array}{l}\text { Plate } \\
\text { No. }\end{array}$ & Title & $\begin{array}{l}\text { After } \\
\text { page }\end{array}$ \\
\hline 1. & $\begin{array}{l}\text { Seeds of Hexaploids: New Plant Types (DI-1266- } \\
1 \& \text { DIL-1266-2) and extant variety (PBW-343) }\end{array}$ & 62 \\
\hline 2. & $\begin{array}{l}\text { Seeds of Tetraploids: HD-4530, HI-8498 and } \\
\text { PDW- } 233\end{array}$ & 62 \\
\hline 3. & $\begin{array}{l}\text { Spikes of Hexaploids: New Plant Types (Dl- } \\
\text { 1266-1 \& DIL-1266-2) and extant variety (PBW- } \\
343 \text { ) }\end{array}$ & 67 \\
\hline 4. & $\begin{array}{l}\text { Spikes of Tetraploids: HD- } 4530, \mathrm{HI}-8498 \text { and } \\
\text { PDW-233 }\end{array}$ & 67 \\
\hline
\end{tabular}




\section{CONTENTS}

\begin{tabular}{|c|c|c|}
\hline $\begin{array}{c}\text { Chapter } \\
\text { No. }\end{array}$ & Title & Page No. \\
\hline 1. & INTRODUCTION & $1-4$ \\
\hline 2. & REVIEW OF LITERATURE & $5-21$ \\
\hline 3. & MATERIALS AND METHODS & 22-32 \\
\hline 4. & EXPERIMENTAL RESULTS & $33-60$ \\
\hline 5. & DISCUSSION & $61-78$ \\
\hline 6. & SUMMARY AND CONCLUSIONS & 79-83 \\
\hline & BIBLIOGROPHY & i-xxviii \\
\hline
\end{tabular}


Table 5. Genotypic differences in leaf area ( $\mathrm{cm}^{2} /$ plant) among hexaploid and tetraploid wheat

\begin{tabular}{|c|c|c|c|c|}
\hline \multirow{2}{*}{ Genotypes } & \multicolumn{4}{|c|}{ Days after anthesis } \\
\hline & 5 & 15 & 25 & 35 \\
\hline Hexaploid & & & & \\
\hline DL 1266-1 & 295.59 b & $353.26 \mathrm{~b}$ & $398.13 \mathrm{~b}$ & $289.77 \mathrm{~b}$ \\
\hline DL 1266-2 & 344.73 a & 401.69 a & 458.36 a & 348.96 a \\
\hline PBW 343 & 268.52 c & 333.01 bc & $389.56 \mathrm{~b}$ & $300.45 \mathrm{~b}$ \\
\hline Sub Mean & 302.95 & 362.65 & 415.35 & 313.06 \\
\hline Tetraploid & & & & \\
\hline PDW 233 & $230.40 \mathrm{~d}$ & $318.51 \mathrm{c}$ & $340.65 \mathrm{c}$ & $232.85 \mathrm{~b}$ \\
\hline HD 4530 & $253.14 \mathrm{~cd}$ & $323.96 \mathrm{c}$ & $319.46 \mathrm{c}$ & $273.20 \mathrm{bc}$ \\
\hline HI 8498 & $238.92 \mathrm{~cd}$ & $321.10 \mathrm{C}$ & $315.65 \mathrm{c}$ & $254.05 \mathrm{~cd}$ \\
\hline Sub Mean & 240.83 & 321.19 & 325.25 & 253.37 \\
\hline Grand Mean & 271.89 & 341.92 & 370.30 & 283.21 \\
\hline
\end{tabular}

In a column, means followed by a common letter are not significantly different at $5 \%$ level. 
Table 6. Genotypic differences in leaf weight (g/plant) among hexaploid and tetraploid wheat

\begin{tabular}{|c|c|c|c|c|c|}
\hline \multirow{2}{*}{ Genotypes } & \multicolumn{5}{|c|}{ Days after anthesis } \\
\hline & 5 & 15 & 25 & 35 & Harvest \\
\hline Hexaploid & & & & & \\
\hline DL 1266-1 & $2.84 \mathrm{a}$ & $3.59 \mathrm{~b}$ & $4.23 \mathrm{ab}$ & $2.45 \mathrm{a}$ & $1.98 \mathrm{a}$ \\
\hline DL 1266-2 & $2.86 \mathrm{a}$ & $4.28 \mathrm{a}$ & $4.99 a$ & $2.27 \mathrm{ab}$ & $1.99 \mathrm{a}$ \\
\hline PBW 343 & $2.62 \mathrm{ab}$ & $3.49 \mathrm{~b}$ & $3.30 \mathrm{bc}$ & $2.12 \mathrm{bc}$ & $1.96 \mathrm{a}$ \\
\hline Sub Mean & 2.77 & 3.79 & 4.17 & 2.28 & 1.98 \\
\hline Tetraploid & & & & & \\
\hline PDW 233 & $2.09 \mathrm{a}$ & $2.31 d$ & $2.59 \mathrm{C}$ & $1.81 \mathrm{C}$ & $1.59 \mathrm{~b}$ \\
\hline HD 4530 & $2.33 \mathrm{bc}$ & $2.94 \mathrm{C}$ & $3.21 b c$ & $1.83 \mathrm{C}$ & $1.68 \mathrm{~b}$ \\
\hline HI 8498 & $2.22 \mathrm{c}$ & $2.85 \mathrm{c}$ & $3.06 \mathrm{bc}$ & $1.82 \mathrm{C}$ & $1.67 \mathrm{~b}$ \\
\hline Sub Mean & 2.21 & 2.70 & 2.95 & 1.82 & 1.65 \\
\hline Total Mean & 2.49 & 3.24 & 3.56 & 2.05 & 1.81 \\
\hline
\end{tabular}

In a column, means followed by a common letter are not significantly different at $5 \%$ level. 
Table 7. Genotypic differences in specific leaf area $\left(\mathrm{dm}^{2} / \mathrm{g}\right)$ among hexaploid and tetraploid wheat

\begin{tabular}{|c|c|c|c|c|}
\hline \multirow{2}{*}{ Genotypes } & \multicolumn{4}{|c|}{ Days after anthesis } \\
\hline & 5 & 15 & 25 & 35 \\
\hline Hexaploid & & & & \\
\hline DL 1266-1 & $1.053 \mathrm{C}$ & $0.984 \mathrm{bcd}$ & $0.941 \mathrm{c}$ & $1.348 \mathrm{~d}$ \\
\hline DL 1266-2 & $1.031 \mathrm{bc}$ & $0.939 \mathrm{~d}$ & $0.924 \mathrm{c}$ & $1.551 \mathrm{a}$ \\
\hline PBW 343 & $1.020 \mathrm{dc}$ & $0.954 \mathrm{~cd}$ & $1.180 \mathrm{ab}$ & $1.417 \mathrm{c}$ \\
\hline Sub mean & 1.034 & 0.959 & 1.015 & 1.438 \\
\hline Tetraploid & & & & \\
\hline PDW 233 & $1.098 \mathrm{a}$ & $1.379 \mathrm{a}$ & $1.219 \mathrm{a}$ & $1.286 \mathrm{e}$ \\
\hline HD 4530 & $1.087 \mathrm{a}$ & $1.102 \mathrm{bc}$ & $1.061 \mathrm{bc}$ & $1.493 \mathrm{~b}$ \\
\hline HI 8498 & $1.075 \mathrm{~b}$ & $1.127 \mathrm{~b}$ & $1.044 \mathrm{~b}$ & $1.396 \mathrm{c}$ \\
\hline Sub Mean & 1.087 & 1.202 & 1.108 & 1.391 \\
\hline Total Mean & 1.091 & 1.081 & 1.062 & 1.415 \\
\hline
\end{tabular}

In a column, means followed by a common letter are not significantly different at $5 \%$ level. 
Table 8. Genotypic differences in specific leaf weight $\left(\mathrm{g} / \mathrm{dm}^{2}\right)$ among hexaploid and tetraploid wheat

\begin{tabular}{|c|c|c|c|c|}
\hline \multirow{2}{*}{ Genotypes } & \multicolumn{4}{|c|}{ Days after anthesis } \\
\hline & 5 & 15 & 25 & 35 \\
\hline Hexaploid & & & & \\
\hline DL 1266-1 & $0.95 a b$ & $1.02 \mathrm{a}$ & $1.06 \mathrm{a}$ & $0.74 a b$ \\
\hline DL 1266-2 & $0.97 a$ & $1.07 \mathrm{a}$ & $1.08 \mathrm{a}$ & $0.65 \mathrm{~d}$ \\
\hline PBW 343 & $0.98 a$ & $1.05 \mathrm{a}$ & $0.85 \mathrm{~cd}$ & $0.71 \mathrm{bcd}$ \\
\hline Sub mean & 0.92 & 1.05 & 1.00 & 0.70 \\
\hline Tetraploid & & & & \\
\hline PDW 233 & $0.91 \mathrm{c}$ & $0.73 c$ & $0.82 \mathrm{~d}$ & $0.78 \quad a$ \\
\hline HD 4530 & $0.92 \mathrm{bc}$ & $0.91 \mathrm{~b}$ & $0.94 \mathrm{bc}$ & $0.67 \mathrm{~cd}$ \\
\hline HI 8498 & $0.93 \mathrm{bc}$ & $0.89 \mathrm{~b}$ & $0.96 \mathrm{~b}$ & $0.72 a b c$ \\
\hline Sub Mean & 0.92 & 0.84 & 0.91 & 0.72 \\
\hline Total Mean & 0.92 & 0.95 & 0.95 & 0.71 \\
\hline
\end{tabular}

In a column, means followed by a common letter are not significantly different at $5 \%$ level. 
Table 9. Genotypic differences in leaf area ratio $\left(\mathrm{cm}^{2} / \mathrm{g}\right)$ among hexaploid and tetraploid wheat

\begin{tabular}{|c|c|c|c|c|}
\hline \multirow{2}{*}{ Genotypes } & \multicolumn{4}{|c|}{ Days after anthesis } \\
\hline & 5 & 15 & 25 & 35 \\
\hline Hexaploid & & & & \\
\hline DL 1266-1 & $19.09 \mathrm{C}$ & $16.00 \mathrm{c}$ & $13.33 \mathrm{~b}$ & $8.19 \mathrm{c}$ \\
\hline DL 1266-2 & $21.21 b c$ & $16.61 \mathrm{bc}$ & $13.94 \mathrm{ab}$ & $10.21 \mathrm{a}$ \\
\hline PBW 343 & $22.68 \mathrm{ab}$ & $16.79 \mathrm{bc}$ & $14.60 \mathrm{a}$ & $10.15 \mathrm{a}$ \\
\hline Sub Mean & 20.99 & 16.47 & 13.96 & 9.52 \\
\hline Tetraploid & & & & \\
\hline PDW 233 & $23.09 a b$ & $17.41 \mathrm{ab}$ & $12.32 \mathrm{c}$ & $8.30 \mathrm{c}$ \\
\hline HD 4530 & $25.60 \mathrm{a}$ & $18.43 \mathrm{a}$ & $13.53 \mathrm{~b}$ & $9.62 \mathrm{a}$ \\
\hline HI 8498 & $24.69 a$ & $18.54 \mathrm{a}$ & $13.27 \mathrm{~b}$ & $9.03 \mathrm{~b}$ \\
\hline Sub Mean & 24.46 & 18.12 & 13.04 & 8.98 \\
\hline Total Mean & 22.73 & 17.30 & 13.50 & 9.25 \\
\hline
\end{tabular}

In a column, means followed by a common letter are not significantly different at $5 \%$ level. 
Table 10. Genotypic differences in stem dry weight (g/plant) among hexaploid and tetraploid wheat

\begin{tabular}{|c|c|c|c|c|c|}
\hline \multirow{2}{*}{ Genotypes } & \multicolumn{5}{|c|}{ Days after anthesis } \\
\hline & 5 & 15 & 25 & 35 & Harvest \\
\hline Hexaploid & & & & & \\
\hline DL 1266-1 & $6.62 a$ & $9.31 \mathrm{a}$ & $12.17 \mathrm{ab}$ & $13.12 \mathrm{a}$ & $15.69 \mathrm{a}$ \\
\hline DL 1266-2 & 6.99 a & 9.57 a & $12.35 \mathrm{a}$ & $13.48 \mathrm{a}$ & $15.54 \mathrm{a}$ \\
\hline PBW 343 & $5.84 \mathrm{~b}$ & $8.59 \mathrm{~b}$ & $11.92 \mathrm{~b}$ & $13.17 \mathrm{a}$ & $14.16 \mathrm{~b}$ \\
\hline Sub Mean & 6.48 & 9.16 & 12.15 & 13.26 & 15.13 \\
\hline Tetraploid & & & & & \\
\hline PDW 233 & $5.16 \mathrm{c}$ & $8.54 \mathrm{~b}$ & $11.78 \mathrm{~b}$ & $12.69 \mathrm{~b}$ & $13.47 \mathrm{~b}$ \\
\hline HD 4530 & $5.22 \mathrm{c}$ & $8.44 \mathrm{~b}$ & $11.89 \mathrm{~b}$ & $12.58 \mathrm{~b}$ & $13.52 \mathrm{~b}$ \\
\hline HI 8498 & $5.12 \mathrm{c}$ & $8.56 \mathrm{~b}$ & $11.73 \mathrm{~b}$ & $12.36 \mathrm{~b}$ & $13.24 \mathrm{~b}$ \\
\hline Sub Mean & 5.17 & 8.51 & 11.80 & 12.54 & 13.41 \\
\hline Total Mean & 5.83 & 8.83 & 11.97 & 13.06 & 14.27 \\
\hline
\end{tabular}

In a column, means followed by a common letter are not significantly different at $5 \%$ level. 
Table 11. Genotypic differences in ear dry weight (g/plant) among hexaploid and tetraploid wheat

\begin{tabular}{|c|c|c|c|c|c|}
\hline \multirow{2}{*}{ Genotypes } & \multicolumn{5}{|c|}{ Days after anthesis } \\
\hline & 5 & 15 & 25 & 35 & Harvest \\
\hline Hexaploids & & & & & \\
\hline DL 1266-1 & $7.76 \mathrm{a}$ & $12.46 \mathrm{a}$ & $16.99 \mathrm{~b}$ & $21.58 \mathrm{~b}$ & $25.56 \mathrm{~b}$ \\
\hline DL 1266-2 & $7.80 \mathrm{a}$ & $13.55 \mathrm{a}$ & $18.89 a$ & $24.56 \mathrm{a}$ & $27.89 a$ \\
\hline PBW 343 & $5.38 \mathrm{~b}$ & $8.79 \mathrm{~b}$ & $11.46 \mathrm{c}$ & $14.45 \mathrm{c}$ & $16.23 \mathrm{c}$ \\
\hline Sub Mean & 6.98 & 11.60 & 15.78 & 20.20 & 23.23 \\
\hline Tetraploids & & & & & \\
\hline PDW 233 & $4.35 \mathrm{~b}$ & $6.53 c$ & $8.65 d$ & $11.13 \mathrm{~d}$ & $12.45 \mathrm{~d}$ \\
\hline HD 4530 & $4.27 \mathrm{~b}$ & $6.35 c$ & $8.51 \mathrm{~d}$ & $10.85 \mathrm{~d}$ & $12.01 \mathrm{~d}$ \\
\hline HI 8498 & $4.23 \mathrm{~b}$ & $6.25 c$ & $8.22 \mathrm{~d}$ & $10.56 \mathrm{~d}$ & $12.08 d$ \\
\hline Sub Mean & 4.28 & 6.38 & 8.46 & 10.85 & 12.08 \\
\hline Total Mean & 5.63 & 8.99 & 12.12 & 15.52 & 17.65 \\
\hline
\end{tabular}

In a column, means followed by a common letter are not significantly different at $5 \%$ level. 
Table 14. Genotypic differences in absolute growth rate of ear (g/day) among hexaploid and tetraploid wheat

\begin{tabular}{|l|c|c|c|c|}
\hline \multirow{2}{*}{ Genotypes } & \multicolumn{4}{|c|}{ Days after anthesis } \\
\cline { 2 - 5 } & $\mathbf{5}$ & $\mathbf{1 5}$ & $\mathbf{2 5}$ & $\mathbf{3 5}$ \\
\hline Hexaploid & & & $0.467 \mathrm{~b}$ & $0.398 \mathrm{a}$ \\
DL 1266-1 $1266-2$ & $0.520 \mathrm{~b}$ & $0.445 \mathrm{~b}$ & $0.567 \mathrm{a}$ & $0.333 \mathrm{~b}$ \\
PBW 343 & $0.566 \mathrm{a}$ & $0.534 \mathrm{a}$ & $0.299 \mathrm{c}$ & $0.178 \mathrm{c}$ \\
Sub Mean & $0.341 \mathrm{c}$ & $0.267 \mathrm{c}$ & $\mathbf{0 . 4 4 4}$ & $\mathbf{0 . 3 0 3}$ \\
Tetraploid & $\mathbf{0 . 4 7 6}$ & $\mathbf{0 . 4 1 5}$ & & $0.132 \mathrm{~d}$ \\
PDW 233 & & & $0.248 \mathrm{~cd}$ & $0.116 \mathrm{~d}$ \\
HD 4530 & $0.218 \mathrm{~d}$ & $0.212 \mathrm{~cd}$ & $0.234 \mathrm{~d}$ & $0.122 \mathrm{~d}$ \\
HI 8498 & $0.208 \mathrm{~d}$ & $0.216 \mathrm{~cd}$ & $0.234 \mathrm{~d}$ & $\mathbf{0 . 1 2 3}$ \\
Sub Mean & $0.202 \mathrm{~d}$ & $0.197 \mathrm{~d}$ & $\mathbf{0 . 2 3 9}$ & $\mathbf{0 . 2 1 3}$ \\
\hline Total Mean & $\mathbf{0 . 2 0 9}$ & $\mathbf{0 . 2 0 8}$ & $\mathbf{0 . 3 4 1}$ & $\mathbf{0 . 3 1 2}$ \\
\hline
\end{tabular}


In a column, means followed by a common letter are not significantly different at $5 \%$ level.

\begin{tabular}{|c|c|c|c|c|}
\hline \multirow{2}{*}{ Genotypes } & \multicolumn{4}{|c|}{ Days after anthesis } \\
\hline & $5-15$ & $15-25$ & $25-35$ & 35 DAA-Harvest \\
\hline \multicolumn{5}{|l|}{ Hexaploid } \\
\hline DL 1266-1 & $0.054 a$ & $0.031 \mathrm{ab}$ & $0.024 \mathrm{bc}$ & 0.017 a \\
\hline DL 1266-2 & $0.054 a$ & $0.033 a$ & $0.026 a$ & $0.013 \mathrm{~b}$ \\
\hline PBW 343 & $0.049 \mathrm{~b}$ & $0.027 \mathrm{~b}$ & $0.023 \mathrm{c}$ & $0.012 b c$ \\
\hline Sub Mean & 0.052 & 0.030 & 0.024 & 0.014 \\
\hline \multicolumn{5}{|l|}{ Tetraploid } \\
\hline PDW 233 & $0.041 \mathrm{c}$ & $0.028 a b$ & $0.025 a b$ & $0.011 \mathrm{bc}$ \\
\hline HD 4530 & $0.040 \mathrm{c}$ & $0.029 a b$ & $0.024 b c$ & $0.010 \mathrm{c}$ \\
\hline HI 8498 & $0.039 \mathrm{c}$ & $0.027 \mathrm{~b}$ & $0.025 a b$ & $0.011 b c$ \\
\hline Sub Mean & 0.040 & 0.028 & 0.025 & 0.011 \\
\hline Total Mean & 0.046 & 0.070 & 0.025 & 0.011 \\
\hline
\end{tabular}


In a column, means followed by a common letter are not significantly different at $5 \%$ level.

Table 16. Genotypic differences in seed weight (mg/grain) among hexaploid and tetraploid wheat

\begin{tabular}{|c|c|c|c|c|c|}
\hline \multirow{2}{*}{ Genotypes } & \multicolumn{5}{|c|}{ Days after anthesis } \\
\hline & 5 & 15 & 25 & 35 & Harvest \\
\hline \multicolumn{6}{|l|}{ Hexaploid } \\
\hline DL 1266-1 & $6.27 \mathrm{a}$ & $15.56 a$ & $37.57 \mathrm{a}$ & $54.89 a$ & $60.15 a$ \\
\hline DL 1266-2 & $6.43 \mathrm{a}$ & 16.35 a & $38.47 \mathrm{a}$ & $56.12 \mathrm{a}$ & $61.25 \mathrm{a}$ \\
\hline PBW 343 & $5.24 \mathrm{~b}$ & $13.15 \mathrm{bc}$ & $30.56 \mathrm{~b}$ & $45.27 \mathrm{~b}$ & $49.58 \mathrm{~b}$ \\
\hline Sub Mean & 5.98 & 15.02 & 35.53 & 52.09 & 56.99 \\
\hline \multicolumn{6}{|l|}{ Tetraploid } \\
\hline PDW 233 & $5.17 \mathrm{~b}$ & $12.26 \mathrm{bc}$ & $28.69 \mathrm{~b}$ & $40.35 \mathrm{~b}$ & $43.69 \mathrm{~b}$ \\
\hline HD 4530 & $5.12 \mathrm{~b}$ & $11.83 \mathrm{C}$ & $26.14 \mathrm{~b}$ & $36.45 \mathrm{~b}$ & $39.54 b$ \\
\hline HI 8498 & $5.27 \mathrm{~b}$ & $14.29 a b$ & $26.57 \mathrm{~b}$ & $37.12 \mathrm{~b}$ & $40.26 \mathrm{~b}$ \\
\hline Sub Mean & 5.19 & 12.80 & 27.13 & 37.97 & 41.16 \\
\hline Total Mean & 5.58 & 13.91 & 31.33 & 45.03 & 49.08 \\
\hline
\end{tabular}


In a column, means followed by a common letter are not significantly different at $5 \%$ level.

Table 17. Genotypic differences in absolute growth rate of seed (mg/day) among hexaploid and tetraploid wheat

\begin{tabular}{|l|c|c|c|c|}
\hline \multirow{2}{*}{ Genotypes } & \multicolumn{4}{|c|}{ Days after anthesis } \\
\cline { 2 - 5 } & $\mathbf{5 - 1 5}$ & $\mathbf{1 5}-\mathbf{2 5}$ & $\mathbf{2 5}-\mathbf{3 5}$ & $\mathbf{3 5}$ - Harvest \\
\hline Hexaploid & & & & \\
DL 1266-1 $1266-2$ & $0.929 \mathrm{a}$ & $2.201 \mathrm{a}$ & $1.732 \mathrm{a}$ & $0.526 \mathrm{a}$ \\
PBW 343 & $0.992 \mathrm{a}$ & $2.212 \mathrm{a}$ & $1.765 \mathrm{a}$ & $0.513 \mathrm{a}$ \\
Sub Mean & $0.788 \mathrm{~b}$ & $1.741 \mathrm{~b}$ & $1.471 \mathrm{~b}$ & $0.431 \mathrm{~b}$ \\
Tetraploid & $\mathbf{0 . 9 0 3}$ & $\mathbf{2 . 0 5 1}$ & $\mathbf{1 . 6 5 6}$ & $\mathbf{0 . 4 9 0}$ \\
PDW 233 & & & & \\
HD 4530 & $0.709 \mathrm{bc}$ & $1.643 \mathrm{~b}$ & $1.166 \mathrm{c}$ & $0.334 \mathrm{c}$ \\
HI 8498 & $0.671 \mathrm{c}$ & $1.431 \mathrm{~b}$ & $1.031 \mathrm{c}$ & $0.309 \mathrm{c}$ \\
Sub Mean & $0.701 \mathrm{c}$ & $1.428 \mathrm{~b}$ & $1.055 \mathrm{c}$ & $0.314 \mathrm{c}$ \\
\hline Total Mean & $\mathbf{0 . 6 9 3}$ & $\mathbf{1 . 5 0 0}$ & $\mathbf{1 . 0 8 4}$ & $\mathbf{0 . 3 1 9}$ \\
\hline
\end{tabular}


In a column, means followed by a common letter are not significantly different at $5 \%$ level.

Table 18. Genotypic differences in grain growth rate (g/g/day) among hexaploid and tetraploid wheat

\begin{tabular}{|l|c|c|c|c|}
\hline \multirow{2}{*}{ Genotypes } & \multicolumn{4}{|c|}{ Days after anthesis } \\
\cline { 2 - 5 } & $\mathbf{5 - 1 5}$ & $\mathbf{1 5}-\mathbf{2 5}$ & $\mathbf{2 5}-\mathbf{3 5}$ & $\mathbf{3 5}$ - Harvest \\
\hline Hexaploid & & & & $0.009 \mathrm{a}$ \\
DL 1266-1 & $0.091 \mathrm{a}$ & $0.088 \mathrm{a}$ & $0.041 \mathrm{a}$ & $0.009 \mathrm{a}$ \\
PBW 1266-2 343 & $0.093 \mathrm{a}$ & $0.086 \mathrm{a}$ & $0.037 \mathrm{abc}$ & $0.009 \mathrm{a}$ \\
Sub Mean & $0.092 \mathrm{a}$ & $0.084 \mathrm{ab}$ & $0.039 \mathrm{ab}$ & $\mathbf{0 . 0 0 9}$ \\
Tetraploid & $\mathbf{0 . 0 9 2}$ & $\mathbf{0 . 0 8 6}$ & $\mathbf{0 . 0 3 9}$ & $0.008 \mathrm{a}$ \\
PDW 233 & & & & $0.009 \mathrm{a}$ \\
HD 4530 & $0.086 \mathrm{ab}$ & $0.085 \mathrm{a}$ & $0.034 \mathrm{bc}$ & $0.008 \mathrm{a}$ \\
HI 8498 & $0.079 \mathrm{~b}$ & $0.079 \mathrm{bc}$ & $0.033 \mathrm{c}$ & $\mathbf{0 . 0 0 8}$ \\
Sub Mean & $0.077 \mathrm{~b}$ & $0.077 \mathrm{c}$ & $0.033 \mathrm{c}$ & $\mathbf{0 . 0 0 9}$ \\
\hline Total Mean & $\mathbf{0 . 0 8 1}$ & $\mathbf{0 . 0 8 0}$ & $\mathbf{0 . 0 3 3}$ & $\mathbf{0 . 0 3 6}$ \\
\hline
\end{tabular}


In a column, means followed by a common letter are not significantly different at $5 \%$ level.

Table 12. Genotypic differences in total dry weight (g/plant) among hexaploid and tetraploid wheat

\begin{tabular}{|l|c|c|c|c|c|}
\hline \multirow{2}{*}{ Genotypes } & \multicolumn{5}{|c|}{ Days after anthesis } \\
\cline { 2 - 6 } & $\mathbf{5}$ & $\mathbf{1 5}$ & $\mathbf{2 5}$ & $\mathbf{3 5}$ & Harvest \\
\hline Hexaploid & & & & & \\
DL 1266-1 & $15.66 \mathrm{a}$ & $22.08 \mathrm{~b}$ & $29.86 \mathrm{~b}$ & $32.86 \mathrm{ab}$ & $38.29 \mathrm{a}$ \\
DL 1266-2 & $16.25 \mathrm{a}$ & $24.19 \mathrm{a}$ & $32.88 \mathrm{a}$ & $34.19 \mathrm{a}$ & $39.39 \mathrm{a}$ \\
PBW 343 & $11.84 \mathrm{~b}$ & $19.83 \mathrm{c}$ & $26.68 \mathrm{c}$ & $29.59 \mathrm{bc}$ & $32.32 \mathrm{~b}$ \\
Sub Mean & $\mathbf{1 4 . 5 8}$ & $\mathbf{2 2 . 0 3}$ & $\mathbf{2 9 . 8 1}$ & $\mathbf{3 2 . 2 1}$ & $\mathbf{3 6 . 6 7}$ \\
Tetraploid & & & & & $31.17 \mathrm{~b}$ \\
PDW 233 & $9.98 \mathrm{bc}$ & $18.30 \mathrm{~cd}$ & $25.62 \mathrm{~cd}$ & $28.06 \mathrm{c}$ & $32.01 \mathrm{~b}$ \\
HD 4530 & $9.89 \mathrm{bc}$ & $17.58 \mathrm{~d}$ & $25.18 \mathrm{~cd}$ & $28.41 \mathrm{c}$ & $31.64 \mathrm{~b}$ \\
HI 8498 & $9.68 \mathrm{c}$ & $17.32 \mathrm{~d}$ & $24.08 \mathrm{~d}$ & $28.80 \mathrm{c}$ & $\mathbf{3 1 . 6 1}$ \\
Sub Mean & $\mathbf{9 . 8 5}$ & $\mathbf{1 7 . 7 3}$ & $\mathbf{2 4 . 9 6}$ & $\mathbf{2 8 . 4 2}$ & $\mathbf{3 4 . 1 4}$ \\
\hline Total Mean & $\mathbf{1 2 . 2 2}$ & $\mathbf{1 9 . 8 8}$ & $\mathbf{2 7 . 3 8}$ & $\mathbf{3 0 . 3 2}$ & \\
\hline
\end{tabular}


In a column, means followed by a common letter are not significantly different at $5 \%$ level.

Table 14. Genotypic differences in net assimilation rate $\left(\mathrm{mg} / \mathrm{cm}^{2} / \mathrm{day}\right)$ among hexaploid and tetraploid wheat

\begin{tabular}{|l|c|c|c|}
\hline \multirow{2}{*}{ Genotypes } & \multicolumn{3}{|c|}{ Days after anthesis } \\
\cline { 2 - 4 } & $\mathbf{5 - 1 5}$ & $\mathbf{1 5}-\mathbf{2 5}$ & $\mathbf{2 5}-\mathbf{3 5}$ \\
\hline Hexaploid & & & $0.880 \mathrm{c}$ \\
DL 1266-1 $1266-2$ & $2.973 \mathrm{~b}$ & $2.073 \mathrm{~b}$ & $0.327 \mathrm{~d}$ \\
PBW 343 & $2.132 \mathrm{~b}$ & $2.024 \mathrm{bc}$ & $0.848 \mathrm{c}$ \\
Sub Mean & $2.667 \mathrm{a}$ & $1.900 \mathrm{c}$ & $\mathbf{0 . 6 8 5}$ \\
Tetraploid & $\mathbf{2 . 2 5 7}$ & $\mathbf{1 . 9 9 9}$ & \\
PDW 233 & & & $0.897 \mathrm{c}$ \\
HD 4530 & $3.058 \mathrm{a}$ & $2.309 \mathrm{a}$ & $1.057 \mathrm{~b}$ \\
HI 8498 & $2.679 \mathrm{a}$ & $2.288 \mathrm{a}$ & $1.422 \mathrm{a}$ \\
Sub Mean & $2.748 \mathrm{a}$ & $2.111 \mathrm{~b}$ & $\mathbf{1 . 1 2 5}$ \\
\hline Total Mean & $\mathbf{2 . 8 2 8}$ & $\mathbf{2 . 2 3 6}$ & $\mathbf{0 . 9 0 5}$ \\
\hline
\end{tabular}


In a column, means followed by a common letter are not significantly different at $5 \%$ level.

\begin{tabular}{|c|c|c|c|c|}
\hline & \multicolumn{4}{|c|}{ Days after anthesis } \\
\hline & $5-15$ & $15-25$ & $25-35$ & 35 - Harvest \\
\hline Hexaploid & & & & \\
\hline DL 1266-1 & $0.034 \mathrm{c}$ & $0.030 \mathrm{~b}$ & $0.009 \mathrm{c}$ & 0.015 a \\
\hline DL 1266-2 & $0.039 \mathrm{c}$ & $0.031 \mathrm{~b}$ & $0.004 \mathrm{~d}$ & $0.014 a b$ \\
\hline PBW 343 & $0.052 \mathrm{~b}$ & $0.029 \mathrm{~b}$ & $0.010 \mathrm{c}$ & $0.009 \mathrm{~d}$ \\
\hline Sub Mean & 0.042 & 0.030 & 0.008 & 0.013 \\
\hline Tetraploid & & & & \\
\hline PDW 233 & $0.061 \mathrm{a}$ & $0.034 a$ & $0.008 \mathrm{c}$ & $0.011 \mathrm{~cd}$ \\
\hline HD 4530 & $0.058 \mathrm{a}$ & $0.036 \mathrm{a}$ & $0.013 \mathrm{~b}$ & 0.012 bc \\
\hline HI 8498 & $0.059 a$ & $0.034 a$ & $0.016 a$ & 0.012 bc \\
\hline Sub Mean & 0.059 & 0.035 & 0.012 & 0.012 \\
\hline Total Mean & 0.050 & 0.032 & 0.010 & 0.012 \\
\hline
\end{tabular}


In a column, means followed by a common letter are not significantly different at 5\% level.

Table 22. Genotypic differences among hexaploid and tetraploid wheat in flag leaf chlorophyll 'a' content (mg/g fr.wt.) 


\begin{tabular}{|c|c|c|c|}
\hline \multirow{2}{*}{ Genotypes } & \multicolumn{3}{|c|}{ Days after anthesis } \\
\hline & 10 & 20 & 30 \\
\hline Hexaploid & & & \\
\hline DL 1266-1 & $2.892 \mathrm{a}$ & $1.990 \mathrm{~b}$ & $1.239 \mathrm{~b}$ \\
\hline DL 1266-2 & $2.919 a$ & $2.440 \mathrm{a}$ & $1.331 \mathrm{a}$ \\
\hline PBW 343 & $2.775 \mathrm{a}$ & $1.727 \mathrm{~b}$ & $1.087 \mathrm{c}$ \\
\hline Sub Mean & 2.862 & 2.052 & 1.219 \\
\hline Tetraploid & & & \\
\hline PDW 233 & $2.634 \mathrm{a}$ & $1.551 \mathrm{c}$ & $0.869 \mathrm{~d}$ \\
\hline HD 4530 & $2.587 a$ & $1.616 \mathrm{c}$ & $0.962 \mathrm{~d}$ \\
\hline HI 8498 & $1.694 \mathrm{~b}$ & $1.588 \mathrm{C}$ & $0.973 \mathrm{e}$ \\
\hline Sub Mean & 2.305 & 1.585 & 0.934 \\
\hline Total Mean & 2.584 & 1.819 & 1.077 \\
\hline
\end{tabular}

In a column, means followed by a common letter are not significantly different at $5 \%$ level. 
Table 23. Genotypic differences among hexaploid and tetraploid wheat in flag leaf chlorophyll 'b' content (mg/g fr. wt.)

\begin{tabular}{|l|c|c|c|}
\hline \multirow{2}{*}{ Genotypes } & \multicolumn{3}{|c|}{ Days after anthesis } \\
\cline { 2 - 4 } & $\mathbf{1 0}$ & $\mathbf{2 0}$ & $\mathbf{3 0}$ \\
\hline Hexaploid & & & $0.991 \mathrm{~b}$ \\
DL 1266-1 & $1.602 \mathrm{ab}$ & $1.501 \mathrm{a}$ & $1.104 \mathrm{a}$ \\
DL 1266-2 & $1.725 \mathrm{a}$ & $1.679 \mathrm{a}$ & $0.935 \mathrm{c}$ \\
PBW 343 & $1.446 \mathrm{bc}$ & $1.255 \mathrm{~b}$ & $\mathbf{1 . 0 1 0}$ \\
Sub Mean & $\mathbf{1 . 5 9 1}$ & $\mathbf{1 . 4 7 8}$ & \\
Tetraploid & & & $0.735 \mathrm{f}$ \\
PDW 233 & $1.412 \mathrm{bc}$ & $1.102 \mathrm{~b}$ & $0.828 \mathrm{e}$ \\
HD 4530 & $1.381 \mathrm{c}$ & $1.211 \mathrm{~b}$ & $0.876 \mathrm{~d}$ \\
HI 8498 & $1.317 \mathrm{c}$ & $1.155 \mathrm{~b}$ & $\mathbf{0 . 8 1 3}$ \\
Sub Mean & $\mathbf{1 . 3 7 0}$ & $\mathbf{1 . 1 5 6}$ & $\mathbf{0 . 9 1 1}$ \\
\hline Total Mean & $\mathbf{1 . 4 8 1}$ & $\mathbf{1 . 3 1 7}$ & \\
\hline
\end{tabular}


In a column, means followed by a common letter are not significantly different at $5 \%$ level.

Table 25. Genotypic differences among hexaploid and tetraploid wheat in flag leaf total chlorophyll a/b ratio

\begin{tabular}{|l|c|c|c|}
\hline \multirow{2}{*}{ Genotypes } & \multicolumn{3}{|c|}{ Days after anthesis } \\
\cline { 2 - 4 } & $\mathbf{1 0}$ & $\mathbf{2 0}$ & $\mathbf{3 0}$ \\
\hline Hexaploid & & & $1.250 \mathrm{a}$ \\
DL 1266-1 & $1.805 \mathrm{ab}$ & $1.326 \mathrm{~b}$ & $1.206 \mathrm{~b}$ \\
PBW 343 & $1.688 \mathrm{~b}$ & $1.453 \mathrm{a}$ & $1.163 \mathrm{c}$ \\
Sub Mean & $1.863 \mathrm{ab}$ & $1.376 \mathrm{ab}$ & $\mathbf{1 . 2 0 6}$ \\
Tetraploid & $\mathbf{1 . 7 8 5}$ & $\mathbf{1 . 3 8 5}$ & $1.114 \mathrm{~d}$ \\
PDW 233 & & & $1.162 \mathrm{c}$ \\
HD 4530 & $1.665 \mathrm{~b}$ & $1.420 \mathrm{a}$ & $1.111 \mathrm{~d}$ \\
HI 8498 & $1.873 \mathrm{ab}$ & $1.334 \mathrm{~b}$ & $\mathbf{1 . 1 2 9}$ \\
Sub Mean & $1.970 \mathrm{a}$ & $1.375 \mathrm{ab}$ & $\mathbf{1 . 1 6 8}$ \\
\hline Total Mean & $\mathbf{1 . 8 3 6}$ & $\mathbf{1 . 3 7 6}$ & $\mathbf{1 . 3 8 1}$ \\
\hline
\end{tabular}


In a column, means followed by a common letter are not significantly different at $5 \%$ level.

Table 24. Genotypic differences among hexaploid and tetraploid wheat in flag leaf total chlorophyll content

(mg/g fr. wt.)

\begin{tabular}{|l|c|c|c|}
\hline \multirow{2}{*}{ Genotypes } & \multicolumn{3}{|c|}{ Days after anthesis } \\
\cline { 2 - 4 } & $\mathbf{1 0}$ & $\mathbf{2 0}$ & $\mathbf{3 0}$ \\
\hline Hexaploid $1266-1$ & $3.113 \mathrm{a}$ & $3.841 \mathrm{ab}$ & $2.224 \mathrm{~b}$ \\
DL 1266-2 & $3.096 \mathrm{a}$ & $3.878 \mathrm{a}$ & $2.437 \mathrm{a}$ \\
PBW 343 & $2.887 \mathrm{ab}$ & $2.882 \mathrm{abc}$ & $2.154 \mathrm{~b}$ \\
Sub Mean & $\mathbf{3 . 0 2 8}$ & $\mathbf{3 . 5 3 4}$ & $\mathbf{2 . 2 7 2}$ \\
Tetraploid & & & \\
PDW 233 & $2.192 \mathrm{c}$ & $2.553 \mathrm{~b}$ & $1.391 \mathrm{~d}$ \\
HD 4530 & $2.517 \mathrm{bc}$ & $2.827 \mathrm{~b}$ & $1.573 \mathrm{c}$ \\
HI 8498 & $2.238 \mathrm{c}$ & $2.743 \mathrm{~b}$ & $\mathbf{1 . 4 8 7}$ \\
Sub Mean & $\mathbf{2 . 3 1 6}$ & $\mathbf{2 . 7 0 8}$ & $\mathbf{1 . 8 7 9}$ \\
\hline Total Mean & $\mathbf{2 . 6 7 2}$ & $\mathbf{3 . 1 2 1}$ & \\
\hline
\end{tabular}


In a column, means followed by a common letter are not significantly different at $5 \%$ level.

Table 21. Genotypic differences among hexaploid and tetraploid wheat in flag leaf photosynthetic rate $\left(\mu \mathrm{mol} / \mathrm{m}^{2} / \mathrm{s}\right)$

\begin{tabular}{|c|c|c|c|c|}
\hline \multirow{2}{*}{ Genotypes } & \multicolumn{4}{|c|}{ Days after anthesis } \\
\hline & 5 & 15 & 25 & 35 \\
\hline \multicolumn{5}{|l|}{ Hexaploid } \\
\hline DL 1266-1 & $26.63 \mathrm{~b}$ & $24.04 a b$ & $19.43 a b c$ & $12.94 \mathrm{ab}$ \\
\hline DL 1266-2 & 29.39 a & 25.68 a & $21.23 \mathrm{a}$ & $14.54 \mathrm{a}$ \\
\hline PBW 343 & $24.49 \mathrm{~cd}$ & $20.59 \mathrm{bc}$ & $16.89 \mathrm{C}$ & $11.89 a b c$ \\
\hline Sub Mean & 26.77 & 23.44 & 19.18 & 13.12 \\
\hline \multicolumn{5}{|l|}{ Tetraploid } \\
\hline PDW 233 & $25.53 \mathrm{bc}$ & $22.60 \mathrm{abc}$ & $17.12 \mathrm{c}$ & $10.62 \mathrm{bc}$ \\
\hline HD 4530 & $21.63 \mathrm{e}$ & $19.56 \mathrm{C}$ & $19.97 \mathrm{ab}$ & $9.97 \mathrm{c}$ \\
\hline HI 8498 & $23.67 d$ & $21.52 b c$ & $17.82 \mathrm{bc}$ & $11.13 \mathrm{bc}$ \\
\hline Sub Mean & 23.61 & 21.23 & 18.30 & 10.57 \\
\hline Total Mean & 25.19 & 22.33 & 18.74 & 11.85 \\
\hline
\end{tabular}


In a column, means followed by a common letter are not significantly different at $5 \%$ level.

\begin{tabular}{|c|c|c|c|c|}
\hline \multirow{2}{*}{ Genotypes } & \multicolumn{4}{|c|}{ Days after anthesis } \\
\hline & 5 & 15 & 25 & 35 \\
\hline \multicolumn{5}{|l|}{ Hexaploid } \\
\hline DL 1266-1 & $1.784 a b$ & $2.129 \mathrm{~b}$ & $1.961 \mathrm{ab}$ & $1.093 \mathrm{a}$ \\
\hline DL 1266-2 & $1.853 \mathrm{a}$ & $2.592 \mathrm{a}$ & $2.019 a$ & $1.126 \mathrm{a}$ \\
\hline PBW 343 & $1.702 \mathrm{bc}$ & $2.001 \mathrm{c}$ & $1.818 \mathrm{abc}$ & $1.086 \mathrm{a}$ \\
\hline Sub Mean & 1.780 & 2.241 & 1.933 & 1.102 \\
\hline \multicolumn{5}{|l|}{ Tetraploid } \\
\hline PDW 233 & $1.408 \mathrm{~d}$ & $1.551 \mathrm{e}$ & $1.164 \mathrm{C}$ & $0.867 \mathrm{~b}$ \\
\hline HD 4530 & $1.612 \mathrm{c}$ & $1.856 \mathrm{~d}$ & $1.790 \mathrm{ab}$ & $0.812 \mathrm{~b}$ \\
\hline HI 8498 & $1.481 \mathrm{~d}$ & $1.817 \mathrm{~d}$ & $1.692 \mathrm{~b}$ & $0.853 \mathrm{~b}$ \\
\hline Sub Mean & 1.500 & 1.741 & 1.549 & 0.844 \\
\hline Total Mean & 1.640 & 1.991 & 1.741 & 0.973 \\
\hline
\end{tabular}


In a column, means followed by a common letter are not significantly different at $5 \%$ level.

Table 26. Genotypic differences among hexaploid and tetraploid wheat in total sugars content (mg/g dry wt.) of developing grains

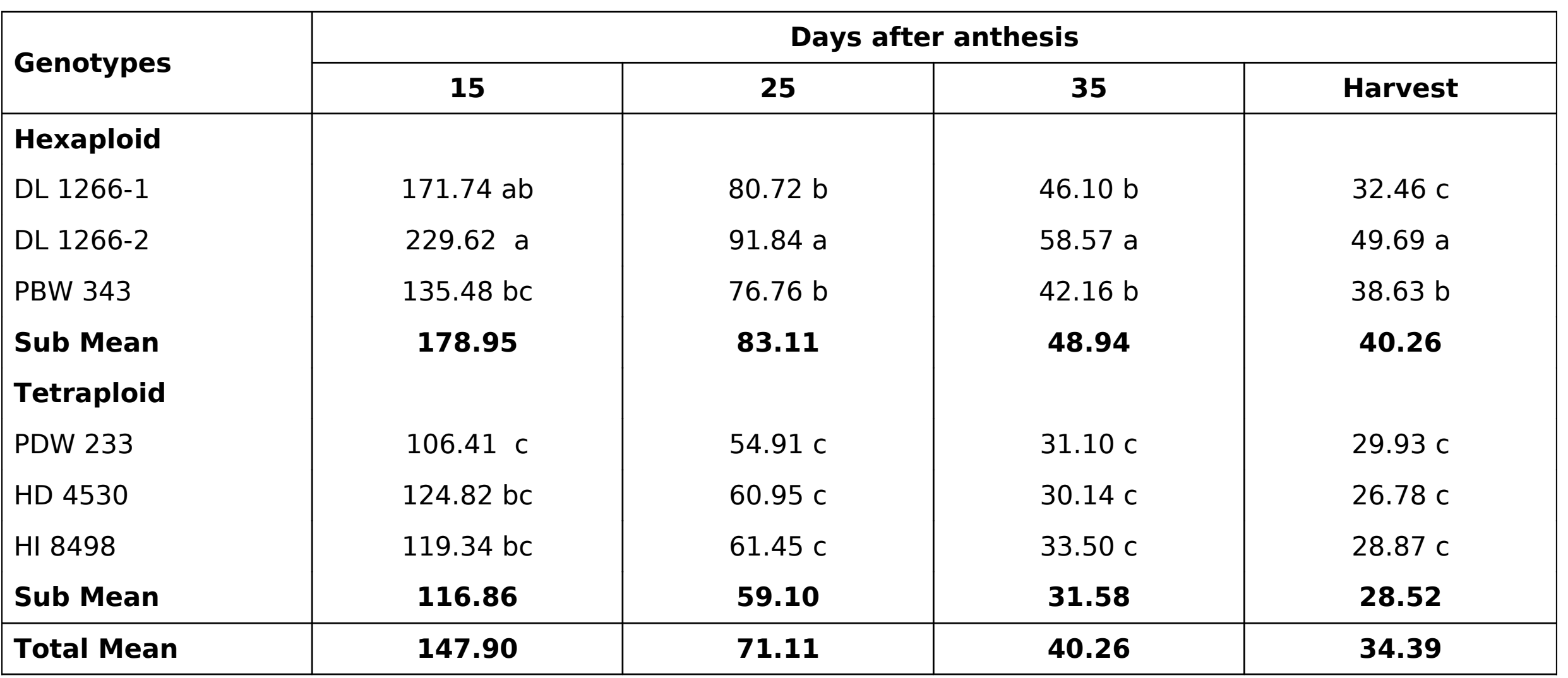


In a column, means followed by a common letter are not significantly different at 5\% level.

Table 27. Genotypic differences among hexaploid and tetraploid wheat in starch content (mg/g dry wt) of developing

\section{grains}

\begin{tabular}{|c|c|c|c|c|}
\hline \multirow{2}{*}{ Genotypes } & \multicolumn{4}{|c|}{ Days after anthesis } \\
\hline & 15 & 25 & 35 & Harvest \\
\hline \multicolumn{5}{|l|}{ Hexaploid } \\
\hline DL 1266-1 & $315.00 a b$ & $528.00 \mathrm{ab}$ & $677.00 \mathrm{ab}$ & $700.00 \mathrm{ab}$ \\
\hline DL 1266-2 & 342.00 a & 564.00 a & 699.00 a & $710.00 \mathrm{a}$ \\
\hline PBW 343 & $278.00 \mathrm{bc}$ & $506.00 \mathrm{abc}$ & $644.00 \mathrm{bc}$ & $655.00 \mathrm{bc}$ \\
\hline Sub Mean & 311.67 & 532.67 & 673.16 & 688.33 \\
\hline \multicolumn{5}{|l|}{ Tetraploid } \\
\hline PDW 233 & $222.00 \mathrm{~d}$ & $437.00 \mathrm{~d}$ & $629.00 \mathrm{c}$ & $635.00 \mathrm{c}$ \\
\hline HD 4530 & $256.00 \mathrm{~cd}$ & $472.00 \mathrm{bcd}$ & $618.00 \mathrm{c}$ & $624.00 \mathrm{c}$ \\
\hline HI 8498 & $244.00 \mathrm{~cd}$ & $456.00 \mathrm{~cd}$ & $606.00 \mathrm{c}$ & $614.00 \mathrm{c}$ \\
\hline Sub Mean & 240.67 & 455.00 & 617.80 & 624.78 \\
\hline Total Mean & 276.17 & 493.83 & 645.48 & 656.33 \\
\hline
\end{tabular}


In a column, means followed by a common letter are not significantly different at $5 \%$ level.

Table 28. Genotypic differences in endogenous content of Indole-acetic acid (IAA) content ( $\mu \mathrm{g} / \mathrm{g}$ fr. wt.) of developing

grains among hexaploid and tetraploid wheat

\begin{tabular}{|l|c|c|c|c|}
\hline \multirow{2}{*}{ Genotypes } & \multicolumn{4}{|c|}{ Days after anthesis } \\
\cline { 2 - 5 } Hexaploid & $\mathbf{7}$ & $\mathbf{1 5}$ & $\mathbf{2 5}$ & $\mathbf{3 5}$ \\
DL 1266-1 & $11.25 \mathrm{a}$ & $29.48 \mathrm{a}$ & $18.49 \mathrm{a}$ & $11.16 \mathrm{a}$ \\
DL 1266-2 & $12.58 \mathrm{a}$ & $31.24 \mathrm{a}$ & $17.25 \mathrm{ab}$ & $10.38 \mathrm{~b}$ \\
PBW 343 & $8.68 \mathrm{~b}$ & $22.10 \mathrm{bc}$ & $16.47 \mathrm{~b}$ & $10.26 \mathrm{~b}$ \\
Sub Mean & $\mathbf{1 0 . 8 4}$ & $\mathbf{2 7 . 6 1}$ & $\mathbf{1 7 . 4 0}$ & $\mathbf{1 0 . 6 0}$ \\
Tetraploid & & & & \\
PDW 233 & $8.15 \mathrm{~b}$ & $19.48 \mathrm{c}$ & $13.89 \mathrm{c}$ & $9.09 \mathrm{c}$ \\
HD 4530 & $8.24 \mathrm{~b}$ & $22.47 \mathrm{~b}$ & $15.43 \mathrm{bc}$ & $9.45 \mathrm{c}$ \\
HI 8498 & $8.22 \mathrm{~b}$ & $20.20 \mathrm{~cd}$ & $14.26 \mathrm{c}$ & $9.48 \mathrm{c}$ \\
Sub Mean & $\mathbf{8 . 2 0}$ & $\mathbf{2 0 . 7 2}$ & $\mathbf{1 4 . 5 3}$ & $\mathbf{9 . 3 4}$ \\
\hline Total Mean & $\mathbf{9 . 5 2}$ & $\mathbf{2 4 . 1 6}$ & $\mathbf{1 5 . 9 7}$ & $\mathbf{9 . 9 7}$ \\
\hline
\end{tabular}


In a column, means followed by a common letter are not significantly different at $5 \%$ level.

Table 29. Genotypic differences in endogenous Gibberellic acid $\left(G A_{3}\right)$ content ( $\mu \mathrm{g} / \mathrm{g}$ fr. wt.) of developing grains among

hexaploid and tetraploid wheat

\begin{tabular}{|c|c|c|c|c|}
\hline \multirow{2}{*}{ Genotypes } & \multicolumn{4}{|c|}{ Days after anthesis } \\
\hline & 7 & 15 & 25 & 35 \\
\hline \multicolumn{5}{|l|}{ Hexaploid } \\
\hline DL 1266-1 & $34.59 \mathrm{a}$ & $22.60 \mathrm{~b}$ & $9.65 a b$ & $4.56 \mathrm{a}$ \\
\hline DL 1266-2 & $35.60 \mathrm{a}$ & $26.13 a$ & $10.45 \quad a$ & $3.58 \mathrm{ab}$ \\
\hline PBW 343 & $26.48 \mathrm{~b}$ & $20.42 \mathrm{bc}$ & $8.58 \mathrm{abc}$ & $3.58 \mathrm{ab}$ \\
\hline Sub Mean & 32.22 & 23.05 & 9.56 & 3.91 \\
\hline \multicolumn{5}{|l|}{ Tetraploid } \\
\hline PDW 233 & $27.57 \mathrm{~b}$ & $20.59 \mathrm{bc}$ & $6.41 \mathrm{c}$ & $2.45 b c$ \\
\hline HD 4530 & $25.89 \mathrm{~b}$ & $19.87 \mathrm{bc}$ & 7.12 bc & $2.36 \mathrm{bc}$ \\
\hline HI 8498 & $24.45 b$ & $17.58 \mathrm{C}$ & $6.47 \mathrm{c}$ & $2.14 \mathrm{C}$ \\
\hline Sub Mean & 25.97 & 19.35 & 6.67 & 2.32 \\
\hline Total Mean & 29.10 & 21.20 & 8.11 & 3.03 \\
\hline
\end{tabular}


In a column, means followed by a common letter are not significantly different at $5 \%$ level.

Table 30. Genotypic differences in endogenous Abscisic acid (ABA) content ( $\mu \mathrm{g} / \mathrm{g}$ fr. wt.) of developing grains among

hexaploid and tetraploid wheat

\begin{tabular}{|c|c|c|c|c|}
\hline \multirow{2}{*}{ Genotypes } & \multicolumn{4}{|c|}{ Days after anthesis } \\
\hline & 7 & 15 & 25 & 35 \\
\hline \multicolumn{5}{|l|}{ Hexaploid } \\
\hline DL 1266-1 & $9.48 a b$ & $22.35 \mathrm{~b}$ & $32.59 \mathrm{~b}$ & $13.66 \mathrm{ab}$ \\
\hline DL 1266-2 & $10.47 \mathrm{a}$ & $26.58 a$ & 34.58 a & $14.59 \mathrm{a}$ \\
\hline PBW 343 & $7.54 \mathrm{abc}$ & $20.36 \mathrm{~b}$ & $25.48 \mathrm{~d}$ & $12.45 \mathrm{bc}$ \\
\hline Sub Mean & 9.16 & 23.10 & 30.88 & 13.57 \\
\hline \multicolumn{5}{|l|}{ Tetraploid } \\
\hline PDW 233 & $7.58 \mathrm{c}$ & $19.48 \mathrm{bc}$ & $26.48 \mathrm{~cd}$ & $11.98 \mathrm{C}$ \\
\hline HD 4530 & $7.87 \mathrm{bc}$ & $16.58 \mathrm{c}$ & $28.48 \mathrm{C}$ & $11.14 \mathrm{C}$ \\
\hline HI 8498 & $6.46 \mathrm{c}$ & $19.58 \mathrm{bc}$ & $27.58 \mathrm{c}$ & $12.36 \mathrm{bc}$ \\
\hline Sub Mean & 7.30 & 18.55 & 27.51 & 11.83 \\
\hline Total Mean & 8.23 & 20.82 & 29.20 & 12.70 \\
\hline
\end{tabular}


In a column, means followed by a common letter are not significantly different at $5 \%$ level.

Table 4. Genotypic differences in morphological characters at harvest among hexaploid and tetraploid wheat

\begin{tabular}{|l|c|c|c|c|}
\hline Genotypes & Plant height $\mathbf{( c m )}$ & $\begin{array}{c}\text { Tiller } \\
\text { number/plant }\end{array}$ & Ear number/plant & Ear length (cm) \\
\hline Hexaploid & $104.66 \mathrm{a}$ & $4.6 \mathrm{c}$ & $3.8 \mathrm{bc}$ & $16.50 \mathrm{a}$ \\
DL 1266-1 & $100.21 \mathrm{a}$ & $4.9 \mathrm{c}$ & $3.7 \mathrm{c}$ & $17.33 \mathrm{a}$ \\
DL 1266-2 & $89.12 \mathrm{~d}$ & $9.0 \mathrm{a}$ & $6.0 \mathrm{a}$ & $15.50 \mathrm{a}$ \\
PBW 343 & $\mathbf{9 8 . 0 0}$ & $\mathbf{6 . 2}$ & $\mathbf{4 . 5}$ & $\mathbf{1 6 . 4 4}$ \\
Sub Mean & & & $5.8 \mathrm{a}$ & \\
Tetraploid & $87.00 \mathrm{bc}$ & $8.6 \mathrm{ab}$ & $5.6 \mathrm{a}$ & $7.33 \mathrm{~b}$ \\
PDW 233 & $97.22 \mathrm{ab}$ & $7.7 \mathrm{~b}$ & $5.0 \mathrm{ab}$ & $8.50 \mathrm{~b}$ \\
HD 4530 & $81.67 \mathrm{~cd}$ & $7.7 \mathrm{~b}$ & $\mathbf{5 . 5}$ & $\mathbf{8 . 0 5}$ \\
HI 8498 & $\mathbf{8 8 . 6 3}$ & $\mathbf{8 . 0}$ & $\mathbf{5 . 0}$ & $\mathbf{1 2 . 2 5}$ \\
Sub Mean & $\mathbf{9 3 . 3 1}$ & $\mathbf{7 . 1}$ & \\
\hline Total Mean & & &
\end{tabular}


In a column, means followed by a common letter are not significantly different at $5 \%$ level.

Table 3. Genotypic differences in yield and yield components at harvest among hexaploid and tetraploid wheat

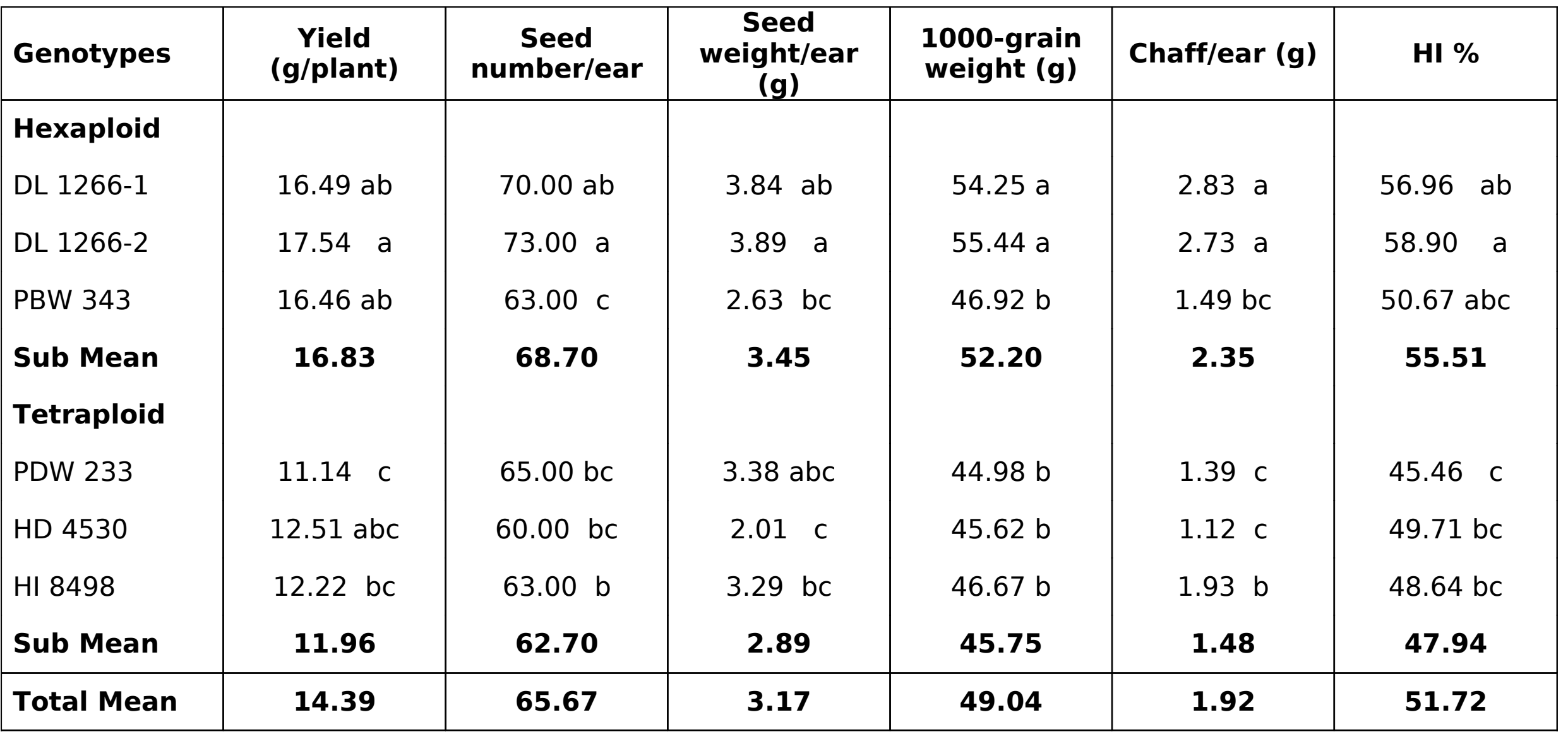


In a column, means followed by a common letter are not significantly different at $5 \%$ level.

Table 32. Correlation co-efficients between hormonal contents and absolute grain growth rate among hexaploid and

tetraploid wheat

\begin{tabular}{|c|c|c|c|c|}
\hline Hormones & 5-15 DAA & 15-25 DAA & 25-35 DAA & 35 DAA - Harvest \\
\hline IAA 7 DAA & $0.975^{* *}$ & $0.942 * *$ & $0.907^{*}$ & $0.902 *$ \\
\hline IAA 15 DAA & $0.968 * *$ & $0.981 * *$ & $0.930 * *$ & $0.924^{* *}$ \\
\hline IAA 25 DAA & $0.883^{*}$ & $0.951 * *$ & $0.952 * *$ & $0.959 * *$ \\
\hline IAA 35 DAA & 0.809 & $0.875^{*}$ & 0.887* & $0.918 * *$ \\
\hline GA 7 DAA & $0.955^{* *}$ & $0.925^{* *}$ & 0.884* & 0.891* \\
\hline GA 15 DAA & $0.930 * *$ & $0.871^{*}$ & $0.858 *$ & $0.836^{*}$ \\
\hline GA 25 DAA & $0.925^{* *}$ & $0.850 *$ & $0.883^{*}$ & $0.879 *$ \\
\hline GA 35 DAA & $0.846^{*}$ & $0.886^{*}$ & $0.926^{* *}$ & $0.948 * *$ \\
\hline ABA 7 DAA & $0.948^{* *}$ & $0.929 * *$ & $0.880 *$ & $0.864 *$ \\
\hline ABA 15 DAA & $0.935^{* *}$ & $0.876^{*}$ & $0.870 *$ & $0.839 *$ \\
\hline ABA 25 DAA & $0.838 *$ & 0.797 & 0.716 & $0.728 *$ \\
\hline
\end{tabular}




\begin{tabular}{|c|c|c|c|c|}
\hline ABA 35 DAA & $0.909 * *$ & 0.829* & 0.842* & $0.851 *$ \\
\hline \multicolumn{5}{|c|}{$\begin{array}{l}\text { Table 33. Correlation co-efficier } \\
\text { hexaploid and tetraploid } \\
\text { wheat }\end{array}$} \\
\hline Hormones & 5-15 DAA & 15-25 DAA & 25-35 DAA & 35 DAA - Harvest \\
\hline IAA 7 DAA & $0.978^{* *}$ & 0.651 & 0.0608 & 0.607 \\
\hline IAA 15 DAA & $0.971^{* *}$ & 0.789 & 0.639 & 0.618 \\
\hline IAA 25 DAA & $0.881 *$ & $0.929 * *$ & $0.838^{*}$ & $0.841 *$ \\
\hline IAA 35 DAA & $0.815^{*}$ & 0.829 & 0.790 & 0.883 \\
\hline GA 7 DAA & $0.969 * *$ & 0.616 & 0.570 & 0.605 \\
\hline GA 15 DAA & $0.931 * *$ & 0.575 & 0.615 & 0.546 \\
\hline GA 25 DAA & $0.927 * *$ & 0.526 & 0.721 & 0.711 \\
\hline GA 35 DAA & $0.849 *$ & 0.809 & $0.873^{*}$ & $0.931^{* *}$ \\
\hline ABA 7 DAA & $0.953 * *$ & 0.684 & 0.579 & 0.526 \\
\hline ABA 15 DAA & $0.929 * *$ & 0.601 & 0.645 & 0.546 \\
\hline ABA 25 DAA & $0.855^{*}$ & 0.440 & 0.313 & 0.387 \\
\hline
\end{tabular}




\begin{tabular}{|l|l|l|l|l|}
\hline ABA 35 DAA & $0.910 *$ & 0.459 & 0.614 & 0.670 \\
\hline
\end{tabular}

* Significant at 5\% $(r=0.811)$; ** Significant at $1 \%(r=0.917)$ 
Table 31. Correlation co-efficients between the endogenous hormones among hexaploid and tetraploid wheat

\begin{tabular}{|c|c|c|c|c|c|c|c|c|c|c|c|c|}
\hline & $\begin{array}{c}\text { IAA } 7 \\
\text { DAA }\end{array}$ & $\begin{array}{c}\text { IAA } 15 \\
\text { DAA }\end{array}$ & $\begin{array}{c}\text { IAA } 25 \\
\text { DAA }\end{array}$ & $\begin{array}{c}\text { IAA } 35 \\
\text { DAA }\end{array}$ & $\begin{array}{l}\text { GA } 7 \\
\text { DAA }\end{array}$ & $\begin{array}{c}\text { GA } 15 \\
\text { DAA }\end{array}$ & $\begin{array}{c}\text { GA } 25 \\
\text { DAA }\end{array}$ & $\begin{array}{c}\text { GA } 35 \\
\text { DAA }\end{array}$ & $\begin{array}{c}\text { ABA } 7 \\
\text { DAA }\end{array}$ & $\begin{array}{c}\text { ABA } 15 \\
\text { DAA }\end{array}$ & $\begin{array}{c}\text { ABA } 25 \\
\text { DAA }\end{array}$ & $\begin{array}{c}\text { ABA } 35 \\
\text { DAA }\end{array}$ \\
\hline $\begin{array}{r}\text { IAA } 7 \\
\text { DAA }\end{array}$ & 1.000 & $0.977^{* *}$ & 0.802 & 0.735 & $0.963 * *$ & 0.909* & 0.870* & 0.739 & $0.946 * *$ & $0.917^{*}$ & $0.933^{* *}$ & $0.939 * *$ \\
\hline $\begin{array}{c}\text { IAA } 15 \\
\text { DAA }\end{array}$ & & 1.000 & 0.882* & 0.798 & $0.944 * *$ & 0.882* & 0.825* & 0.789 & $0.951^{* *}$ & $0.892 *$ & $0.882^{*}$ & $0.860^{*}$ \\
\hline $\begin{array}{c}\text { IAA } 25 \\
\text { DAA }\end{array}$ & & & 1.000 & $0.958^{* *}$ & 0.796 & 0.715 & $0.905^{*}$ & 0.665 & $0.840 *$ & 0.810 & 0.614 & 0.696 \\
\hline $\begin{array}{c}\text { IAA } 35 \\
\text { DAA }\end{array}$ & & & & 1.000 & 0.746 & 0.584 & $0.958^{* *}$ & 0.788 & 0.718 & $0.967 * *$ & 0.766 & $0.900 *$ \\
\hline $\begin{array}{l}\text { GA } 7 \\
\text { DAA }\end{array}$ & & & & & 1.000 & $0.935^{* *}$ & $0.922 * *$ & 0.778 & $0.963^{* *}$ & $0.907 *$ & $0.908^{*}$ & 0.880* \\
\hline $\begin{array}{c}\text { GA } 15 \\
\text { DAA }\end{array}$ & & & & & & 1.000 & $0.958 * *$ & 0.686 & $0.975^{* *}$ & $0.990 * *$ & 0.777 & 0.800 \\
\hline $\begin{array}{c}\text { GA } 25 \\
\text { DAA }\end{array}$ & & & & & & & 1.000 & 0.788 & $0.905^{*}$ & $0.933^{* *}$ & 0.724 & 0.833* \\
\hline $\begin{array}{c}\text { GA } 35 \\
\text { DAA }\end{array}$ & & & & & & & & 1.000 & 0.718 & 0.665 & 0.552 & 0.695 \\
\hline $\begin{array}{c}\text { ABA } 7 \\
\text { DAA }\end{array}$ & & & & & & & & & 1.000 & 0.375 & $0.840^{*}$ & 0.800 \\
\hline $\begin{array}{c}\text { ABA } 15 \\
\text { DAA }\end{array}$ & & & & & & & & & & 1.000 & 0.766 & 0.810 \\
\hline $\begin{array}{c}\text { ABA } 25 \\
\text { DAA }\end{array}$ & & & & & & & & & & & 1.000 & 0.900* \\
\hline $\begin{array}{c}\text { ABA } 35 \\
\text { DAA }\end{array}$ & & & & & & & & & & & & 1.000 \\
\hline
\end{tabular}

* Significant at $5 \%(r=0.811)$; ** Significant at $1 \%(r=0.917)$ 
Table 1. Yield performance of hexaploid and tetraploid wheat genotypes

\begin{tabular}{|c|c|c|c|c|c|}
\hline Genotypes & Yield (g/plant) & $\begin{array}{c}\text { Seed } \\
\text { number/plant }\end{array}$ & $\begin{array}{c}\text { Seed } \\
\text { number/ear }\end{array}$ & $\begin{array}{l}\text { 1000-grain } \\
\text { weight }(g)\end{array}$ & $\mathrm{HI} \%$ \\
\hline \multicolumn{6}{|l|}{ Hexaploid } \\
\hline DL 1266-1 & $16.49 a b$ & $266 \mathrm{~b}$ & $70.00 \mathrm{ab}$ & $54.25 \mathrm{a}$ & $56.96 a b$ \\
\hline DL 1266-2 & $17.54 \quad \mathrm{a}$ & $270 \mathrm{~b}$ & $73.00 \mathrm{a}$ & $55.44 \mathrm{a}$ & $58.90 \quad a$ \\
\hline PBW 343 & $16.46 a b$ & $300 a$ & $63.00 \mathrm{c}$ & $46.92 \mathrm{~b}$ & $50.67 \mathrm{abc}$ \\
\hline Sub Mean & 16.83 & 278.67 & 68.70 & 52.20 & 55.51 \\
\hline Tetraploid & & & & & \\
\hline PDW 233 & $11.14 \mathrm{C}$ & $278 b$ & $65.00 \mathrm{bc}$ & $44.98 \mathrm{~b}$ & $45.46 \mathrm{c}$ \\
\hline HD 4530 & $12.51 \mathrm{abc}$ & $280 \mathrm{~b}$ & $60.00 \mathrm{bc}$ & $45.62 \mathrm{~b}$ & $49.71 b c$ \\
\hline HI 8498 & $12.22 \mathrm{bc}$ & $275 b$ & $63.00 \mathrm{~b}$ & $46.67 \mathrm{~b}$ & $48.64 \mathrm{bc}$ \\
\hline Sub Mean & 11.96 & 277.67 & 62.70 & 45.75 & 47.94 \\
\hline Total Mean & 14.39 & 274.83 & 65.67 & 49.04 & 51.72 \\
\hline
\end{tabular}

In a column, means followed by a common letter are not significantly different at $5 \%$ level. 
Table 2. Physiological parameters of seed yield of hexaploid and tetraploid wheat genotypes

\begin{tabular}{|c|c|c|c|c|c|}
\hline Genotypes & Yield (g/plant) & $\begin{array}{c}\text { Total dry } \\
\text { weight (g) }\end{array}$ & $\begin{array}{c}\text { Leaf area }\left(\mathrm{cm}^{2}\right) \\
\text { at } 25 \text { DAA }\end{array}$ & HI \% & $\begin{array}{c}\text { Fruting } \\
\text { co-efficient }\end{array}$ \\
\hline Hexaploid & & & & & \\
\hline DL 1266-1 & $16.49 a b$ & 38.29 a & $398.13 \mathrm{~b}$ & $56.96 a b$ & $0.43 c$ \\
\hline DL 1266-2 & 17.54 a & 39.39 a & $458.36 a$ & $58.90 \quad$ a & $0.45 b$ \\
\hline PBW 343 & $16.46 a b$ & $32.32 \mathrm{~b}$ & $389.56 \mathrm{~b}$ & $50.67 \mathrm{abc}$ & 0.51 a \\
\hline Sub Mean & 16.83 & 36.67 & 415.35 & 55.51 & 0.46 \\
\hline Tetraploid & & & & & \\
\hline PDW 233 & $11.14 \mathrm{C}$ & $31.17 \mathrm{~b}$ & $340.65 c$ & $45.46 \quad \mathrm{c}$ & $0.36 \mathrm{e}$ \\
\hline HD 4530 & $12.51 \mathrm{abc}$ & $32.01 \mathrm{~b}$ & $319.46 \mathrm{c}$ & $49.71 \mathrm{bc}$ & $0.39 \mathrm{~d}$ \\
\hline HI 8498 & $12.22 \mathrm{bc}$ & $31.64 \mathrm{~b}$ & $315.65 c$ & 48.64 bc & $0.39 \mathrm{~d}$ \\
\hline Sub Mean & 11.96 & 31.61 & 325.25 & 47.94 & 0.38 \\
\hline Total Mean & 14.39 & 34.14 & 370.30 & 51.72 & 0.42 \\
\hline
\end{tabular}

In a column, means followed by a common letter are not significantly different at 5\% level. 
Table 35. Yield attributes and physiological parameters of seed yield per cent wise over hexaploid wheat DL-1266-2

\begin{tabular}{|c|c|c|c|c|c|c|c|}
\hline Genotypes & $\begin{array}{c}\text { Yield } \\
\text { (g/plant) }\end{array}$ & $\begin{array}{c}\text { Seed } \\
\text { number/pla } \\
\text { nt }\end{array}$ & $\begin{array}{c}\text { Seed } \\
\text { number/ea } \\
r\end{array}$ & $\begin{array}{c}\text { 1000-grain } \\
\text { weight }\end{array}$ & $\begin{array}{c}\text { Total dry } \\
\text { matter (g) }\end{array}$ & $\begin{array}{c}\text { Leaf area } \\
\left(\mathrm{cm}^{2}\right) \text { at } 25 \\
\text { DAA }\end{array}$ & HI \% \\
\hline Hexaploid & & & & & & & \\
\hline DL 1266-1 & 94.01 & 98.52 & 95.89 & 97.85 & 97.21 & 86.86 & 96.71 \\
\hline DL $1266-2$ & 100.00 & 100.00 & 100.00 & 100.00 & 100.00 & 100.00 & 100.00 \\
\hline PBW 343 & 93.84 & 111.11 & 86.30 & 84.63 & 82.05 & 84.99 & 86.03 \\
\hline $\begin{array}{l}\text { Sub Mean } \\
\text { Tetraploid }\end{array}$ & 95.95 & 103.21 & 94.06 & 94.16 & 93.09 & 90.62 & 94.24 \\
\hline PDW 233 & 69.67 & 102.96 & 86.30 & 84.18 & 79.13 & 74.32 & 82.58 \\
\hline HD 4530 & 63.51 & 103.70 & 89.04 & 81.13 & 81.26 & 69.70 & 77.18 \\
\hline HI 8498 & 71.32 & 101.85 & 82.19 & 82.29 & 80.32 & 68.87 & 84.40 \\
\hline Sub Mean & 68.17 & 102.84 & 85.84 & 82.23 & 80.24 & 70.96 & 81.39 \\
\hline $\begin{array}{l}\text { Total } \\
\text { Mean }\end{array}$ & 82.06 & 103.02 & 89.95 & 88.35 & 86.66 & 80.79 & 87.82 \\
\hline
\end{tabular}


Fig. 2. Seed weight at different growth stages in whe genotypes

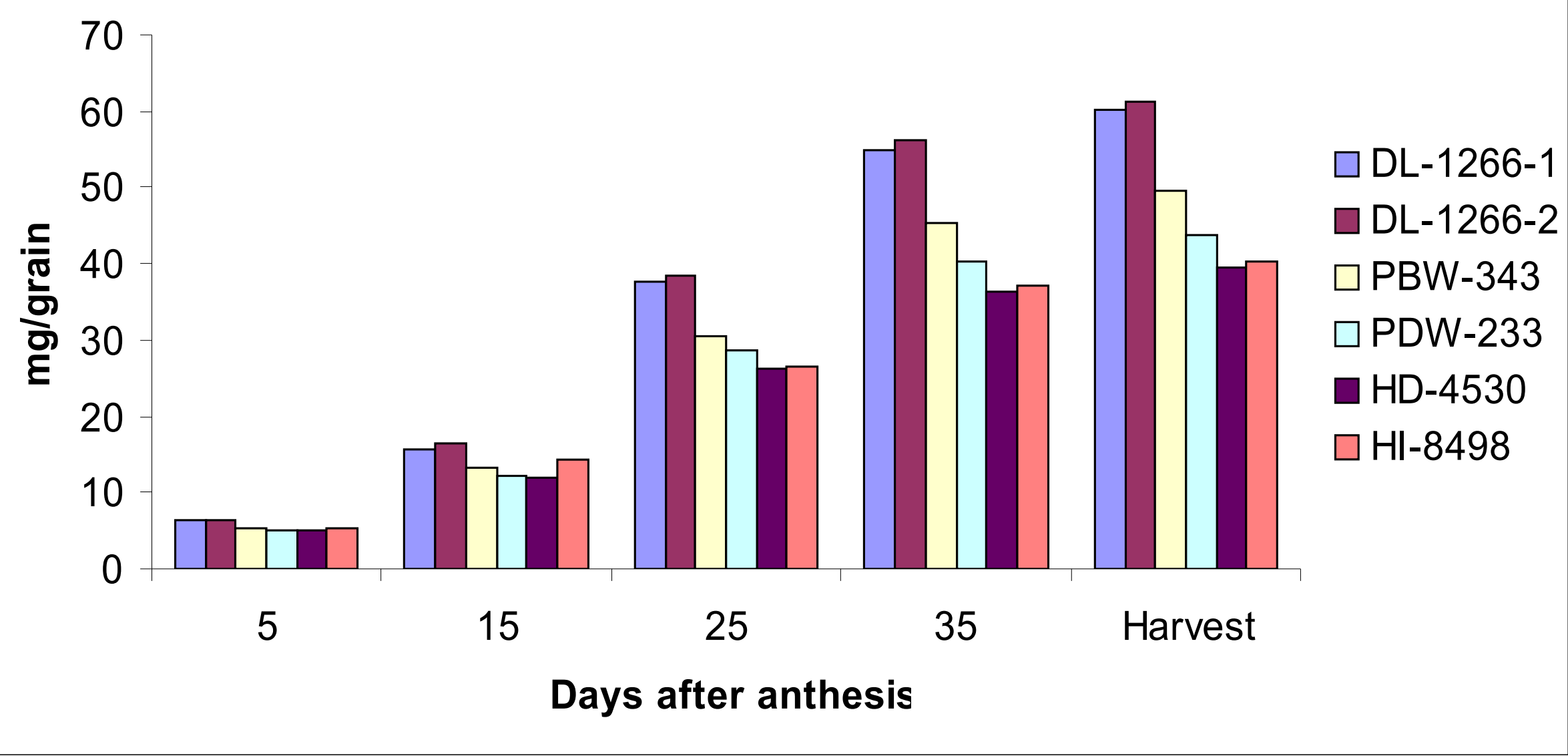


Fig. 3. Grain growth rate of different wheat genotypes

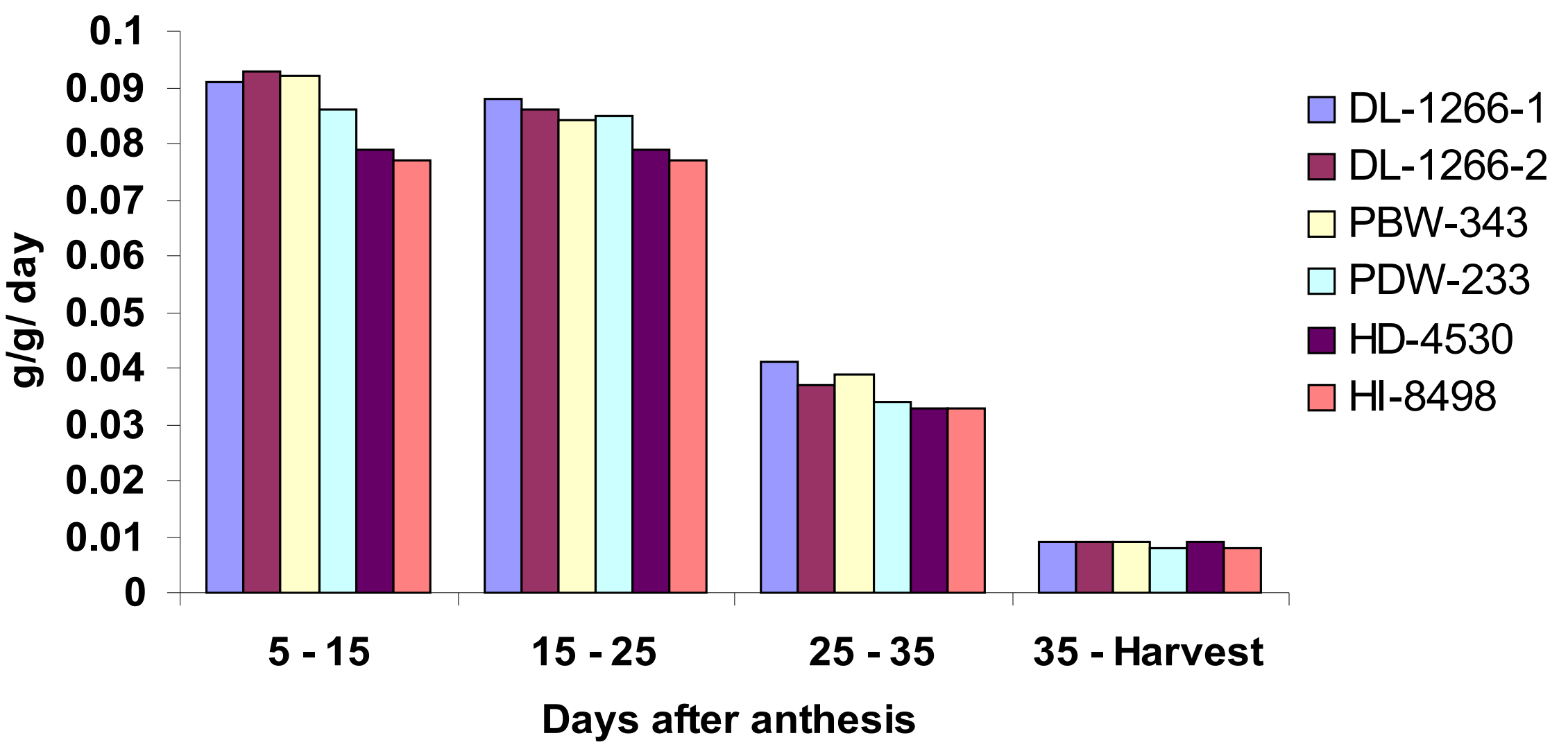


Fig. 4. Endogenous hormonal content in developing grains of hexaploid wheat DL-1266-1

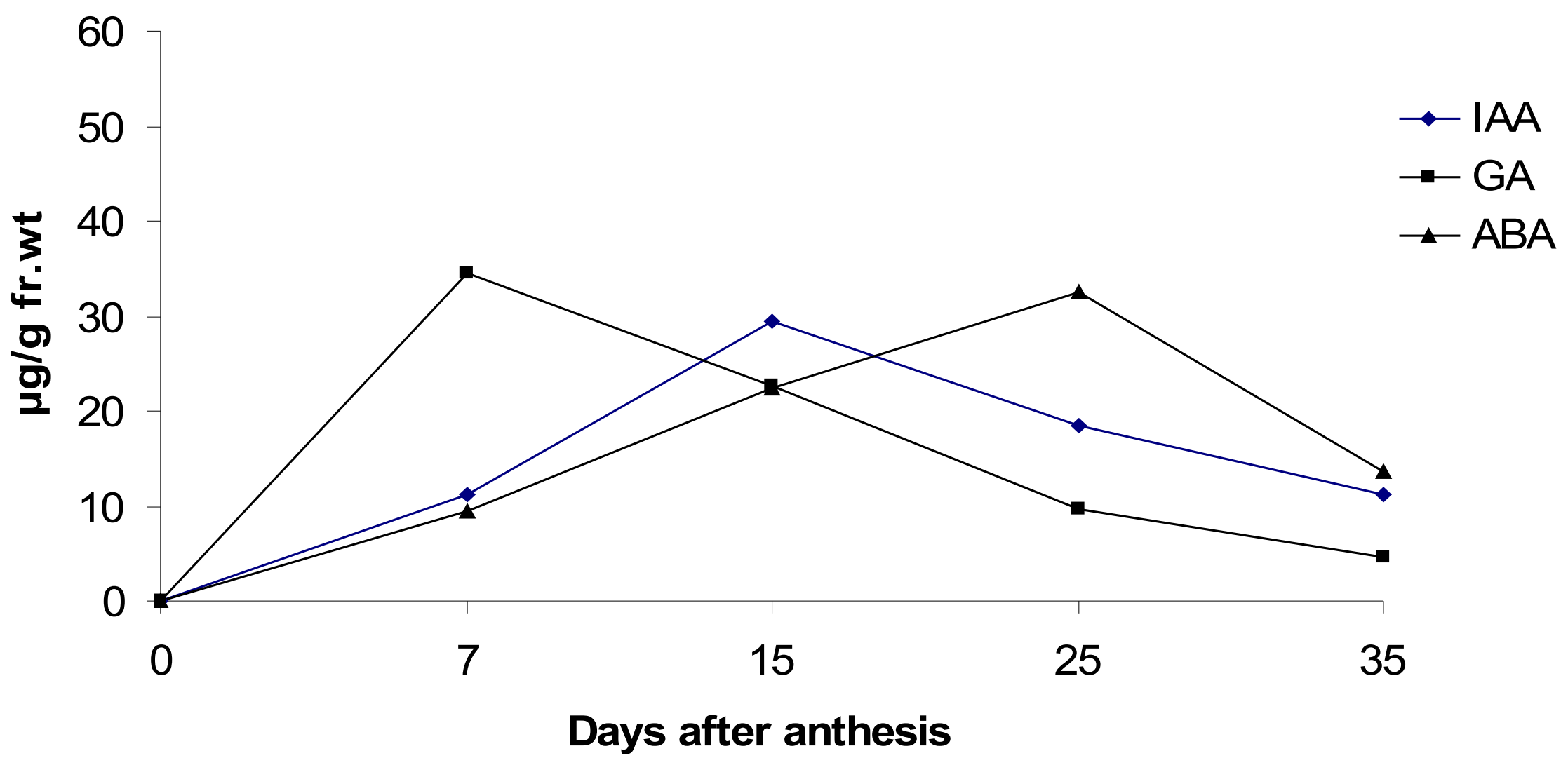


Fig. 5. Endogenous hormonal content in develol grains of hexaploid wheat DL-1266-2

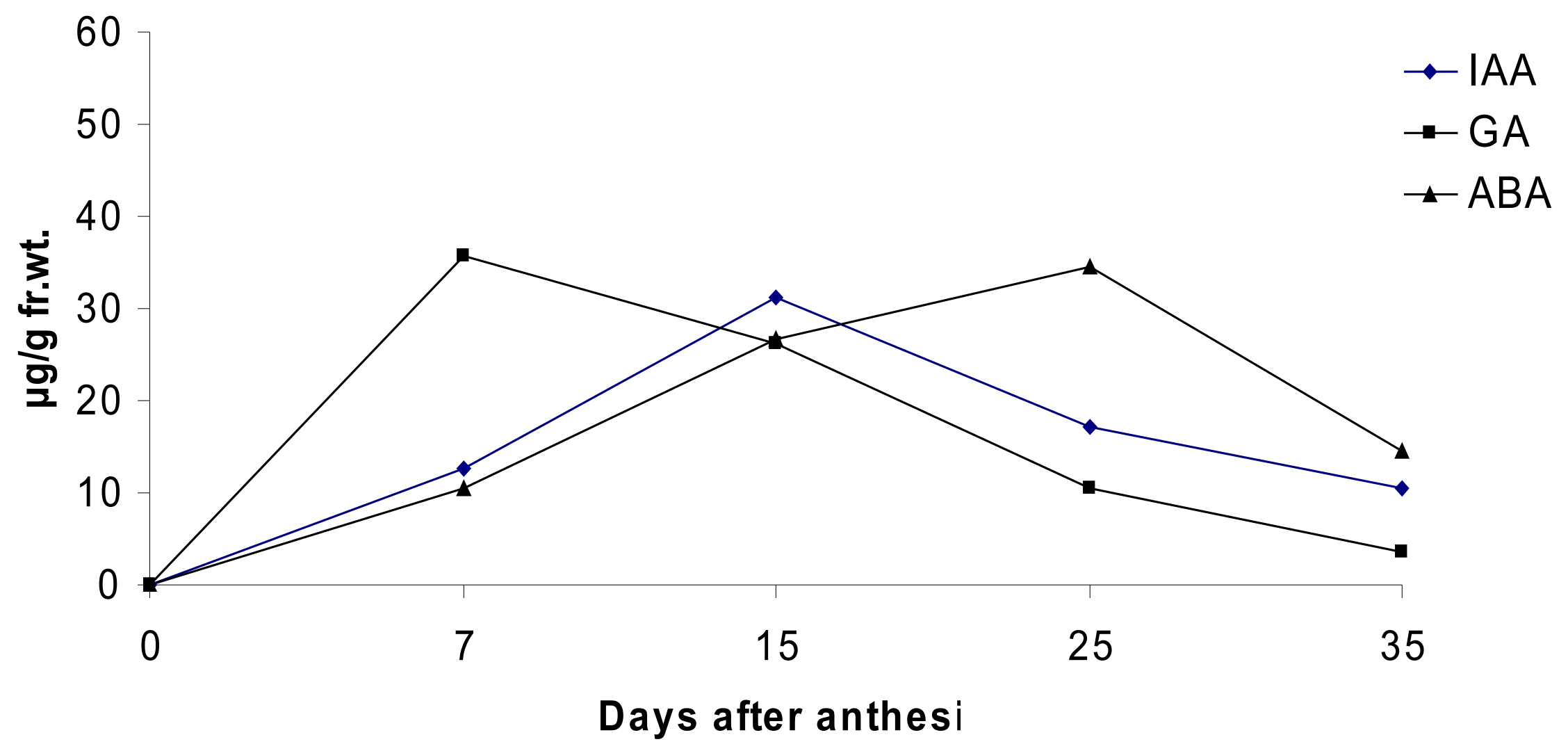


Fig. 6. Endogenous hormonal content in developing grains of hexaploid wheat PDW-343

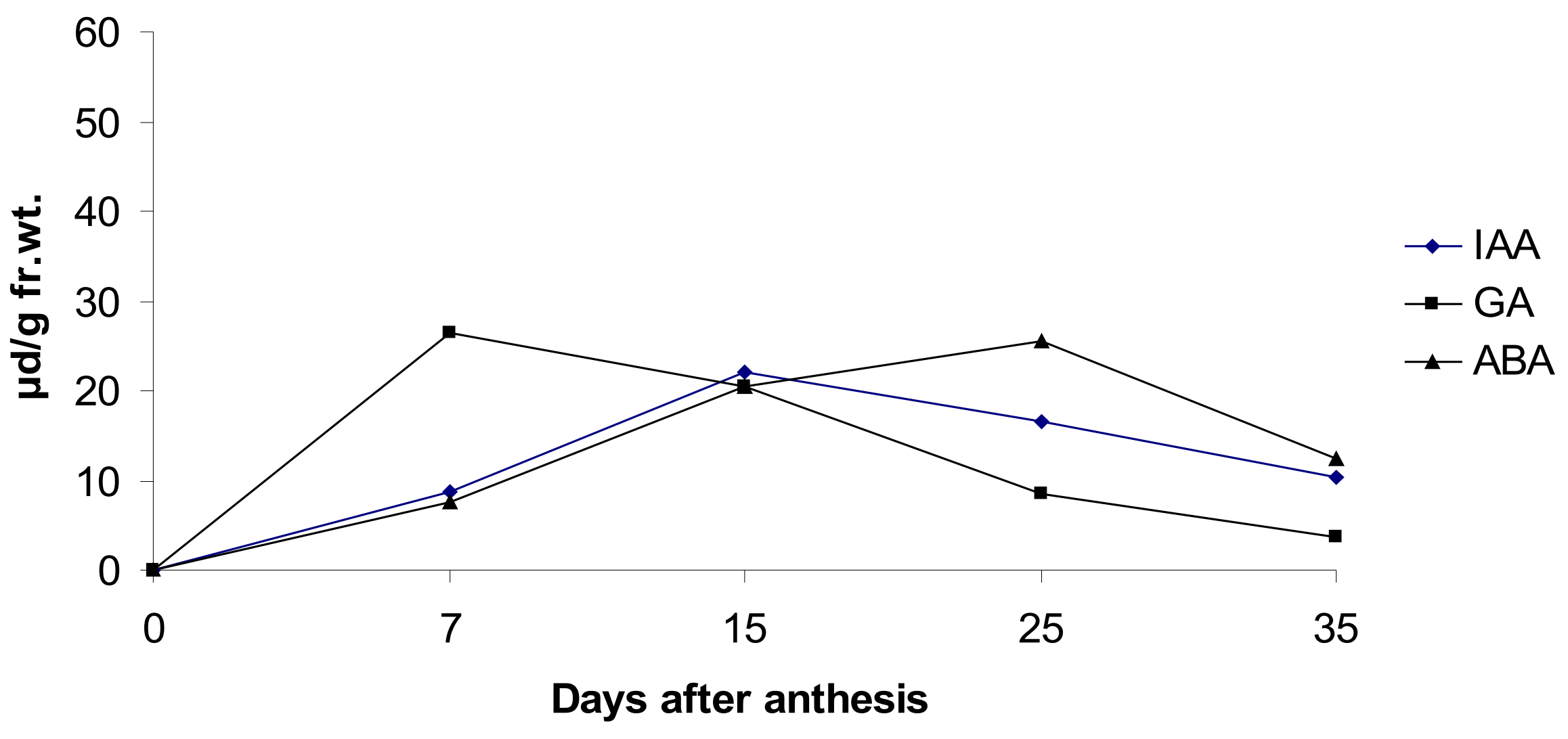


Fig. 7. Endogenous hormonal content in developing grains of tetraploid wheat PDW-233

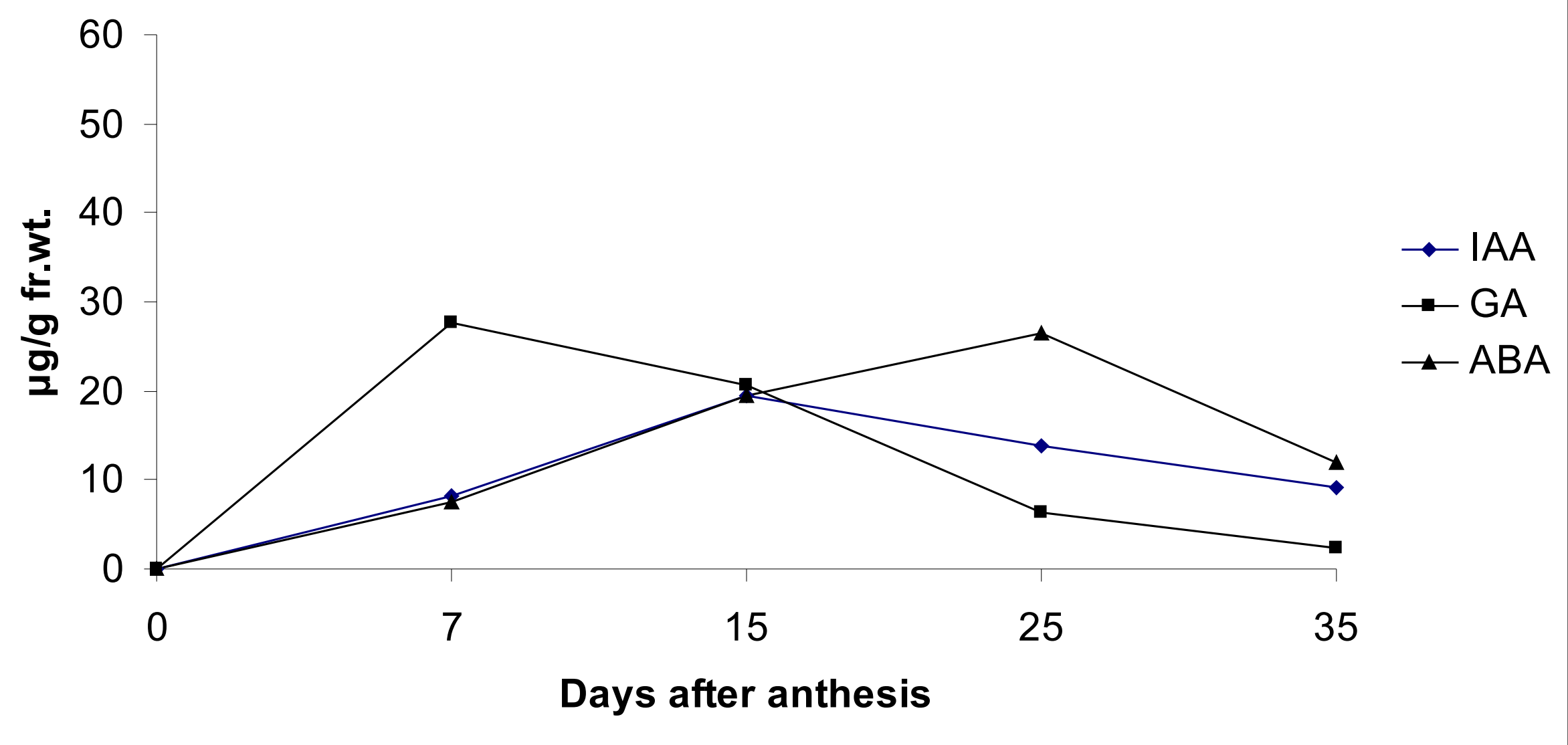


Fig. 8. Endogenous hormonal content in developing grains of tetraploid wheat HD-4530

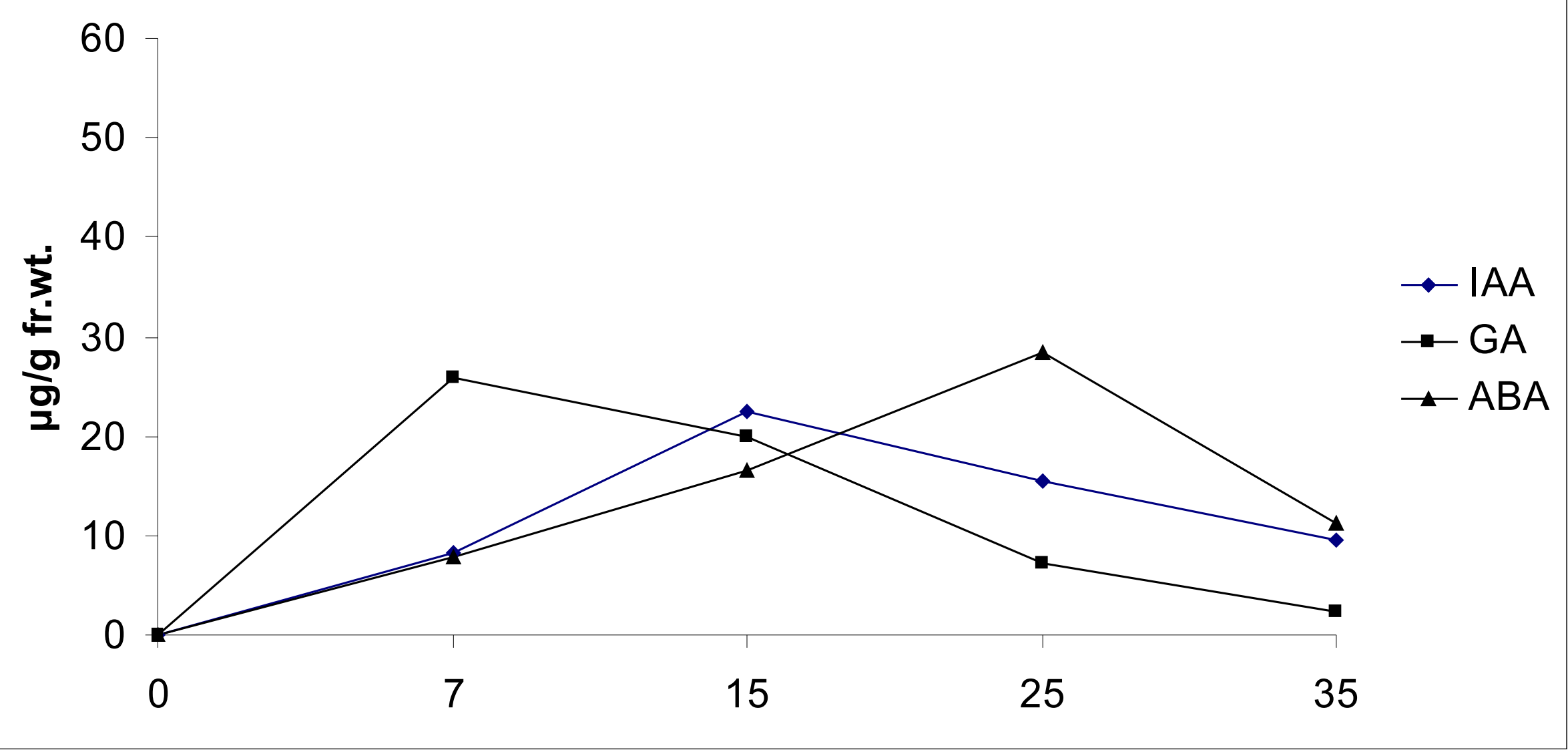


Fig. 9. Endogenous hormonal content in developi grains of tetraploid wheat $\mathrm{HI}-8498$

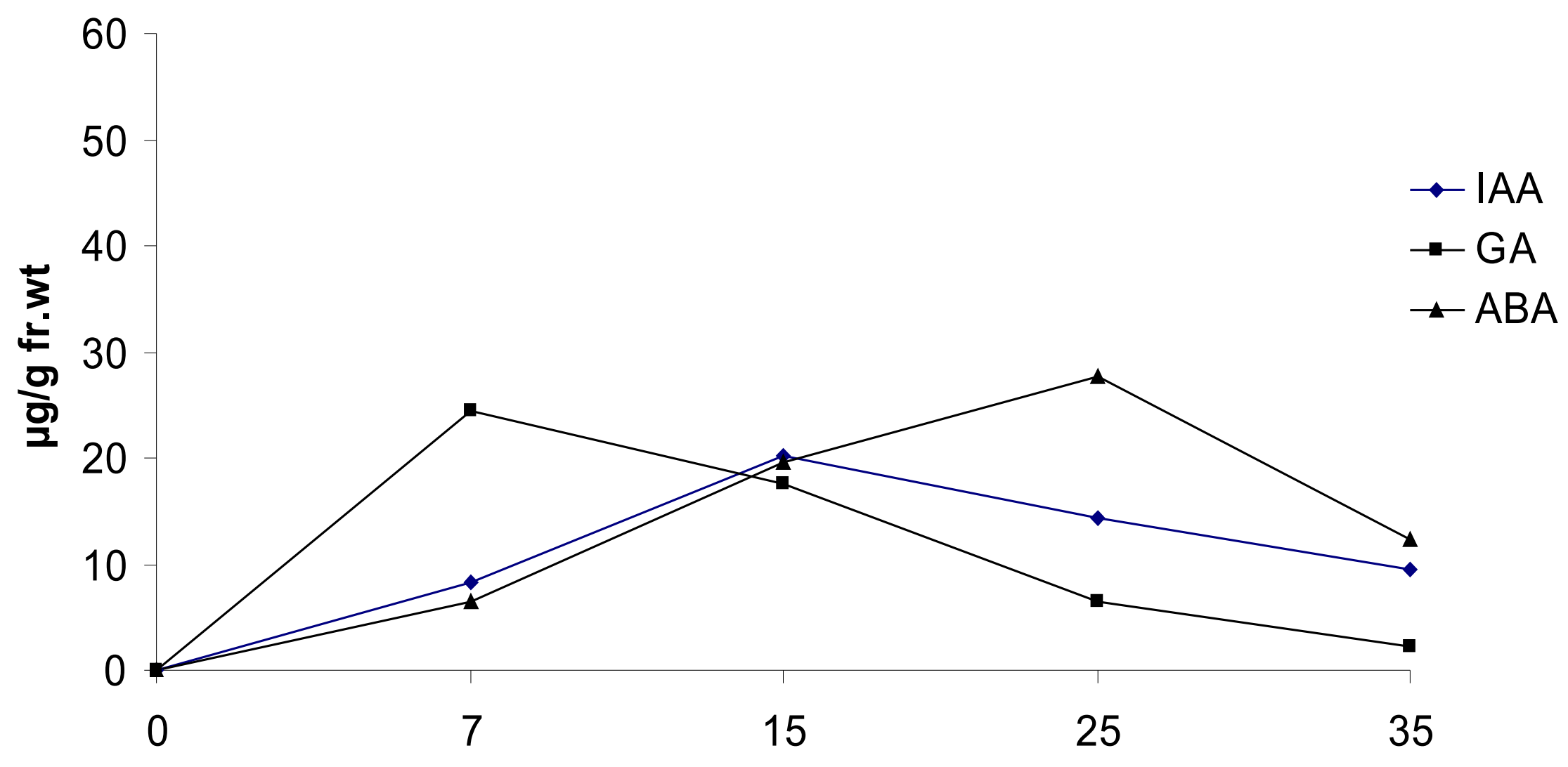


Fig. 10. Total sugar content in developing grains of wheat genotypes

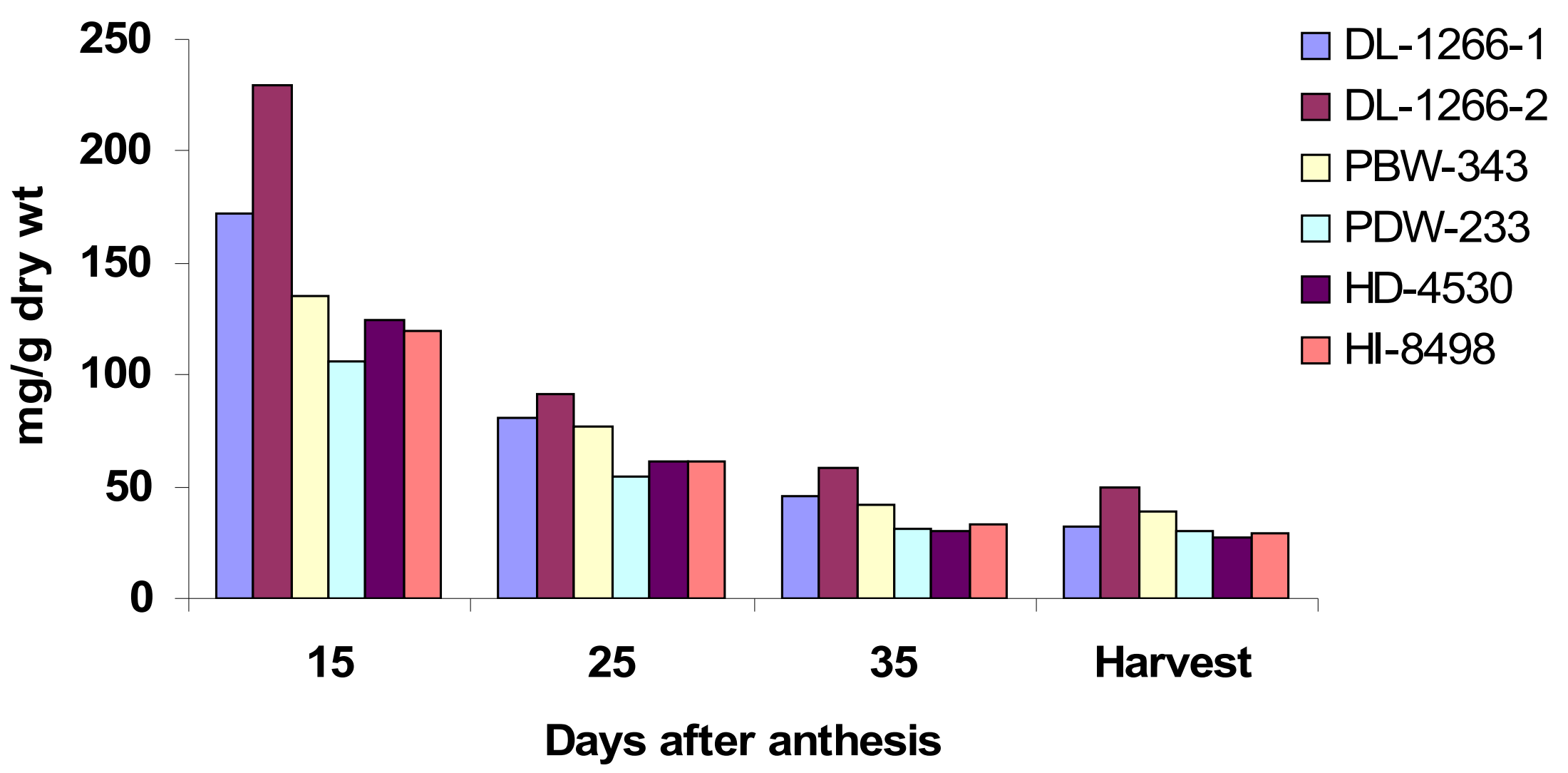




\section{Fig. 1. Yield performance of wheat genoty}

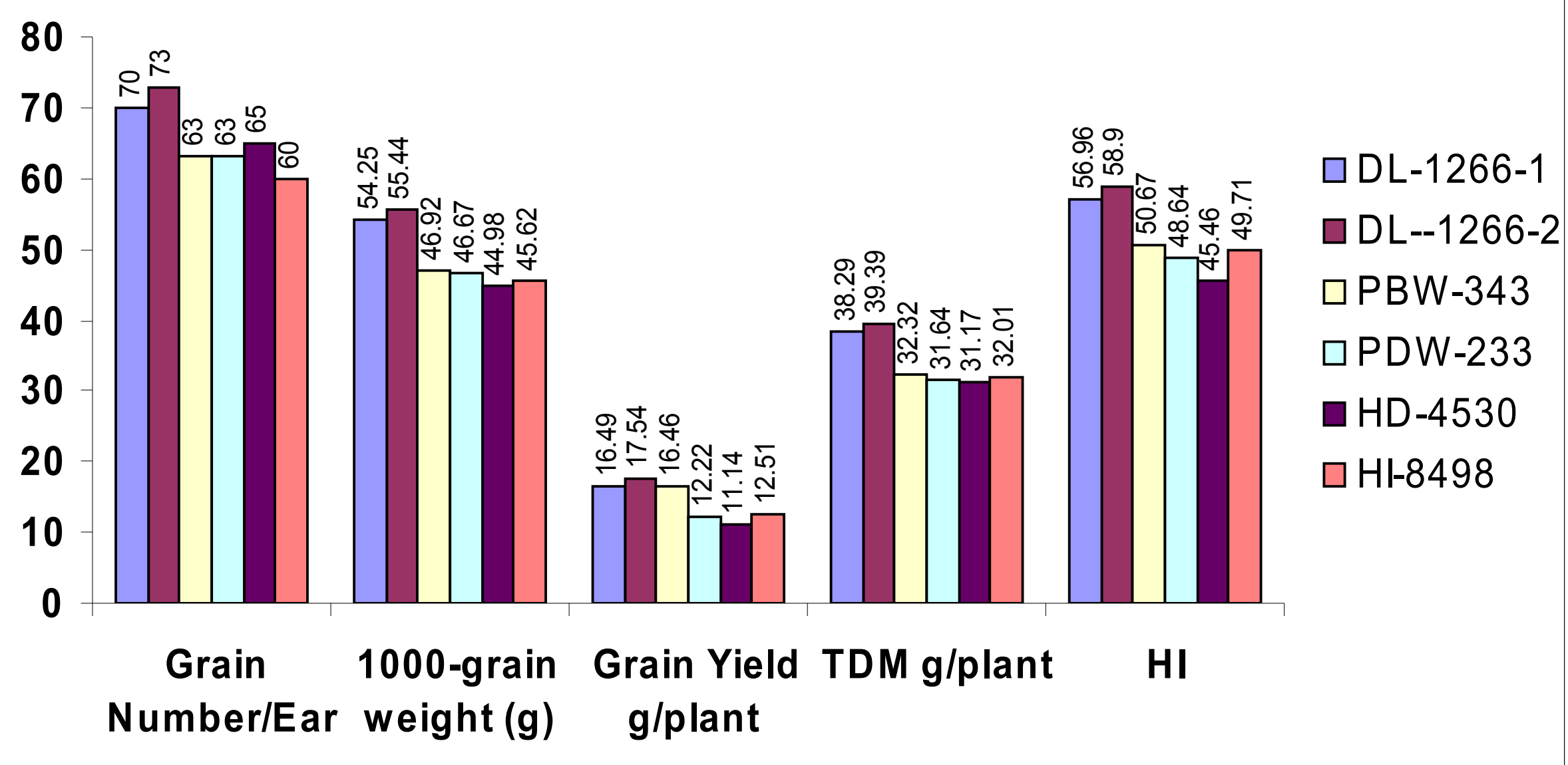


Fig. 11. Starch content in developing grains of whe genotypes

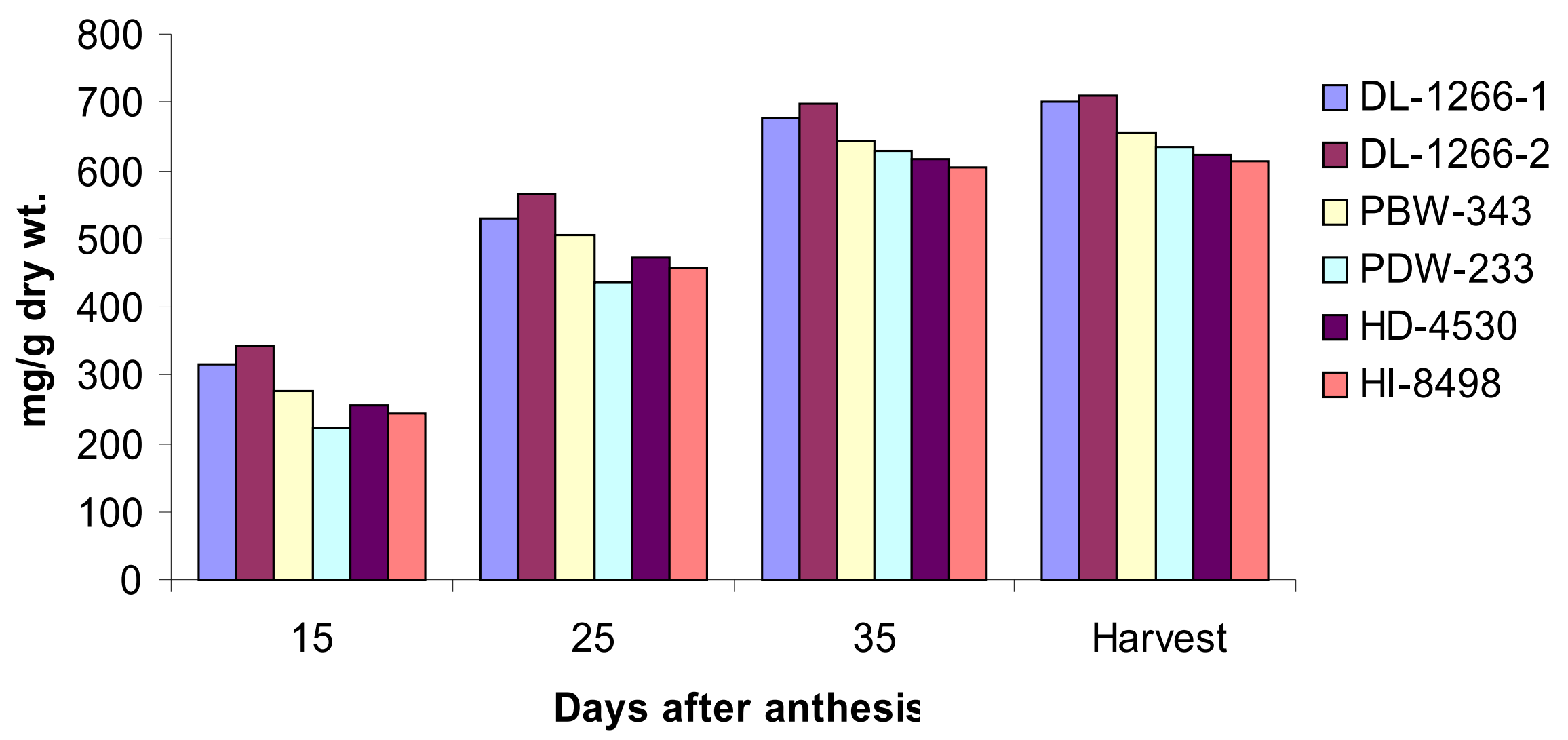


Table 34. Correlation coefficients between few selected characters among hexaploid and tetraploid wheats

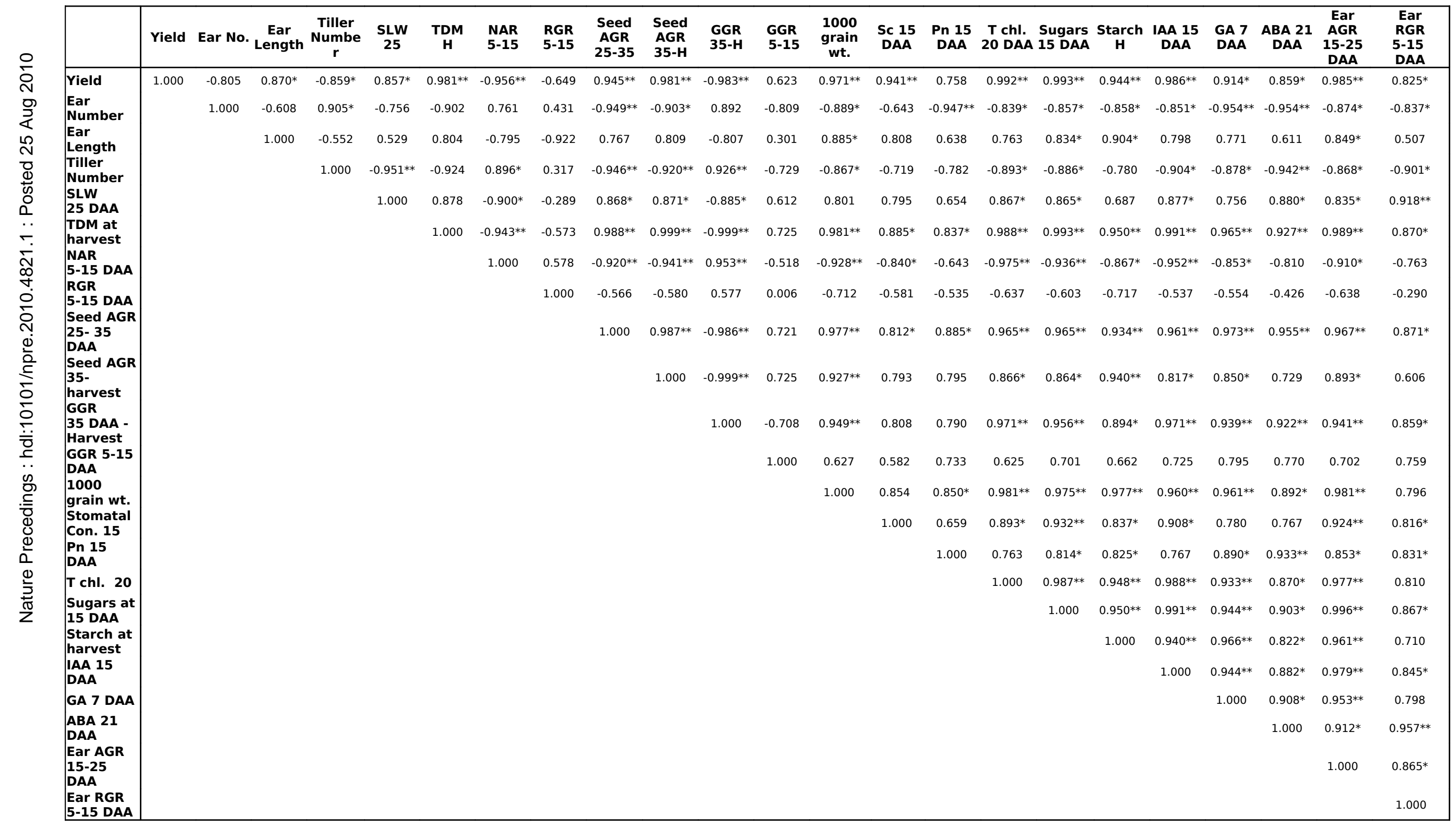




\section{DISCUSSION}

The present study was carried out to investigate the factors affecting grain growth of hexaploids and tetraploids and the relationship of endogenous growth hormones (IAA, $G A_{3} \& A B A$ ) to regulate translocation of assimilates during grain development.

\section{YIELD DETERMINING ATTRIBUTES}

In wheat, modern cultivars like DL-1266-1 \& DL-1266-2, and PBW-343 was compared with tetraploids (PDW-233, HD-4530 \& HI8498) (Plate 1 and 2). Grain size differed widely not only between the cultivars but also on the location of the mature ear. Grains formed in the middle spikelets are bolder than those located in apical and basal positions of the ear. Crop yield is the ultimate outcome of the whole life cycle and the differences in economic productivity are generally caused owing to variation in the photosynthesis (i.e., area, duration or efficiency) or the capacity of the sink (i.e., developing grains) to grow and the partitioning co-efficient of the photo assimilates into economically useful (grains) and un-useful components. Opinions differ in respect of their merits (Stoy, 1969; Thorne, 1971; Wardlaw, 1968; Neals and Incoll, 1968; Watson, 1971). 
Yield potential is an extremely complex character, a matter for recognition rather than delight. Some of the important parameters determining the yielding ability of wheat are summarized as follows:

\begin{tabular}{lll}
\hline SI. & \multicolumn{1}{c}{ Attributes } & Authority \\
No. & & \\
\hline 1 & Source-sink manipulation to influence & \\
& photosynthetic rate &
\end{tabular}

A. For Reduced demand from Atsmon et al. (1986), leaves: removal of ears/grains. Slafer and Andrade (1983), Slafer and

B. For enhanced demand from Savin (1994). leave: Ear photosynthesis King et al. (1976), inhibited/removal or shading of Atsmon et al. (1967), leaves.

Watson and Duffus (1988), Reynolds et al. (1994).

2. Some responses of photosynthetic rate to changed demand

A. Fall in CER with reduced Rawson et al. (1976), demand

Atsmon et al. (1986).

King et al. (1967).

B. Rise in CER with increased demand

3. Duration of the foliage at flowering Bingham (1969), cum maturity phase Sharma and Sandha (1993).

4. Production efficiency of the foliage Carr and Wardlaw 
(1965),

Bingham

5. Duration of grain growth

(1969),

Asana and Bagga

(1966), King et al.

(1967), Takahashi et

6. Rate of grain growth

al. (1993).

King et al. (1967),

Miralles et al. (1996).

7. Sink capacity

Evans et al. (1972),

Guo et al. (1994).

8. Grain number

Gales and Ayling

(1982), Lee et al.

(1987), Slafer and

Rawson

(1994),

Koshkin and Tararina

(1990), Kumari and

Ghildiyal (1997).

Rawson

(1971),

Lersson and Heneen

(1992).

10. 1000-grain weight

Voltas et al. (1992),

D’Egidio et al (1996),

Liu et al. (1996).

From the generalization given above it may be speculated that differences in seed yield which is a fraction of biological yield (i.e. total dry matter produced) depends not only on photosynthesis (surface area duration and efficiency) but also on the potentiality of 
the seed to accumulate organic assimilates as well. No one process provides the master key to greater yield potential and quite different process may limit the yield of different cultivars at one site and season, or of one cultivar at different site (Crosbie and Mock, 1981; Willman et al., 1987). Mnay more factors within a spikelet at different positions of the ear may also have effect on the seed yield. Some of the notable among them are:

1. Inter-gain competition (Yoshida, 1987; Ho, 1988; Bai et al. 1989; Farrar, 1993, Slafer and Rawson, 1994).

2. Vascular supply and flow of assimilates (Patrick and Wardlaw, 1984, Wardlaw, 1990; Komor et al., 1993; Wood et al., 1994).

3. Duration and rate of grain growth (Chang, 1982; Takahashi, 1993; Miralles et al. 1996).

4. Capacity of the grain to accumulate assimilates resulting from augmented sink strength through endogenously produced plant growth regulators within the developing grain (Warrier et al. 1987; Kondaiah, 1991; Rabie, 1996).

It still remains to be seen which of the above attributes have a greater relevance. The present study stepped up further in understanding the differences in grain size vis-à-vis the role played by endogenous IAA, $\mathrm{GA}_{3}$ and $\mathrm{ABA}$ along with sugar and starch accumulation. 
The 1000-gain weight is the important yield determinant parameter and it will give the idea of grain filling and size. Analysis of hexaploid and tetraploid wheat having different grain size showed that DL-1266-2 had higher 1000-grain weight $(55.44 \mathrm{~g})$ than the tetraploids which is ranging from 44 to $46 \mathrm{~g}$. The yield determining attributed like seed number/ear and grain number/plant showed that by virtue of possessing higher seed weight, hexaploids registered higher 1000-grain weight than tetraploids. Hexaploids registered more leaf area and total dry matter production as compared to tetraploids (Table 35).

In spite of higher seed number/plant to the tune of 3 per cent, tetraploids showed 32 percent reduction in seed yield/plant than hexaploids (DI-1266-2) and in the other attributes like grain number/ear and 1000-grain weight they showed reductions of 9 and 12 per cent respectively (Table 35). It indicates a complex phenomenon govern the yield in plants.

\section{YIELD AND YIELD COMPONENTS}

Yield is the ultimate manifestation of morphological, physiological, biochemical processes and growth parameters and is considered to result from trapping and the conversion of solar energy efficiently. Improvement in yield can be realised in two ways i.e., by 
adopting the existing varieties to grow better in their environment or by altering the relative proportion of different plant parts so as to increase the yield of economically important parts (Humphries and Bond, 1969).

In the present investigation, the hexaploids especially new plant types recorded higher grain yield when compared to tetraploids. Evans (1978) reported that the grain yield in wheat is determined by three components viz., number of ears per unit area, number of kernels per ear and weight of kernels. The data on yield and yield components showed that the tetraploids had higher ear number per plant but lesser number of seeds per ear and lower seed weight per ear. Whereas, the hexaploids particularly, new plant types had fewer tillers per plant but more number of seeds per ear by virtue of longer ear length and higher seed weight per ear. The most important yield component, 1000-grain weight was also more in hexaploids (Plate 1 and 2). The higher grain yield in new plant types was mainly due to the higher number of grains per ear and the heavier individual grain weight. The higher starch content (Fig. 11) in new plant types was also contributed towards to the higher grain yield. Increase in both the components might have helped in increased distribution of assimilates to the developing grains and less to the stem leading to higher grain yield. Spiertz and Van de Haar (1978) also reported that higher the yield components better will be grain yield and harvest index. 


\section{MORPHOLOGICAL CHARACTERS}

The available land for agriculture is decreasing day by day due to urbanization and also there is increase in the cost of production. Hence, it is necessary to improve yield per unit area to meet the challenges ahead in self-sufficiency of food requirements. In this direction, introspection of the genetic variation in various morphophysiological changes that have occurred in the developing high yielding varieties in future. Such studies can be used as powerful physiological indices both for screening the available genotypes for desirable traits and for directing the research efforts towards evolving plant ideotypes for various purposes.

The mean plant height was found to be higher in hexaploids over tetraploids in general, and among them DL-1266-1 and DL-12662 (new plant types) recorded higher plant height compared to any other genotype. Similarly, the ear length was also higher in these new plant types (Plate. 3 and 4). But, the tiller number/plant and ear number/plant were significantly higher in tetraploids. The new plant types bred for the higher ear length for maximisation of yield/plant characteristically possessed few tillers/plant and spikes/plant. From this, it is inferred that the modern hexaploids in the process of evolution and selection had reduced the infertile tillers and possessed longer ear heads having more grains/spike. This is supported by the 
correlation studies that between ear number/plant had significant positive correlation $(r=0.905)$ with tiller number/plant. While, there was significant negative correlation between tiller number/plant and yield/plant $(r=-0.859)$ and ear number/plant $(r=-805)$. A negative correlation though non-significant was also found between ear number/plant and ear length/plant.

The new plant types possessing higher plant height and longer ear heads recorded higher grain yield. In the present investigation, it seems that the higher plant height (Table 4 and stem weight (Table 10) offered minimum competition for the assimilate accumulation in the developing grains which ultimately resulted in higher grain yield. Bhat (1976) reported that a better allocation of assimilates to the grains in hexaploid wheat is a variable and heritable character. While, Syme (1972) and Fischer and Kertesz (1976) reported a close relationship of resource allocation to the grains with yield potential.

\section{PLANT GROWTH AND DEVELOPMENT}

Crop growth and yield are the manifestation of morphological, physiological, biochemical and growth parameters. Future strategies, for obtaining higher yields should lay emphasis on tapping the biological potential of the crop. For this, a better understanding of morpho-physiological traits that influence crop yields would provide the basis for exploiting genetic potentiality for realising higher yields. 
Growth and productivity of crop cultivars is achieved through a series of growth and developmental processes.

Significant differences were observed between the genotypes in total dry matter accumulation and its distribution between plant parts. The hexaploids in general accumulated higher biomass and the allocation of assimilates in the grains were also more, thus resulting in higher grain yield. A significant positive relationship $(r=0.981)$ was also found between the total dry matter at harvest and grain yield. Whan et al. (1996) also found a positive correlation between dry matter production and grain yield.

In the process of evolution and domestication of wheat, the hexaploids have been found to have lesser biological yield than the tetraploids (Bamakhramah et al., 1984). But, in the present investigation, the tetraploids on the contrary possessed lesser biological yield compared to hexaploids. Since, the present study comprised of new plant types of hexaploids which were specially bred to match the plant ideotypes developed by Donald (1968) possessing a single culm, strong stem, dwarf stature and large spike. This altogether resulted in higher biomass, due to heavier stem and thick broad leaves. If we take into account the hexaploids other than the new plant types mentioned earlier (DL-1266-1 and DL-1266-2), the others has lower total dry matter, which is in agreement with Bamakhramah et al. (1984). Dobben (1962) reported that the harvest 
index of cereal cultivars tend to rise progressively with little change in biological yield.

The growth, development and biomass production in plant largely depends in photosynthates produced by green leaves and the flag leaf blade is the principal source of photo-assimilates imported by the grains during grain filling (Rawson et al., 1976). The data on mean leaf area in the present study was found to increase from 5 to 25 DAA and declined later at 35 DAA. Interestingly, the new plant type DL1266-2 recorded the maximum leaf area at all the stages and yielded higher and the genotypes, HD-4530 and HI-8498 which had an early reduction in leaf area (at 25 DAA) yielded less. This clearly demonstrates the significance of leaf area duration in yield determination in wheat. Our results are in accordance with the earlier reports of Duncan et al. (1981), Rosenow et al. (1983) Ludlow and Muchow (1990) and Ashraf et al. (1992).

The leaf area ratio (LAR) indicates the size of the assimilatory surface area in relation to the total dry matter. Simane et al. (1993) reported that it is determined partly by biomass allocation (LWR) and partly by leaf morphology (SLA). The data on LAR showed that the tetraploids had higher LAR at 5 and 15 DAA, whereas at 25 and 35 DAA, hexaploids showed higher LAR but the mean LAR of the genotypes showed a steady decline from 5 to 35 DAA. This decline in LAR at later stages could be due to decrease in leaf area due to senescence and translocation of all assimilates to the growing sink. 
Van den Boogaard, (1996), also reported a decline in LAR at later stages. The higher LAR at initial stages could be due to higher leaf area and growth rates.

The mean specific leaf area (SLA) declined from 5 to 25 DAA and increased further at 35 DAA. Among the genotypes, hexaploids recorded higher SLA at 5 and 35 DAA; while, the tetraploids recorded higher SLA at 15 and 25 DAA. It is known that there is inverse relationship between SLA and SLW and decrease in SLA at 15 and 25 DAA could be due to higher specific leaf weight (SLW). The specific leaf weight, which indicates leaf thickness, was found to be higher in hexaploids and it was maximum at 15 and 25 DAA. The increase in SLW could be due to stacking of mesophyll cells and increased photosynthetic activity leading to higher accumulation of photosynthates (Konings, 1989; Poorter, 1989). For meeting the requirements of assimilates, either the SLA has to be more or SLW. In the present study, there is a decline in SLA and this decrease is more than compensated by an increase of SLW and it has supported the demand of assimilates at grain filling stage. Further, correlation study indicated a positive relationship between SLW and grain yield. Pramod Kumar et al. (1998) and Subrahmanyam and Dutta (2000) also found a positive relationship of SLW with grain yield, as have been observed in the present investigation. 
The relative growth rate (RGR) represents the increase in dry matter per unit dry matter already present per unit time and it was found to be maximum in tetraploids at 5 - 15 DAA in the present study. The plants with higher RGR have opportunity to acquire a larger share of limiting resources like moisture than slow growing ones (Poorter, 1989). The RGR of genotypes in the present investigation decreased from 5-15 DAA to 25-35 DAA. Simane et al. (1993) also reported similar results. This may be due to the decline of leaf area/unit plant (Spitters and Kramer, 1986). Interestingly, the genotypes with higher LAR recorded higher RGR, which is in agreement with the reports of Van den Boogaard et al. (1996). Simane et al (1993) also reported a positive significant correlation between RGR and LAR. As the components of RGR are NAR, LAR, LWR and SLA, any variation in these parameters will bring changes in RGR.

The net assimilation rate (NAR) in the present study decreased with advancement in growth in all the genotypes from 5 - 15 DAA to 25 - 35 DAA and the higher rates of NAR were recorded by tetraploids. In contrast to the earlier report by Pramod Kumar et al. (1998), showed a positive association between NAR and grain yield, negative correlation was found in the present study between NAR at 5 - 15 DAA and yield. 
Analysis of ear growth and development of the genotypes in study revealed that the mean absolute growth rate of ear had increased from 5-15 DAA to 25-35 DAA. When compared among the genotypes, the hexaploids had higher AGR of ear at the early stages i.e., at 5 DAA and at 15 DAA and maintained at a higher rate till the harvest stage. The hexaploids especially, new plant types recorded higher AGR of ear. This increase in rate is both due to the increase in seed weight (Table 14, Fig. 2 and Fig. 3) and the chaff (Table 17). When the growth of ear heads is analysed in terms of relative growth rate, the RGR of ear was also higher for hexaploids at 5 - 15 DAA and thereafter, it declined in both the hexaploids and tetraploids until 35 DAA - harvest. The mean RGR had decreased from 5 - 15 DAA to 35 DAA - harvest. At rapid growth of grain growth phase (7 to 14 DAA), the AGR of ear in hexaploids recorded slightly higher than tetraploids. This might be because of the substantial increase in seed weight of hexaploids than the tetraploids at the end of rapid growth phase (Fig. $1 \& 2$ ). But, the higher AGR of ear found at 25-35 DAA in tetraploids infers that they are slow at grain filling initially and at this stage, the ear might have filled up all its spikelets. Looking at the RGR of ear values, which were higher in hexaploids than tetraploids, it can be said that they were faster than the tetraploids in ear growth and also they were with relatively higher growth of seed. The correlation study between the AGR of ear and RGR of ear and with yield shows significant positive relationship with yield. The relationship between RGR of ear and AGR of ear was also positive and significant. 
The absolute grain growth rate of hexaploids and tetraploids were found to be at higher rate at all the. With the increment in time, the hexaploids especially the new plant types continued to increase at faster rate than the tetraploids. The mean grain growth rate of seed in the genotypes was found to be higher initially and then declined with the increase of time. Though the hexaploids (especially new plant types) had initially higher relative grain growth rate, they were slightly similar as that of tetraploids at 25-35 DAA and 35 DAAharvest. This infers that the hexaploids with higher rates of grain filling (RGR of ear) could be able to fill all the spikelets in the ear head and increase the grain weight. The hexaploids with higher grain filling rates initially and at rapid growth stage (15 DAA) might have filled up all the spikelets and also increased the seed weights. The new plant types had higher rate of GA content at initial stages of grain growth and also IAA at the end of (Fig. $3 \& 4$ ). This might have caused the new plant types to increase in the cell size and cell division at the initial stages by GA and at later stages, IAA might have exerted pressure in the translocation of assimilates. The ABA content was increased at the end soft dough stage (14 to 21 DAA) this might have also helped in the translocation of assimilates to the sink which was high at capacity due to endogenous hormonal activity (Seth and Waering, 1967; Singh and Gerung, 1982). 
Sayed and Gadallah (1983) reported that grain yield in wheat was more closely related to the rate than the duration of grain filling. The correlations between yield and AGR of seed with yield and RGR of seed and yield were significantly and strongly positive. Gebeyehoue et al. (1982) found that both rate and duration of grain filling were positively associated with final grain weight. In the present investigation, the hexaploids with higher rates of ear growth had increased the chaff weight as well as seed weight and the tetraploids had increased only the seed weight more than chaff weight. Though the chaff weight (Table 17) was found to be higher in hexaploids, it had relatively lesser percent contribution towards the ear weight had resulted in higher yields in hexaploid new plant types. Darroch and Baker (1990) have reported significant genotypic differences in rate and duration of grain filling in spring wheat.

\section{HORMONAL REGULATION OF SEED DEVELOPMENT}

Results showed that the endogenous hormonal contents in grains during grain development changed in sequence. At 7 DAA, gibberellic acid (GA) content was maximum and at 15 DAA (rapid growth phase), indole-acetic acid (IAA) reached the maximum; while at 21 DAA (dough stage), the $A B A$ was maximum. Further, $A B A$ reached all time high, GA the least, IAA being intermediate at 30 DAA. Among the genotypes, hexaploids (Fig. 4, 5, and 6) recorded higher 
concentrations of endogenous hormones compared to tetraploids (Fig. 6, 7, and 8).

Increase in GA content at early embryonic stage where a rapid enlargement of embryo (Qin and Tang, 1984) takes place implies that GA had signaled the translocation of metabolites to the active sink such as the developing grain (Monula et al., 1980). The characteristic decrease in GA content at 21 DAA can be explained by the hypothesis put forth by Krishnamoorthy (1981) that at that stage, conjugation might have taken place and it existed in the storage from in the matured grain to be used during germination. IAA content of the developing grains increased as the grains entered into the rapid grain growth phase (7 - 14 DAA). Bangerth et al. (1985), Lur and Setter (1993) and Yang et al. (2001) also found similar results.

The increase in auxin concentration stimulates cell division which in turn enhances the translocation of photosynthates towards developing sinks (Seth and Waering, 1967; Singh and Gerung, 1982). Abscisic acid content in the grain was found to be low at the early grain filling stage is in accordance with Yang et al. (2001) but at 25 DAA (dough stage); it reached the highest level. Apart from synthesis of $A B A$ by the inner layers of the pericarp containing chloroplasts (Radely, 1976), the hormone might have been translocated from other parts of the plant and resulted in higher concentration. The higher $A B A$ concentration found in new plant types might have 
enhanced the import of assimilates and it resulted in the higher grain filling and ultimately, higher grain yield. Similar results were reported by Dewdney and Mc Wha (1979); Patrick (1983) and Schussler et al. (1984). There are also reports by earlier workers that the ABA is elevated in the grains during maturation for induction of dormancy. The higher levels of ABA (hard dough stage), minimal level of GA and intermediate levels of IAA at 30 DAA suggests that at this stage, maintenance of embryo dormancy appears to be an active process involving ABA (Morris et al., 1991).

\section{BIOPHYSICAL AND BIOCHEMICAL CHARACTERS}

The stomatal conductance increased after 7 DAA and reached maximum at 15 DAA and then declined thereafter until 35 DAA. Maximum stomatal conductance was found in hexaploids, especially the new plant types at 15 DAA. Sudden increase in stomatal conductance at this stage could be due to higher demand of photosynthates for grain filling. Whenever, there is increased demand, it has to be met by increasing the rate of $\mathrm{CO}_{2}$ exchange and other mechanisms. Earlier reports of Rawson and Evans (1970) and Evans and Rawson (1971) support the present findings. They observed a decline in the net $\mathrm{CO}_{2}$ exchange rate of flag leaf just after anthesis which increased during rapid grain filling stage indicating the demand by the developing ear. The present findings are in accordance with the Frederick and Camberato (1995) also who 
reported that there was an increase in leaf net $\mathrm{CO}_{2}$ exchange rate (CER) at anthesis and decrease rapidly during the grain filling stage. Correlation study indicated that stomatal conductance is having a positive and highly significant association with grain yield and AGR of seeds and ear. Pramod Kumar et al. (1998) also reported a similar correlation between yield and stomatal conductance.

The data on photosynthetic rate indicated higher values in hexaploids over tetraploids. Such variability among the genotypes could be attributed to differences, in structural and anatomical differences in mesophyll and carboxylation resistance between the species. Similarly, Sharma-Natu and Ghildiyal (1993) also reported species differences in phototsynthetic rate. The photosynthetic rate was more at 7 and 15 DAA compared to 25 and 35 DAA. Since there was higher demand for photosynthates at grain filling periods which coincided with 7 and 15 DAA and hence the photosynthetic rate was more at these stages. A strong dependence of flag leaf photosynthesis in wheat on the requirement for assimilates by the developing grains has been reported earlier by Birecka and Dakic Wlodkowska (1963) and King et al. (1967). In the present investigation, a significant positive correlation between photosynthetic rate and AGR of seed $(r=0.885)$ was observed which is in accordance with the earlier reports. The higher photosynthetic rate in DL-1266-2 can be attributed mainly to higher SLW and stomatal conductance. Subrahmanyam and Dutta (2000) reported a positive association between SLW, stomatal conductance and photosynthetic 
rate. The results of the present investigation also showed a significant positive relationship with stomatal conductance $(r=0.885)$ and photosynthetic rate $(r=0.837)$ with total dry matter. The flag leaf has for a long time been regarded as the most important source of assimilate supply to the ears in wheat (Trorne, 1965; Evans and Dustaone, 1970).

The total chlorophyll content in flag leaves of hexaploids was higher than in tetraploids. The mean total chlorophyll content increased slightly at 20 DAA when compared to 10 DAA and it decreased at 30 DAA. This shows that there was more chlorophyll content at rapid grain growth stage, during which there is a great demand for photosynthates and this might help the plant to fix more co2 and meet the increasing demand for photosynthates. Wright and Smith (1983), Ashraf and Khan (1990), Sinha and Patil (1986) and Estill et al. (1991) reported a wide variation in chlorophyll contents within species. In the present investigation also the genotypes differed significantly in chlorophyll content.

\section{SUGARS AND STARCH DURING GRAIN FILLING}

Results revealed significant differences in the total sugar content of seeds among the genotypes which gradually decreased from 15 DAA until harvest (Fig. 10). Among the genotypes, hexaploids showed higher sugar content than tetraploids at all the 
stages. Kumar and Singh (1981), Singhal et al. (1989) and Sekhon and Singh (1994) found similar results. Mi et al (2002) reported that the soluble sugar content of the grains were greater at anthesis and then decreased during grain filling. The data in the present investigation showed that the genotypes possessed higher sugar content at 14 DAA and then decreased thereafter. Kumar and Singh (1981) also reported similar results.

The starch content of seeds increased from 15 DAA (where sugar content was found to be decreasing) till harvest in all the genotypes (Fig. 11). Among the genotypes, hexaploids (new plant types) had significantly higher starch content compared to tetraploids. The slow starch synthesis in the grains of tetraploids might be one of the reasons for slow grain filling. The tetraploids should have had more endogenous cells, hence cell division might have taken longer time than in hexaploids and starch accumulation might have been delayed (Mi et al. 2002). A delayed starch synthesis resulted in weak sink strength at early stages (Jenner et al., 1991) and might have induced a negative feed back on carbohydrate remobilisation from stem and leaf sheath to the grains (Wardlaw, 1990). An almost equal weight of stems of hexaploids and tetraploids found in the present investigation is in support of this hypothesis. The heavier stems of hexaploids would have benefited the genotypes in resisting lodging at grain filling stage when large spike grown heavier (Austin, 1980). 
The new plant types with a high photosynthetic rate, higher chlorophyll content had high rate of grain filling as seen from Table 12. It has been reported that during grain filling which is a process of starch accumulation, 33 major enzymes are involved in carbohydrate metabolism in developing endosperm (Nakmura et al., 1992). The predominant pathway for starch biosynthesis in plant is composed of three reaction catalysts viz., AGPase, Stsase and BE enzyme (Nakamura et al., 1989; Presis et al., 1991; Okita, 1992; Martin and Smith, 1995). Activates of these three enzymes are closely associated with an increase in starch content during the development of rice endosperm (Nakamura and Yuki, 1992). The new plant types might have had maximum activity of these three enzymes and this may be the probable reason for higher starch synthesis that resulted in higher grain yield. 


\section{SUMMARY AND CONCLUSION}

The present investigation on the role of endogenous hormonal levels during grain development in various genotypes involving hexaploids and tetraploids, with the main objective of determining the grain growth rate and its correlation with the endogenous hormonal levels is summarised as follows.

The mean plant height was found to be higher in hexaploids over tetraploids in general, and among them DL-1266-1 and DL-12662 (new plant types) recorded higher plant height.

Similarly, the ear length was also higher in these new plant types. But, the tiller number/plant and ear number/plant were significantly higher in tetraploids.

The hexaploids in general accumulated higher biomass and the allocation of assimilates in the grains were also more, thus resulting in higher grain yield. A significant positive relationship $(r=0.981)$ was also found between the total dry matter at harvest and grain yield.

The data on mean leaf area was found to increase from 5 to 25 DAA and declined later at 35 DAA. Interestingly, the new plant type DL-1266-2 recorded the maximum leaf area at all the stages and 
yielded higher and the genotypes, HD-4530 and HI-8498 which had a early reduction in leaf area (at 25 DAA) yielded less.

The tetraploids had higher LAR at 5 and 15 DAA, whereas at 25 and 35 DAA, hexaploids showed higher LAR but the mean LAR of the genotypes showed a steady decline from 5 to 35 DAA.

The mean specific leaf area (SLA) declined from 5 to 25 DAA and increased further at 35 DAA. Among the genotypes, hexaploids recorded higher SLA at 5 and 35 DAA; while, the tetraploids recorded higher SLA at 15 and 25 DAA.

The RGR of genotypes in the present investigation decreased from 5 - 15 DAA to 35 DAA - harvest. Interestingly, the genotypes with higher LAR recorded higher RGR,

The net assimilation rate (NAR) in the present study decreased with advancement in growth in all the genotypes from 5 - 15 DAA to 25 - 35 DAA and the higher rates of NAR were recorded by tetraploids.

Analysis of ear growth and development of the genotypes in study revealed that the mean absolute growth rate of ear had decreased from 5 DAA to 35 DAA. When compared among the genotypes, the tetraploids had higher AGR of ear at the early stages i.e., at 5 DAA. And at 15 DAA, the hexaploids especially, new plant types recorded higher AGR of ear.

The data on yield and yield components show that the tetraploids had higher ear number per plant but lesser number of 
seeds per ear and lower seed weight per ear. The most important yield component 1000-grain yield was also possessed by hexaploids.

The hexaploids (new plant types) possessed maximum grain growth rate at 5 - 15 DAA. DL-1266-2 recorded highest grain growth rate $0.093 \mathrm{~g} / \mathrm{g} / \mathrm{day}$.

The results showed that the endogenous hormonal contents in grains during grain development had changed in sequence. At 7 DAA, gibberellic acid (GA) content was at maximum and at 15 DAA (rapid growth phase), indole-acetic acid (IAA) reached maximum and at 25 DAA (dough stage), ABA was at the maximum. At the 35 DAA, ABA reached all time high and GA the least, IAA being intermediate. Among the genotypes, hexaploids recorded higher concentrations of endogenous hormones.

The maximum values for stomatal conductance were found in the hexaploids especially the new plant types at 15 DAA. A positive and highly significant correlation between stomatal conductance and yield and a positive and significant correlation between stomatal conductance and AGR of seed and ear was found.

The photosynthetic rate values show that the hexaploids possessed higher rate than tetraploids. At 7 and 15 DAA, in general, photosynthetic rate was more when compared to 25 DAA and 35 DAA.

The total chlorophyll content in flag leaves of hexaploids was higher than tetraploids. The mean total chlorophyll had increased slightly at 20 DAA when compared to 10 DAA and it decreased at 30 DAA. 
Among the genotypes, hexaploids showed higher sugar content than tetraploids at all the stages of comparison. The data in the present investigation showed that the genotypes possessed higher sugar content at 14 DAA and then decreased afterwards.

The starch content of seeds in all the genotypes increased from 15 DAA (where sugar content was found to be decreasing) till harvest. The new plant types with a high photosynthetic rate, high chlorophyll content and delayed leaf senescence (higher LAD) had high rate of grain filling.

In conclusion the present study showed that,

- The new plant types bred for the higher ear length for maximisation of yield/plant characteristically possessed few tillers/plant and spikes/plant. Modern hexaploids in the process of evolution and selection had reduced the infertile tillers and possessed longer ear heads having more grains/spike.

- In the present investigation, it seems that the higher plant height and stem weight offered minimum competition for the assimilate accumulation in the developing grains which ultimately resulted in higher grain yield in new plant types. The hexaploids in general accumulated higher biomass and the allocation of assimilates in the grains were also more, thus resulting in higher grain yield.

- The higher LAD might have given rise to a higher photosynthetic rate/capacity of the canopy during grain filling which made the new plant types with higher LAD yielded higher. 
- Hexaploids though declined, still maintained higher LAl over tetraploids. This could be one of the possible reasons for yield differences between hexaploids and tetraploids. The decrease in LAI after 25 DAA coincided with the end of rapid grain filling state

- $\quad$ This decline in LAR at later stages could be due to decrease in leaf area due to senescence and translocation of all assimilates to the growing sink.

- It is known that there is inverse relationship between SLA and SLW and decrease in SLA at 15 and 25 DAA could be due to higher specific leaf weight (SLW).

- A slight increase in CGR values at 35 DAA - harvest, could be attributed to the increase in ear dry weight.

- The increase in GA content at the early embryony stage where a rapid enlargement of embryo takes place implies that GA had signaled the translocation of metabolites to the active sink such as the developing grain.

- The increase in auxin concentration might have stimulated cell division and this could have created an attraction for the translocation of photosynthates.

- The higher $A B A$ concentration in the new plant types might have enhanced the import of assimilates. and it resulted in the higher grain filling and ultimately, higher grain yield.

- The maximum values for stomatal conductance were found in the hexaploids especially the new plant types at 15 DAA. At this stage, 
the sudden increase in the values of stomatal conductance in the genotypes might be due to the higher demand of ear during grain filling for the photosynthesis - $\mathrm{CO}_{2}$ exchange.

- The mean total chlorophyll had increased slightly at 20 DAA when compared to 10 DAA and it decreased at 30 DAA. This shows that at the rapid grain growth stage, chlorophyll content was more where it was highly in demand for photosynthesis. 
Ahmadi, A., Baker, D.A. (1999). Effects of abscisic acid (ABA) on grain filling processes in wheat. Plant Growth Regulation, 28(3): 187-197.

Anonymous. (2002). The Hindu Survey of Indian Agriculture, Kasturi and Sons, Ltd. Publishers, Chennai, India.

Anonymous. (2004). The Hindu Survey of Indian Agriculture, Kasturi and Sons, Ltd. Publishers, Chennai, India.

Apel, P. and Lehmann, C.O. (1970). Studies on the relations between the size of the flag leaf and the yield of the ear in wheat and barley. Kulturpflanze, 18: 99-105.

Apel, P. and Tschape, M. (1973). Ear respiration during the grain filling stage in wheat (Triticum aestivum L.). Biochemie und Physiologie der Pflanzen, 164(3): 266-275.

Apel, P., M. Tschape, I. Schalldach and Aurich, O. (1973). Die Bedeutung der Karyopson fur die Photosynthese and Trockensubstanzpro duktion bei weizen. Photosynthetica., 7: 132-139.

Asana, R.D. and Bagga, A.K. (1996). Studies in physiological analysis of yield. Comparison of development of upper and basal grains of spikelets of two wheat varieties. Indian Journal of Plant Physiology, 7: 86-101 
Ashraf, M.Y. and Khan, A.H. (1990). Effect of drought on wheat varieties during vegetative stage. Scintia International, 2:325-327.

Ashraf, M.Y., khan, A.H and Naqvi, S.S.M. (1995). Relationship of chlorophyll content and leaf area with grain yield in wheat genotypes. Indian journal of Plant Phsyiology, 38(2): 162163.

Ashraf, M.Y., Khan, A.H. and Azmi, A.R. (1992). Cell membrane stability and its elation with some physiological process in wheat. Acta Agronomica Hungarica, 41:183-191.

Asthir, B., Kaur, A. and Basra, A.S. (1998). Do phytohormones influence the uptake and metabolism of sucrose in spikelets of wheat? Phyton Horn. 38(2): 293-299.

Atsmon, D., Bush, M.G. and Evans, L.T. (1986). Effects of environmental conditions on expression of the 'Gigas' characters in wheat. Australian Journal of Plant Physiology, 13: $356-376$.

Aufhammer, W. and Bangerth, F. (1982). Growth regulator effects on ear and grain development in wheat. In: McLaren, J.S. (ed.), "Chemical Manipulation of Crop Growth and Development", pp. 359-373.

Austin, R.B. and Edrich, J. (1975). Effect of ear removal on photosynthesis, carbohydrate accumulation and on the 
distribution of assimilated ${ }^{14} \mathrm{C}$ in wheat. Annals of Botany, 39: 141-152.

Austin, R.B., Bingham, J., Blackwell, R.D., Evans, L.T., Ford, M.., Morgan, C.L. and Taylor, M. (1980). Genetic improvements in winter wheat yields since 1900 and associated physiological changes. Journal of Agricultural Science, 94: 675-698.

Austin, R.B., Ford, M.A., Miller, T.E. and Parry, M.A.J. (1987). Progress in Photorespiration. Marinius Nrijhoff Publishers, Dordrecht, Netherlands. 4: 361-368.

Bai., X.F., Cai, Y.P. and Nie, F. (1989). Relationship between abscisic acid and grain filling of rice and wheat. Plant Physiology Communications, 3:40-41.

Bamakhramah, H.S., Halloran, G.M. and Wilson, J.H. (1984). Components of yield in diploid, tetraploid and hexaploid wheats (Triticum spp.) Annals of Botany., 54(1): 51-60.

Bangerth, F., Aufhammer, W. and Baum, O. (1985). IAA level and dry matter accumulation at different positions within a wheat ear. Physiologia Plantarum, 63(1): 121-125.

Banziger, M., Feil, B. and Stamp, P. (1994). Competition between nitrogen accumulation and grain growth for carbohydrates during grain filling of wheat. Crop Science, 34: 440-446.

Bhardwaj, S.N. and Verma, V. (1985). Hormonal regulation of assimilate translocation during grain growth in wheat. Indian Journal of Experimental Botany, 23(12): 719-721. 
Bhardwaj, S.N. and Verma, V. (1987). Regulation of grain size within a developing ear of bread-wheat. Indian Journal of Agricultural sciences, 57(10): 710-715

Bhatt, G.M. (1976). Variation of harvest index in several wheat crosses. Euphytica, 25: 41-50.

Bingham, J. (1969). The physiological determination of grain yield in cereals. Agricultural Production, 44: 30-32.

Birecka, H and Dakic-Wlodkowska, L. (1963). Photosynthesis, translocation and accumulation of assimilates in cereals during grain development. III Spring wheat-photosynthesis and daily accumulation of photosynthates in the grain. Acta. Soc. Bot. Pol., 32: 631-650.

Biryukov, S. and Komarova, V. (1986). Attraction of exogenous sucrose by the ears in different genotypes of winter wheat. In: Sechnyak-L (ed.) “Voprosy-selektsii-i-genetiki-zernovykhkul'tur", 1983, rec'd, 169-180.

Blackman, V.H., (1919). The compound interest law and plant growth. Annals of Botany, 33: 353-360.

Blum, A., Sinmena, B., Mayer, J., Golan, G. and Sholier, L. (1994). Stem reserve mobilization supports wheat-grain filling under heat stress. Australian Journal of Plant Physiology, 21: 771781.

Borkovec, V., Prochazka, S. and Ibrahim, M.E.D., (1990). Transport of ${ }^{14} \mathrm{C}$-sucrose and ${ }^{14} \mathrm{C}$-bezyl adenine in winter wheat (Triticum 
aestivum L.) in the pre-anthesis period. Journal of Agronomy and Crop Science, 165(4): 217-223.

Brocklehurst, P.A. (1977). Factors controlling grain weight in wheat. Nature, 266: 348-349.

Cai, Q.S. (1991). Study of the growth curve and developmental stages of wheat seed. Jiangsu Agricultural Sciences, 2: 14-16.

Caley, C.Y., Duffus, C.M. and Jeffcoat, B. (1990). Photosynthesis in the pericarp of developing wheat grains. Journal of Experimental Botany, 41(224): 303-307.

Chanda S.V., Narmada, K. and Singh, Y.D. (1999). Dry matter accumulation and associated changes in biochemical parameters during wheat grain development. Journal of Agronomy and Crop Science, 182(3): 153-159.

Chang (1982). Study of grain filling in wheat. Acta Agronomica Sinica, 8: 87-93.

Chowdhury, S.I. and Wardlaw, I.F., (1978). The effect of temperature on kernel development in cereals. Australian Journal of Agricultural Research, 29(2): 205-223.

Colowick, S.P. and Kaplan, N.D. (1957). Methods in enzymology 3: 3040 Academic Press, New York.

Crossbie, T.M. and Mock, J.J. (1981). Changes in physiological traits associated with grain yield improvement in three maize breeding programmes. Crop Science, 65: 612-615. 
Cruz Aguado, J.A., Rodes, R., Perez, I.P., and Dorado, M. (2000). Morphological characteristics and yield components associated with accumulation and loss of dry mass in the internodes of wheat. Field Crops Research, 66(2): 129-139.

D'egidio, M.G., Checchini, C., Pagani, M.A., Lucisano, M. (1996). Technica Molltroria, 47(7): 541-655.

Darroch, B. A. and Baker, R. J. (1990). Grain filling in three spring wheat genotypes: statistical analysis. Crop Science, 30: 525529.

Davies, P.J. (1987). The plant hormones: Their nature, occurrence and functions. In: Davies, P.J. (ed.) “Plant Hormones and their Role in Plant Growth and Development". Martinus Nijhoff Publishers, Dordretch, the Netherlands, pp 1-11

Daynard, T. B., and Kannenberg, L.W. (1976). Relationships between length of the actual and effective grain filling periods and grain yield of corn. Canadian Journal of Plant Science, 56: 237-242.

Dewdney, S.J. and Mc Wha, J.A. (1979). Abscisic acid and the movement of photosynthetic assimilates towards developing wheat (Triticum aestivum L.) grains. Zeitschrift fur Acker und Pflanzenphysiol, 92: 183-186.

Dietrich, J.T., Kaminek, M., Blevins, D.G., Reinbott, T.M. and Morris, R.O. (1995). Changes in cytokinins and cytokinin oxidase activity in developing maize kernels and the effects of 
exogenous cytokinin on kernel development. Plant Physiology and Biochemistry (Paris), 33(3): 327-336.

Dobben, V. (1962). Influence of temperature and light conditions on dry matter distribution, development rate and yield in arable crops. Netherlands Journal of Agricultural Sciences, 10: 377389.

Donald, C.M. (1968). The breeding of crop ideotypes. Euphytica, 17:385-403.

Dong, S.T. (1991). Studies on the relationship between canopy apparent photosynthesis and grain yield in high-yielding winter wheat. Acta Agronomica Sinica, 17(6): 461-469.

Duan L.S., He, Z.P. and Han, B.W. (2000). Features of assimilate export from the flag leaf and partitioning during wheat grain development. Journal of China Agricultural University, 5(1): 69-74.

Duan, J., Tian, C.E., Liang, C.Y., Huang, Y.W. and Liu, H.X. (1999). Dynamic changes of endogenous plant hormones in rice grains in different parts of panicle at grain-filling stage. Acta Botanica Sinica, 41(1): 75-79.

Dubois, M., Giles, K.A., Humilton, J.K., Rebers, P.A. and Simth, F. (1951). A colorimetric method for determination of sugars. Nature (London), 168: 167. 
Duguid, S.D. and Brule-Babel, A.L. (1994). Rate and duration of grain filling in five spring wheat (Triticum aestivum L.) genotypes. Canadian Journal of Plant Science, 74: 681-686.

Duncan, R.R., Blockholt, A.J. and Miller, F.R. (1981). Descriptive comparison of senescent and non-senescent sorghum genotypes. Agronomy Journal, 73: 849-853.

El Gawad, A.A.A., Abo Shetaia, A.M. and Edris A.S. (1985). Potential productivity of wheat in Egypt II. Growth analysis studies of certain wheat cultivars. Annals of Agricultural Science, 30(2): 835-848.

Estill, K., Delaney, R.H., Smith, W.K. and Ditterlin, R.L. (1991). Water relations and productivity of alfalfa leaf chlorophyll variants. Crop Science, 31: 1229-1233.

Evans, L.T. (1978). The influence of irradiance before and after anthesis on grain yield and its components in micro crop of wheat grown in constant day length and temperature regime. Field Crops Research, 1: 5-19.

Evans, L.T. and Dunstone, R.L. (1970). Some physiological aspects of evolution in wheat. Austrailian Journal of Biological Scienices, 23: $725-741$.

Evans, L.T. and Rawson, H.M. (1970). Photosynthesis, translocation and accumulation of assimilates in cereals during grain development in wheat. Australian Journal of Biological Sciences, 23: $245-254$. 
Evans, L.T., Bingham, J and Roskams, M.A. (1972). The pattern of grain set within covos of wheat. Australian Journal of Bological Scienices, 25: 1-8.

Evans, L.T., Wardlaw, I.F. and Fisher, R.A. (1975). Wheat. In Crop Physiology (Ed. L.T. Evans), Cambridge University Press, London, pp. 101-150.

Farrar, J.F. 91993). Sink Strength: What is it and how do we measure it? A forum. Plant cell Environment, 16: 1013-1046.

Fischer, R. A. and Kertesz, F. (1976). Harvest index in spaced populations and grain yield in micro plots as indicators of yielding ability in spring wheat. Crop Science, 16: 55-59.

Fischer, R.A., Bidinger, F. Syme, J.R. and Wall, P.C. (1981). Leaf photosynthesis, leaf permeability, crop growth, and yield of short spring wheat genotypes under irrigation. Crop Science, 21(3): 367-373.

Foti, S., Guarnaccia, P., Cosentino, S. and Sattin, M. (1994). Contribution of awns to ear gas exchanges and grain filling in durum wheat (Triticum durum Desf) grown in mediterranean environment. In: Borin-M (ed.) Proceedings of the third congress of the European Society for Agronomy, Padova University, Abano-Padova, Italy, 18-22 September 1994, 124125. 
Frederick, J.R. (1997). Winter wheat leaf photosynthesis, stomatal conductance, and leaf nitrogen concentration during reproductive development. Crop Science, 37(6): 1819-1826.

Frederick, J.R. and Camberato, J.J. (1995). Water and nitrogen effects on winter wheat in the southeastern Costal Plain: II. Physiological responses. Agronomy Journal 87: 527-533.

Gales, K. (1983). Yield variation of wheat and barley in Britain in relation to crop growth and soil conditions - a review. Journal of the Science of Food and Agriculture, 34(10): 1085-1104.

Gales, K. and Ayling, S.M. (1982). Causes of variation in the yield of wheat in lotcombe laboratory. Annual report. 1981. Agricultural research council, pp 20.

Gebeyehou, G., Knott, D.R. and Baker, R.J. (1982). Relationships among durations of vegetative and grain filling phases, yield components, and grain yield in durum wheat cultivars. Crop Science, 22(2): 287-290.

Gent, M.P.N. and Kiyomoto, R.K. (1992). Canopy photosynthesis and respiration in winter wheat adapted and unadapted to Connecticut. Crop Science, 32(2): 425-431.

Goldbach H. (1975). The abscisic acid content of ripening grains of various barley cultivars in relation to temperature and $\mathrm{N}$ nutrition. Published by Universitat Hohenheim, Stuttgart 80pp. 
Guo, W.S., Feng, C.N., Yan, L.L., Peng, Y.X., Zhu, X.K., Zong, A.G. (1995). Analysis of the source-sink relationship after anthesis in wheat. Acta Agronomica Sinica, 21(3): 334-340.

Guo, W.S., Zhou, Z.X., Luo, S.S., yan, L.L., Peng, Y.X. (1994). Dynamics of photosynthate translocation in wheat flag leaf after anthesis. Acta Agricultural Nucleate Scinica, 21(3): 340344.

Guzy, M.R., Ehdaie, B., Waines, J.G. (1989). Yield and its components in diploid, tetraploid and hexaploid wheats in diverse environments. Annals of Botany, 64(6): 635-642.

Hansen, H and Grossmann, K. (2000). Auxin-induced ethylene triggers abscisic acid biosynthesis and growth inhibition. Plant Physiology, 124: 1437-1448.

Hanway, J.J. and Russell, W.A. (1969). Dry matter accumulation in corn (Zea mays L.) plants. Agronomy Journal, 61: 947-951.

Herzog, H and Geisler G. (1982). Influence of ear size, leaf area and cytokinin applications on the flag leaf development in wheat. Zeitschrift fur Acker und Pflanzenbau, 151(2): 128-136.

Herzog, H. (1980). Source and sink relations during the grain-filling period in six winter wheat cv. Zeitschrift fur Acker und Pflanzenbau, 149(6): 472-487.

Herzog, H. (1982). Grain development and temporary dry matter storage in vegetative organs of wheat genotypes. Zeitschrift fur Acker und Pflanzenbau, 151(5): 388-398. 
Hess, J.R., Carman, J.G. and Banowetz, G.M. (2002). Hormones in wheat kernels during embryony. Journal of Plant Physiology, 159: 379-386.

Hiscox, J.D. and Israelstam, G.F. (1971). Amethod for extraction of chlorophyll from leaf tissue without maceration. Canadian Journal of Botany, 578: 1332-1334.

Ho, L.C. (1988). Metabolism and compartmentation of imported sugars in sink organs in relation to sink strength. Annual Review of Plant Physiology and Plant Molecular Biology, 39: 355-378.

Humphries, E.C. and Bond, W. (1969). Experiments with CCC on wheat: effects of spacing, nitrogen, and irrigation. Annals of Applied Biology 64:375-384.

Jenner C.F. and Rathjen, A.J. (1978). Physiological basis of genetic differences in the growth of the grains of six varieties of wheat. Australian Journal of Plant Physiology, 5: 249-262.

Jenner, C.F. (1974). Factors in the grain regulations: the accumulation of starch. Royal Society of New Zealand Bulletin. 49: 153156.

Jenner, C.F. (1979). Grain-filling in wheat plants shaded for brief periods after anthesis. Australian Journal of Plant Physiology, 6(5-6): 629-641.

Jenner, C.F. (1991). Effect of exposure of wheat ears to high temperature on dry matter accumulation and carbohydrate 
metabolism in grain of two cultivars. 1. Immediate response. Australian Journal of Plant Physiology, 18: 165-177.

Jenner, C.F., Ugalde, T.D., Aspinall, D. (1990). The physiology of starch and protein deposition in the endosperm of wheat. Technical Report Department of Agriculture, South Australia. No. 160, $26 \mathrm{pp}$.

Jiang, D., Yu, Z.W., Li, Y.G., Yu, S.L. (2001). Changes in soluble sugar contents in the leaf, stem and grain of winter wheat and their relationship with grain starch accumulation. Journal of Triticeae Crops, 21(3): 38-41.

Karssesn, C.M. (1982). The role of endogenous hormones during seed development and the onset of primary dormancy. In: P.F. Wareing, (ed.), Plant growth Substances, Academic Press, London, pp 623-632.

Kaur, S. and Singh, G. (1987). Carbohydrate metabolism in relation to grain development in wheat. Annals of Biology Ludhiana, 3(2): 46-51.

Kende, H. and Zeevaart J.A.D. (1997). The five "classical" plant hormones. Plant Cell, 9: 1197-1210.

King, R.W. (1979). Abscisic acid synthesis and metabolism in wheat ears. Australian Journal of Plant Physiology, 6(1): 99-108.

King, R.W., Wardlaw, I.P. and Evans, L.T. (1967). Effect of assimilate utilization on photosynthetic rate in wheat. Planta, 77: 261276. 
Kojima, K. (1995). Simultaneous measurement of ABA, IAA and GA's in citrus - Role of BA in relation to sink ability. Journal of Agricultural Research Quarterly, 29: 179-185.

Komor, E., Liegl, Schobert, C. (1993). Loading and translocation of various cytokinins in phloem and xylem of the seedlings of Rachinus communis L. Planta, 191: 252-255.

Kondaiah, D.M. (1991). Regualtion of sink growth in wheat (Trititcum aestivum). M.Sc., Thesis. Post-Graduate School, IARI, New Delhi-12.

Konings, H. (1989). Physiological and morphological differences between plants with high NAR of high LAR as related to environmental conditions. In "Causes and Consequnces of variation in Growth Rate and Productivity of higher Plants". Eds. H.Lambers, M.L. Cambridge, H. Konings and T.L. Pons. pp 101-123.

Koshkin, E.L. and Tararina, V.V. (1990). Differences in source-sink ratios in wheat and their relationship to grain yield and content of abscisic acid. Plant Physiology and Biochemistry (London), 28(5): 609-616.

Kosina, R. 1981, Analysis of representation of ear structure characters in tetra- and hexaploid forms of spring wheat and in their hybrids. Genetica Polonica., 22(1): 63-78.

Krishnamoorthy, H.N. (1981). Plant growth substances, including applications in agriculture, New Delhi, Tata McGraw Hill. 
Kumar, A., Yadav S.K., Dhiman S.D. (1987). Growth analysis of wheat under irrigated and unirrigated conditions. Indian Journal of Ecology, 14(2): 224-229.

Kumar, R and Singh, R. (1981). Free sugars and their relationship with grain size and starch content in developing wheat grains. Journal of the Science of Food and Agriculture, 32(3): 229234.

Kumar, R. (1980). Studies on the enzymes of carbohydrate metabolism in developing grains of wheat (Triticum aestivum L.). Thesis Abstracts, 6(1): 17-18.

Kumari, S. and Ghildiyal, M.C. (1997). Availability and utilization of assimilates in relation to grain growth within the ear of wheat. Journal of Agronomy and Crop Science, 178(4): 145149.

Larsson, M. and Heneen, W.K. (1992). Studies on seed quality of triticale alpha amylase and starch. Agro Food Industry $\mathrm{Hi}$ Tech, 3(1): 26-28.

Lee, B., Martin, P. and Bangerth, F. (1989). The effect of sucrose on the levels of abscisic acid, indole-acetic acid and zeatin/zeatin riboside in wheat ears growing in liquid culture. Physiologia Plantarum, 77: 73-80.

Liu, X.B. and Li, W.X. (1996). Preliminary studies on the accumulation of grain starch and protein during grain filling in wheat. Acta Agronomica Sinica, 22(6): 736-740. 
Liu, Z.C. (1980). A study of the photosynthetic characteristics of different plant types in rice. Scientia Agricultura Sinica, 3: 310.

Ludlow, M.M. and Muchow, R.C. (1990). A critical evaluation of traits for improving crop yields in water limited environments. Advances in Agronomy, 43: 107-153.

Lupton, F.G.H. (1968). The analysis of grain yield in wheat in terms of photosynthetic ability and efficiency of translocation. Annals of Applied Botany, 61: 109-119.

Lur, H.S. and Setter, T.L. (1993). Role of auxin in maize endosperm development. Plant Physiology. 103: 273-280.

Martin, C. and Smith, A.M. (1995). Starch biosynthesis. Plant Cell, 7: 971-985.

Mengel, K., Judel, G.K. (1981). Effect of light intensity on the activity of starch synthesizing enzymes and starch synthesis in developing wheat grains. Physiologia Plantarum, 51(1): 1318.

Mi, G., Li, T., Zhang, F. and Zhang, J. (2002). Carbohydrate storage and utilization during grain filling as regulated by nitrogen application in two wheat cultivars. Journal of Plant Nutrition, 25(2):213-229.

Michael, G., Auinger, P. and Wilberg, E. (1970). Eingie aspekte Zur hormonellen regulation der korngrosse beigetrude. Zeitschrift fur Acker und Pflanzenernalr Bodenk, 125: 24-35. 
Millet, E. and Pinthus, M.J. (1984). The association between grain volume and grain weight in wheat. Journal of Cereal Science, 2(1): 31-35.

Miralles, D.I., Dominguesz, C.F., Slafer, G.A. (1996). Relationship between grain growth and post-anthesis leaf area duration in dwarf, semi-dwarf and tall isogenc lines of wheat. Journal of Agronomy and Crop Science, 177: 115-122.

Monula, M.A., Bangerth, F. and Story, V. (1980). Gibberellins like substances and indole type auxins in developing grains of normal and high-lysine genotypes of barley. Plant Physiology, 48: 568.

Morris, C.F., Anderberg, R.J. Goldmark, P.J. walker-Simons M.K. (1991). Molecular cloning and expression of abscisic acid-responsive genes in embryos of dormant wheat seeds. Plant Physiology, 95: 814-821.

Muller, J. (1986). Ecophysiological characterization of $\mathrm{CO}_{2}$ exchange in leaves of winter wheat (Triticum aestivum L.) II. Analysis of irradiance and $\mathrm{CO}_{2}$ response curves by a model. Photosynthetica, 20(4): 466-475.

Nakamura, Y. and Yuki, K. (1992). Changes in enzyme activities associated with carbohydrate metabolism during development of rice endosperm. Plant Sciences, 82: 15-20. 
Nakamura, Y. and Yuki, K., Park, S.Y., (1989). Carbohydrate metabolism in the developing endosperm of rice grains. Plant Cell Physiology, 30: 833-839.

Neales, T.F. and Incoll, L.D. (1968). The control of leaf photosynthesis rate by level of assimilate concentration in the leaf. A review of the hypothesis. Botanical Review, 34: 107-125.

Ober E.S. (1991) Water deficit during maize endosperm development: abscisic acid, cell division, and storage product synthesis. In: Dissertation Abstracts International $B$, Sciences and Engineering, 51: 9.

Okita, T.W. (1992). Is there any alternative pathway for starch synthesis? Plant Phsyiology 100: 560-564.

Pande, P.C., Nagarajan, S. and Gambhir, P.N. (1995). Physiological constraints in improvement of grain size and grain filling in wheat. Indian Journal of Plant Physiology, 38(2): 121-125.

Panse. V.G. and Sukhtme, P.V. (1967). Statistical methods for agricultural worker. ICAR Publication, New Delhi-12.

Patrick, J. W. (1983). Photosynthate undloading from seed coasts of Phaseolus vulgaris L. General characteristics and facilitated transfer. Zeitschrift fur Acker und Pflanzenphysiol, 111: 9-18.

Patrick, J.W. and Wardlaw, I.F. (1984). Vascular control of photosynthetic transfer flag leaf to the ear of wheat. Australian Jounal of Plant Physiology, 11: 235-241. 
Pearman, I., Thomas, S.M. and Thorne, G.N. (1979). Effect of nitrogen fertilizer on photosynthesis of several varieties of winter wheat. Annals of Botany, 43: 613-621.

Peat, J.R. (1985). The role of source-sink interactions in cereals in controlling yield. Monograph, British Plant Growth Regulator Group, 12: 227-242.

Pinthus, M.J. and Sar-Shalom, Y. (1978). Annals of Botany, 42: 469471.

Poorter, H. (1989). Interspecific variation in relative growth rate: on ecological causes and physiological consequences. In. Causes and Consequences of Variation in Growth Rate and Productivity of higher Plants. Eds. H. Lambers, M.L. Cambridge, H. Konings and T.L. Pons. SPB Academic Publishing. The Hague. pp 45-68.

Power, J.F., Mills, W.O. and Grunes, D.L. (1967). Effect of soil temperature, phosphorus on growth analysis of barley. Agronomy Journal, 59: 231-234.

Pramod Kumar, Dube, S.B and Chauhan, V.S. (1998). Relationship among yield and some physiological traits in wheat. Indian Journal of Plant Physiology, 3(3): 229-230.

Preiss, J. Ball, K., Smith-White, B., Lglesias, A, Kakefuda, G. and Li., L. (1991). Starch biosynthesis and its regulation. Biochemical Society Trans. 19: 539-547. 
Qin, Z. and Tang, X. (1984). Dynamics of some large biomolecules during the formation of rice endosperm. China Science 12: 1103-1110.

Radely, M. (1976). The development of wheat grain in relation to endosperm growth substances. Journal of Experimental Botany, 27: 1009-1021.

Radford, P.K. (1967). Growth analysis formulae. The uses and abuses. Crop Science, 7: 171-175.

Radley, M. (1976). The development of wheat grain in relation to endogenous growth substances. Journal of Experimental Botany, 27: 1009-1021.

Rahman, M.A., Karim, A.J.M.S., Hoque, M.M. and Egashira, K. (2000). Effects of irrigation and nitrogen fertilization on photosynthesis, leaf area index and dry matter production of wheat on a clay terrace soil of Bangladesh. Journal of the Faculty of Agriculture, Kyushu University. 45(1): 289-300.

Ralph, W. (1984). The conservative wheat plant. Rural Research, 124: 9-12.

Rawson H.M., Gifford, R.M. Bremmer, P.M. (1976). Carbon dioxide exchange in relation to sink demand in wheat. Planta 132: $19-21$

Rawson, H.M. (1971). Tillering patten in wheat with special reference to the shoot at the coleoptile node. Australian Journal of Biological Sciences. 24: 829-841. 
Rawson, H.M. and Evans, L.T. (1971). The contribution of different of stem reserves to grain development in the range of wheat cultivars of different height. Australian Journal of Agricultural Research, 22: 851-863.

Rawson, H.M. and Ruwali, K.N. (1972). Ear branching as a means of increasing grain uniformity in wheat. Australian Journal of Agricultural Research, 23(4): 551-559.

Rawson, H.M., Gifford, R.M. and Bremmer, P.M. (1976). Carbon dioxide exchange in relation of sink demand in wheat. Planta, 132: 19-23.

Reynold, M.P., Balota, M. Delgado, M.I.B., Amani, L., Fisher, R.A. 91994). Physiological and morphological traits associated with spring wheat under late irrigated conditions. Australian Journal of Plant Physiology, 21: 717-730.

Reynolds, M.P., Balota, M., Delgado, M.I.B., Amani, I. and Fischer, R.A. (1994). Physiological and morphological traits associated with spring wheat yield under hot, irrigated conditions. Australian Journal of Plant Physiology, 21(6): 717-730.

Rosenow, D.T., Quisenberry, J.E., Wendt, C.W. and Clark, L.E. (1983). Drought tolerant sorghum and cotton germplasm. In: Plant Production and Management under Drought Conditions (Stone, J.F. and Willis, W.O., eds). Elsevier, Amsterdam, Netherlands, pp. 207-222. 
Saha, C.S., Ahmed, Z.U., Mia, M.M. and Bhuiya, A.D. (1980) Relationship between grain yield and photosynthetic area of different structures above the flag leaf node in wheat. SABRAO Journal, $12(1):$ 25-29.

Saharan, M.R., Dhiman, S.D. and Singh, R. (1985). Growth characteristics of field grown wheat genotypes differing in grain yield. International Journal of Tropical Agriculture, 3(1): 9-21.

Salunkhe, D.K., Chavan, J.K. and Kadam, S.S. (1985). Wheat. In "Post harvest Biotechnology of Cereals". CRC Press, Inc., Boca Raton, Florida. pp 43-63.

Sayed, H.I. and Gadallah, A.M. (1983). Variation in dry matter and grain filling characteristics in wheat cultivars. Field Crops Research, 7(1): 61-71.

Schnyder, H., Gillenberg, C. and Hinz, J. (1993). Fructan contents and dry matter deposition in different tissues of the wheat grain during development. Plant Cell and Environment, 16(2): 179187.

Schussler, J.R. Brenner, M.L. Brun, W.A. (1984). Abscisic acid and its relationship to seed filling in soyabeans. Plant Physiology, 76: 301-306.

Sekhon N.K. and Singh G. (1994). Effect of growth regulators and date of sowing on grain development in wheat. Indian Journal of Plant Physiology, 37(1): 1-4. 
Seth, A.K. and Waering, P.E. (1967). Hormone-directed transport of metabolites and its possible rote in plant senescence. Journal of Experimental Botany, 18: 65-67

Sharma, R.C. (1994). Early generation selection for grain-filing period in wheat. Crop science, 34: 945-948.

Sharma-Natu Poonam and Ghildiayal, M.C. (1993). Diurnal changes in photosynthesis in relation to ribulose-1,5-bisphosphate carboxylase activity and saccharides in wheat leaves. Photosynthetica. 29: 551-556.

Shuting, D. (1994). Canopy apparent photosynthesis, respiration and yield in wheat. Journal of Agricultural Science, Cambridge, 122: 7-12.

Siddique, K.H.M., Belford, R.K. Perry, M.W. and Tennane, D. (1989). Growth, development and light interception of old and modern wheat cultivars in a Mediterranean-type environment. Australian Journal of Agricultural Research, 40: 473-487.

Simane, B., Peacock, J.M. and Struil, P.C. (1993). Differences in developmental plasticity and growth rate among droughtresistant and susceptible cultivars of duram wheat (Triticum turgidum L. var. durum). Plant and soil, 57: 155-166.

Simmons, S.R. and Crookston, R.K. (1979). Rate and duration of ratio in growth kernels formed at specific spiklets of spring wheat. Crop Science, 19: 690-693. 
Singh G., Kaur S., Sharma R. (1989). Endogenous levels of phytohormones in relation to grain development in wheat (Triticum aestivum L). Annals of Plant Physiology, 3(2): 137145.

Singh, G. and Gerung, S.B. (1982). Hormonal role in the problem of sterility in Orizya Sativa. Plant Physiology Biochemistry 9: 22-23.

Singh, V.P., Dahiya, B.N., Chowdhury, R.K. (1977). Genetic studies of grain filling period in wheat. In: Gupta, A.K. (ed.), Genetics and Wheat Improvement. II. Genetics of Economic Traits. 4243.

Singhal, N.C., Srivastava, K.N. and Mehta, S.L. (1989). Pattern of dry matter and protein accumulation in developing wheat seeds and their relationship. Indian Journal of Genetics and Plant Breeding, 49(1): 95-102.

Sinha, N.C. and Patil, B.D. (1986). Screening of barley varieties for drought resistance. Plant Breeding, 97:13-19.

Sivakumar, T. (2002). Relationship of endogous cytokinins and absicic acid with grain development in wheat and triticale, Ph.D. Thesis. Post-Graduate School, IARI, New Delhi-12.

Sivakumar, T. and Virendra Nath (2000). Effect of BA on photosyntheis pigment content in the flag leaf and ear of wheat and Triticale. Indian Journal of Plant Physiology, 5(4): 354-357. 
Sivakumar, T. Virendra Nath, Srivastava, G.C. (2001). Journal of Agromony and Crop Science, 186: 43-46.

Slafer, G. A. and Rawson, H.M. (1994). Sensitivity of wheat phasic development to major environmental factors: A reexamiantion of some assumpations made by physiologis and midelers. Australian Journal of Plant Physiology, 21: 393-426.

Slafer, G.A., Andrade, F.H. (1993). Physiological attributes related to the generation of grain yield I. bread wheat cultivars released at different crops. Field Crop Research, 31:351-367.

Sofield, I., Evans, L.T., Crook, M.G. and Wardlaw, I.F. (1977). Factors influencing the rate and duration of grin filling in wheat. Australian Journal of Plant Physiology, 4: 785-797.

Spiertz, J.H. J. and Van de Haar, H. (1978). Differences in grain growth, crop photosynthesis and distribution of assimilates between a semi-dwarf and a standard of winter wheat. Netherlands Journal of Agricultural Sciences, 26: 233-249.

Spiertz, J.J., Tent Hag, B.A. and Kupers, L.J.P. (1971). Relation between green area duration and grain yield in some varieties of wheat. Netherlands Journal of Agricultural Sciences, 19: 211-222.

Spitters, C.J.T. and Kramer, T. (1986). Differences between spring wheat cultivars in early growth. Euphytica, 35(1): 273-292.

Stamp, P.H. and Geisler, G. (1976). Grain development in relation to grain position in two spring wheat cultivars. Zeitschrift fur Acker und Pflanzenbau, 142(4): 264-274. 
Stoy, V. (1969). Interrelationship among photosynthesis respiration and movement of carbon in developing crops. In Physiological aspects of crop yield. Ed. Eastin, J.D. et al., American Society of Agronomy and Crop Science Society. America, Madison, Wisconisi, (USA), pp. 185-202.

Subrahmanyam, D and Dutta, M. (2000). Relationship between leaf photosynthetic characteristics and yield in buckwheat. Indian Journal of Plant Physiology., 5(4): 328-333.

Sundberg, B. (1990). Influence of extraction solvent (buffer, methanol, acetone) and time on the quantification of indole3-acetic acid in plants. Plant Physiology, 78: 293-297.

Syme, J.R. (1972). Single plant characters as a measure of filed plot performance of wheat cultivars. Australian Journal of Agricultural Research, 26: 753-760.

Takagi M., Yokota T., Murofushi N., Saka H. and Takahashi N. (1989). Quantitative changes of free-base, riboside, ribotide and glucoside cytokinins in developing rice grains. Plant Growth Regulation, 8(4): 349-364.

Takahashi, T., Tsuchihashi, N. and Nakaseko, K. (1993). Grain filling mechanisms in spring wheat. I. Grain filling phases according to the development of plant organs. Japanese Journal of Crop Science, 62(4): 560-564.

Takahashi, T., Tsuchihashi, N., Nakaseko, K. (1994). Grain filling mechanisms in spring wheat: II. Growth, accumulation and 
translocation in the daytime and at night during the four grain filling phases. Japanese Journal of Crop Science, 63(1): 75-80.

Thorne, G. N, Welbank, P.J. and Blackwood, G.C. (1969). Growth and yield of six short varieties of spring wheat derived from Norin 10 and two Europena varieties. Annals of Applied Biology 63: 241-251.

Thorne, G.N. (1971). Physiological factors limiting the yield of arable crops. In "Potential crop production, A case study". Ed. Wareing, P.F. and Cooper, J.P., Heinemann Educational Books Limited, London.

Turner, N.C. and Nicolas, M.E. (1987). Drought resistance of wheat for light-textured soils in a Mediterranean climate. In "Drought tolerance in Winter Cereals". Eds. J.P. Srivastava, E. Porceddu, E. Acevedo and S. Varma. John Wiely \& Sons, Chichester. Pp 203-216.

Tuttobene, R., Lombardo, G.M. and Vagliasindi, C. (1996). Validity of the main indexes of growth analysis used to describe durum wheat (Triticum durum Desf.) growth in the Mediterranean. Rivista di Agronomia, 30(3): 241-247.

Van den Boogard, R. Goubitz, S., Veneklaas, E.J. and Lambers, H. (1996). Carbon and nitrogen economy of four Trititcum aestivum cultivars differing in relative growth rate and water use efficiency. Plant, Cell and Environment, 19; 998-1004. 
Van Sanford, D.A. (1985). Variation in kernel growth characters among soft red winter wheats. Crop Science, 25: 626-630.

Voltos, J., Santiveri, P., royo, C., romagosa, I., Scaife, A. (1962). Rate and duration of grain filling in triticale. "Proceedings of Second Congress of the European Society for Agronomy". Warwick University, UK, 33-38.

Vos-NM-de (1979). Cultivar differences in plant and crop photosynthesis. In: Spiertz, J.H.J. and Kramer. T (ed.) Crop Physiology and Cereal Breeding. Proceedings of a Eucarpia workshop, Photosynthesis and respiration held at Wageningen, the Netherlands, 14-16 November 1978. 71-74 pp.

Wang, Z.L., He, M.R., Yin, Y.P. and Cao, H.M. (1997). Assimilation and partitioning of the photosynthates in late sown winter wheat at grain filling and their response to plant population density. Acta Agronomica Sinica, 23(3): 257-262.

Wardlaw, I.F and Moncur, L. (1976). Source, sink and hormonal control of translocation in wheat. Planta. 128(2): 93-100.

Wardlaw, I.F. (1968). The control and pattern of movement of carbohydrated in plants. Botanical Review, 34: 79-105.

Wardlaw, I.F. (1990). The control of carbon partitioning in plants. New Phytologist, 116: 341-381. 
Warrier, A., Bhardwaj, S.N., Pande, P.C. (1987). Effect of BA on grain growth in aestivum wheat. Plant Cell Phsyiology. 28: 735739.

Watson, D.J. (1952). The physiological basis of variation in yield, Advances in Agronomy, 4: 101-145.

Watson, D.J. (1971). Size, structure and activity of the productive system of crops. In "Potential crop production, A case study" Ed. Wareing. P.F., and Cooper, J.P., Heinemann Educational Books Limited, London, pp. 76-88.

Watson, R.A. and Duffus, C.M. (1988). CO2 fixation by detached cereal caryopsis. Plant Phsyiology, 87: 504-509.

Welbank, P.J., French, S.A. and Witts, K.J. (1966). Dependence of yields of wheat varieties on their leaf area duration. Annals of Botany, 30: 291-299.

Whan, B. R., Carlton, G.P. and Anderson, W.K. (1991). Potential for increasing rate of grain growth in spring wheat. I. Identification of genetic improvement. Australian Journal of Plant Physiology, 47: 17-31.

Wheeler, A.M. (1972). Changes in growth substances during growth of wheat grains. Annals of Applied Biology. 72: 327-334.

Wheeler, A.W., (1976). Some treatments affecting growth substances in developing wheat ears. Annals of Applied Biology, 83(3): 455-462. 
Whitfield, D.M. (1990). Canopy conductance, carbon assimilation and water use in wheat. Agricultural and Forest-Meteorology. 53(1-2): 1-18.

Willman, M.R. Below, E.F., Lambert, R.J., Howey, A.E. and Mies, D.W. (1987). Plant traits related to productivity of maize. I. genetic variability, environmental varation and correlation with grain yield and stalk loading. Crop Science, 27: 1116-1121.

Wood, R.M. Patrick, J.W. Offler, C.E. (1994). The cellular pathway and short distance transfer of photosynthates and potassium in the elongation stem of Phaseolus vulagris L. stem anatomy, solute transport and pool sizes. Annals of Botany, 73: 151160.

Wright, G.S., Smith, R.C.G. and Morgan, J. M. (1983). Differences between two grain sorghum genotypes in adaptation to drought stress. III. Physiological responses. Australian Journal of Agricultural Research, 34:1

Xu, R.S., Tao, L.X., Yu, M.Y. and Wang, X. (1997). Manipulation of grain-filling characteristics of intersubspecific hybrid rice and its effect on the yield. Chinese Journal of Rice Science, 11(2): 124-128.

Yang, J.C., Peng, S.B., Zhu, Q.S. and Gu, S.L. (2000). Grain filling pattern and cytokinin content in the grains and roots of rice plants. Plant Growth Regulation, 30(2): 261-270. 
Yang, J.C., Zhang, J.H., Wang, Z.Q., Zhu, Q.S. and Liu, L.J. (2001). Water deficit-induced senescence and its relationship to the remobilization of pre-stored carbon in wheat during grain filling. Agronomy Journal, 93(1): 196-206.

Yordanov, J and Belikov, P. (1962). Changes in the intensity of photosynthesis in the ontogenesis of spring wheat lutescens 62-Izv. Institute of Biology Metodii Poov (Bulg. Acad. Nauk), 12: 513.

Yordanov, J. and Beikov, P. (1962). Changes in the intensity of photosynthesis in the ontogenesis of spring wheat lutescens 62Izv. Insti. Biol. Metodii Popov (Bulg. Acad. Nauk). 12: 513.

You, N.S., Lei, J.C., Huang L.X., Zheng X.H. and Zhu X.T. (1997). Comparing analysis of endogenous IAA, $\mathrm{GA}_{1+3+4+7}$ in rice male-sterile line with alloplasm-homokaryon. Journal of Fujian Academy of Agricultural Sciences, 12(1): 7-11.

Zamski, E. and Grunberger, Y. (1995). Short- and long-eared highyielding hexaploid wheat cultivars: which has unexpressed potential for higher yield? Annals of Botany. 75(5): 501-506.

Zee, S.Y. and O'Brien, T.P. (1970). Studies on the ontogeny of the pigment strand in the caryopsis of wheat. Australian Journal of Biological Sciences, 23: 1153-1171.

Zhu, Q., Cao, X. and Luo, Y. (1988). Growth analysis on the process of grain filling in rice. Acta Agronomica Sinicia, 14(3): 182-193. 


\section{POST GRADUATE SCHOOL INDIAN AGRICULTURAL RESEARCH INSTITUTE NEW DELHI-110 012}

\section{PROFORMA FOR SUBMITTING ABSTRACT}

Title of thesis

Full name of the
Student
Name \& Address of the
Chairman

: "Studies on endogenous hormonal changes during grain development in wheat genotypes"

: Gutam Sridhar

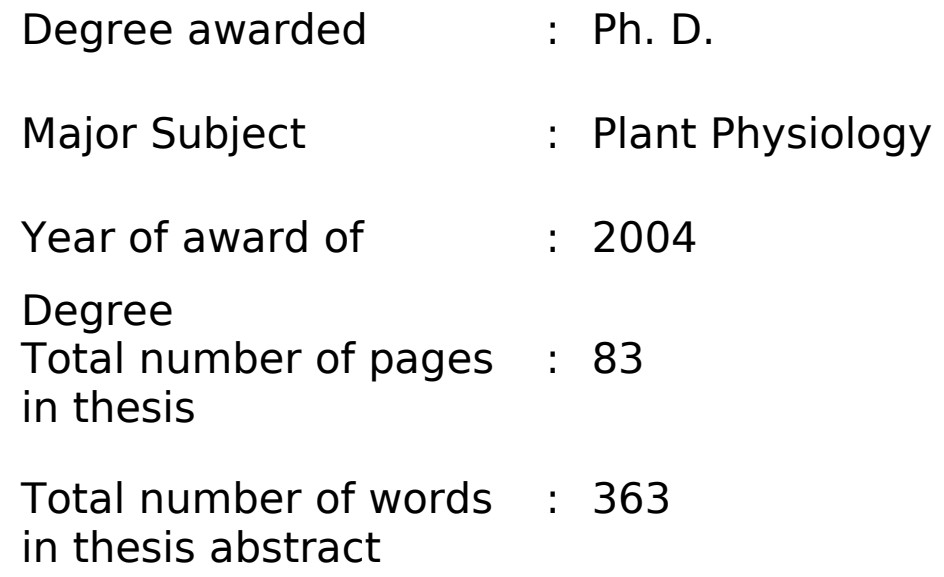




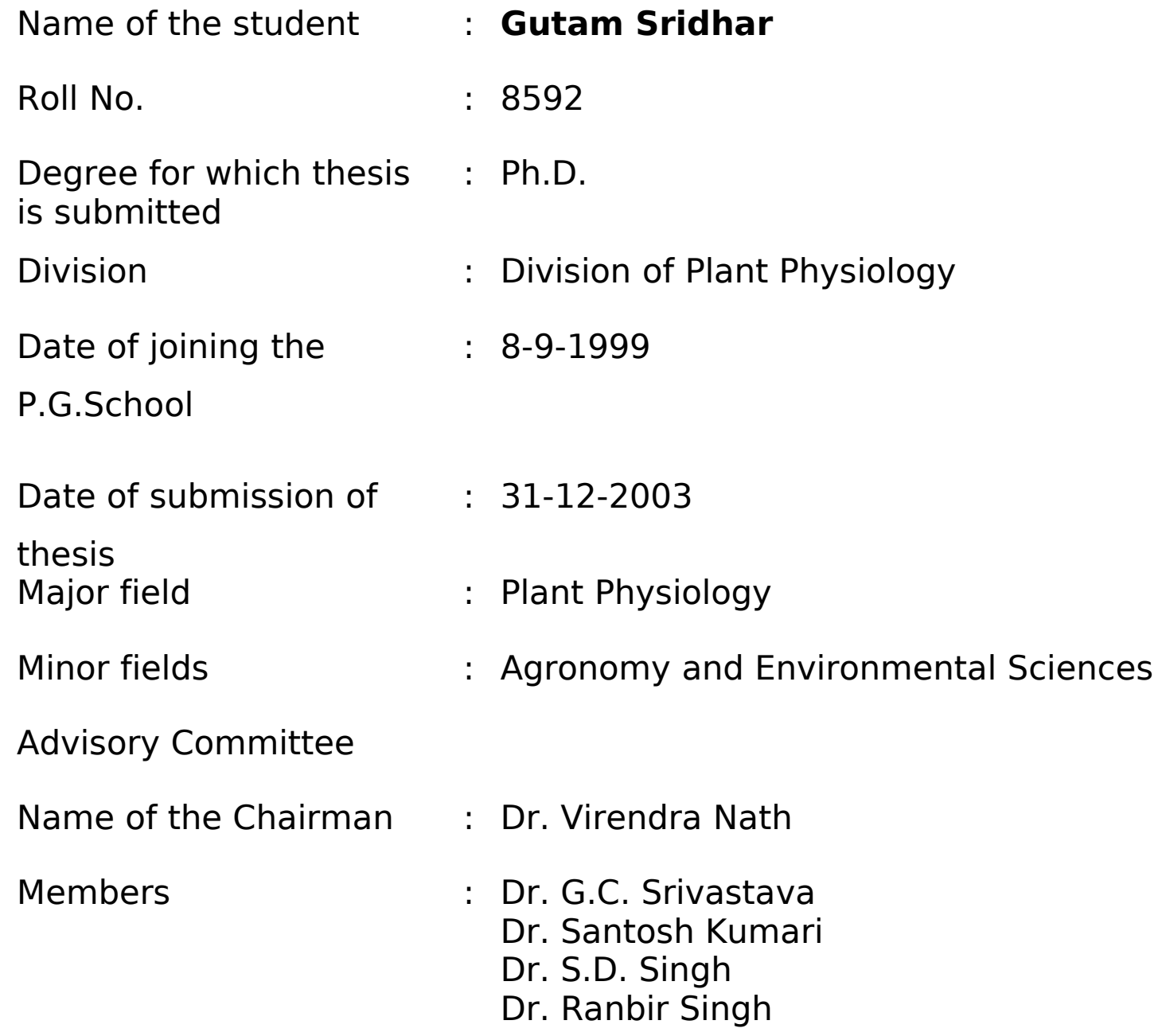

Title of the thesis

\section{Abstract}

: "Studies on endogenous hormonal changes during grain development in wheat genotypes"

Pot culture experiment was conducted in the Rabi seasons of 2001 and 2002 in order to study the genotypic differences in grain growth rates and endogenous hormonal contents in the developing grains. The hexaploid new plant types and extant variety and other tetraploids are taken up for the study. The data on yield and yield components show that the tetraploids had higher ear number per plant but lesser number of seeds per ear and lower seed weight per 
ear. The most important yield component 1000-grain yield was also possessed by hexaploids. The mean plant height was found to be higher in hexaploids over tetraploids in general, and among them DL1266-1 and DL-1266-2 (new plant types) recorded higher plant height. Similarly, the ear length was also higher in these new plant types. But, the tiller number/plant and ear number/plant were significantly higher in tetraploids. The new plant types (hexaploids) possessed maximum grain growth rate at 5-15 DAA. DL-1266-2 recorded highest grain growth rate $0.093 \mathrm{~g} / \mathrm{g} /$ day.

The photosynthetic rate values show that the hexaploids possessed higher rate than tetraploids. At 7 and 15 DAA, in general, photosynthetic rate was more when compared to 25 DAA and 35 DAA. The results showed that the endogenous hormonal contents in grains during grain development had changed in sequence. At 7 DAA, gibberellic acid $\left(\mathrm{GA}_{3}\right)$ content was at maximum and at 15 DAA (rapid growth phase), indole-acetic acid (IAA) reached maximum and at 25 DAA (dough stage), ABA was at the maximum. At the 35 DAA, ABA reached all time high and $\mathrm{GA}_{3}$ the least, IAA being intermediate. Among the genotypes, hexaploids recorded higher concentrations of endogenous hormones. The total chlorophyll content in flag leaves of hexaploids was higher than tetraploids. The mean total chlorophyll had increased slightly at 20 DAA when compared to 10 DAA and it decreased at 30 DAA.

It appears that the high yielding hexaploids (DL-1266-1 \& DI1266-2) by the virtue of possessing more 1000-grain weight and leaf 
area along with endogenous hormones might be responsible for higher yield as compared to tetraploids. It appears that better photosynthetic rate and better mobilization of photosynthates during grain filling stage contributes for higher yield in hexaploids. 